Florida International University FIU Digital Commons

$11-7-2016$

\title{
Childbirth Education in Jordan: Content, Feasibility and Challenges of Implementing a Childbirth Education Program in Jordan
}

Fatima Malkawi Ms

Florida International University, fmalk001@fiu.edu

DOI: 10.25148 /etd.FIDC001198

Follow this and additional works at: https://digitalcommons.fiu.edu/etd

Part of the Health and Physical Education Commons, Nursing Midwifery Commons, and the Public Health and Community Nursing Commons

\section{Recommended Citation}

Malkawi, Fatima Ms, "Childbirth Education in Jordan: Content, Feasibility and Challenges of Implementing a Childbirth Education Program in Jordan" (2016). FIU Electronic Theses and Dissertations. 3035.

https://digitalcommons.fiu.edu/etd/3035 


\section{FLORIDA INTERNATIOAL UNIVERSITY}

Miami, Florida

CHILDBIRTH EDUCATION IN JORDAN: CONTENT, FEASIBILITY AND

CHALLENGES OF IMPLEMENTING A CHILDBIRTH EDUCATION PROGRAM IN

JORDAN

A dissertation submitted in partial fulfilment of the

requirement for the degree of

DOCTOR OF PHILOSOPHY

In

NURSING

by

Fatima Malkawi

2016 


\section{To: Dean Ora Strickland}

Nicole Wertheim College of Nursing Sciences

This dissertation, written by Fatima Malkawi, and entitled, Childbirth Education in Jordan: Content, Feasibility, and Challenges of Implementing a Childbirth Education Program in Jordan, having been approved in respect to style and intellectual content, is referred to you for judgment.

We have read this dissertation and recommend that it be approved.

$\begin{array}{r}\hline \text { JoAnne Youngblut } \\ \hline \text { Jean Hannan } \\ \hline \text { Jennifer Doherty-Restrepo } \\ \hline \text { Dorothy Brooten, Major Professor }\end{array}$

Date of Defense: November 7, 2016

The dissertation of Fatima Malkawi is Approved

Dean Ora Strickland

Nicole Wertheim College of Nursing Sciences

Andre's G. Gil

Vice President for Research and Economic Development and Dean of the University Graduate School

Florida International University, 2016 
(OCopyright 2016 by Fatima Malkawi

All rights reserved 


\section{DEDICATION}

I dedicate this dissertation to my beloved family; my mother and father, my husband Ameen, my children Jehad, Roqaia, Yumna and Ahmad, and my sisters. Your love and support is what keeps me going. Without you in my life I would not done any success. There were difficult times and fun times. The only thing that never changed is your love around me. Thank you and may Allah bless you all.

I also dedicate this work to all Jordanian women and midwives. We have a long way to reach our goals but we are dedicated and we have enough patience and internal power to help us. All what we need is faith and good research. 


\section{ACKNOWLEDGMENTS}

My thanks go first to all the devoted Midwives in Jordan. This work was done because of you and for you. Also, I need to thank the participants in my research for their valuable input and valid recommendations.

A thank you from the heart goes to my mentor, advisor, and mother in research; Dr. Dorothy Brooten. I was very lucky to be your student. I learned most from you not only in research but how to be super kind, super researcher, and to keep working no matter what life threw in my face. Your commitment to help the next generation of researchers is an inspiration.

A very warm thank you for my members of dissertation committee; Dr. JoAnn Youngblut, Dr. Jean Hannan, and Dr. Jennifer Doherty-Restrepo. Thank you for the support, patience and valuable inputs to my work.

I love to thank my friends and colleagues who supported me through and before my degree and especially my best friends Manal, Haya and Kholoud. You were there for me when I needed you the most so thank you. And from the states I love to thank my friends

there and a special thanks to Carmen for her kind support always. You were there to support and help like a true friend.

Thank you all 


\author{
ABSTRACT OF THE DISSERTATION \\ CHILDBIRTH EDUCATION IN JORDAN: CONTENT, FEASIBILITY AND \\ CHALLENGES OF IMPLEMENTING A CHILDBIRTH EDUCATION PROGRAM IN \\ JORDAN \\ by
}

Fatima Malkawi

Florida International University, 2016

Miami, Florida

Professor Dorothy Brooten, Major professor

No childbirth education (CE) programs are available in the public sectors in

Jordan. Many studies from Jordan recommended that pregnant women be educated about their health needs during pregnancy and childbirth. From the literature, CE programs were found to have positive effects on pregnancy and childbirth outcomes.

Four focus groups with pregnant women, midwives and physicians were conducted to examine the perceptions of pregnant women, midwives and physicians regarding the content, feasibility, and challenges of implementing a CE program in Jordan. The 4 focus groups, two with pregnant women (one group with 8 primiparous women and one group with 6 multiparous women), one with 8 midwives, and one with 6 physicians were presented with the content, timing, and a description of three existing $\mathrm{CE}$ programs.

Findings indicated that pregnant women's sources of knowledge about pregnancy and childbirth were mainly from other females and doctors but not from midwives. Younger pregnant women reported the Internet as an important source of pregnancy and 
childbirth knowledge. Findings showed that women were not sure of what they wanted to learn. Midwives and physicians wanted to include warning signs, physical exercises, psychological changes, nutrition, breast feeding, newborn heath, sexually transmitted diseases, pain management, postpartum physiology and care, family planning, and planning of pregnancy as content in a new CE program. All participants reported the need to include husbands in CE. However, husbands were considered a potential challenge to implementing a CE program. Other challenges were cost, staff, clients' responses, and governmental policies. Midwives and physicians thought that CE should be included in free antenatal care.

All participants reported support for a new CE program. Midwives and physicians suggested implementing the new program within the facilities of the Ministry of Health $(\mathrm{MOH})$. This would decrease cost and the need for staffing for the new program. They suggested that the CE program could benefit from potential support from international sponsors that affiliate with the MOH. Potential benefits of CE could potentially help gain support from the MOH decision makers and the community in Jordan. 


\section{TABLE OF CONTENT}

\section{CHAPTER}

\section{PAGE}

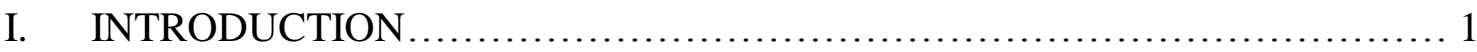

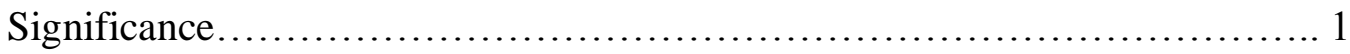

Theoretical framework................................................... 7

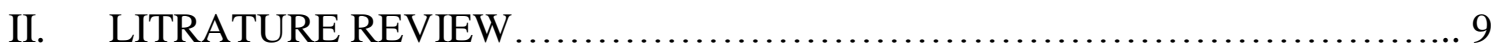

Introduction........................................................... 9

Childbirth in Jordan............................................... 10

Programs of Childbirth Education........................................... 12

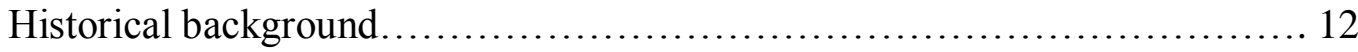

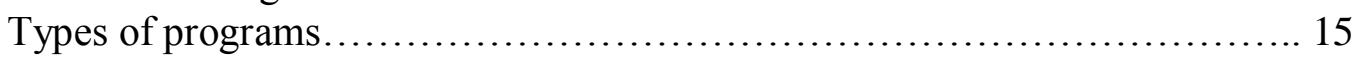

What programs should be considered as candidates in Jordan?...........................55

Summary of the Literature.................................................

III. METHODOLOGY ......................................................... 60

Research design ................................................ 60

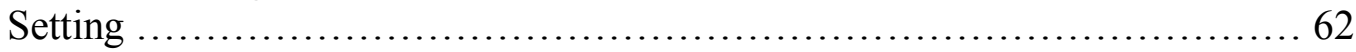

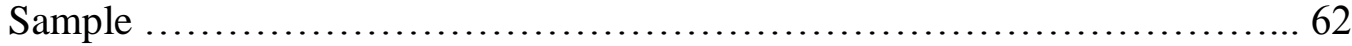

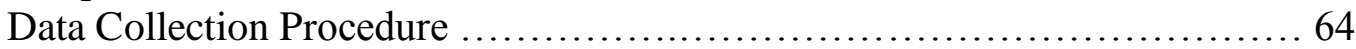

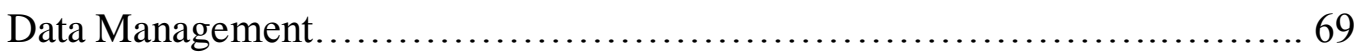

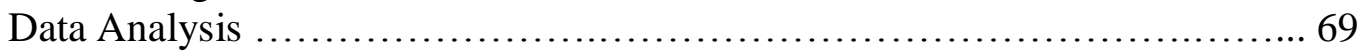

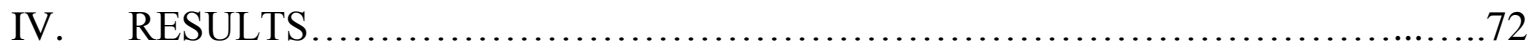

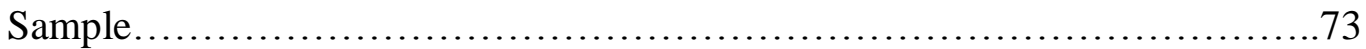

1.How do pregnant women learn about pregnancy and childbirth Jordan?..........74

2.What do pregnant women want to know about pregnancy, labor and delivery, and postpartum?..................................................... 81

3.What do midwives and physicians think should be in a CE program?......... 85 4.When provided with $3 \mathrm{CE}$ programs, what modifications do pregnant women, midwives and physicians suggest in order for the programs to be appropriate for Jordanian culture? ............................................................................... 92

Feasibility of implementing a CE program................................. 104

Challenges of Implementing a CE Program................................. 114

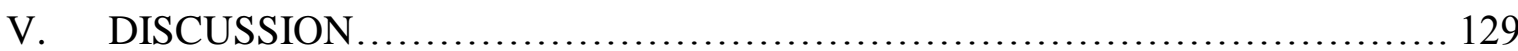

Sources of pregnant women's childbirth knowledge.......................... 129

Pregnant women's learning needs in Jordan.................................. 134

What midwives and physicians thought should be in the CE program.......... 139

The modifications pregnant women, midwives and physicians suggested to make an appropriate CE program for Jordanian women........................159

Feasibilities and challenges of implementing the CE program...................168

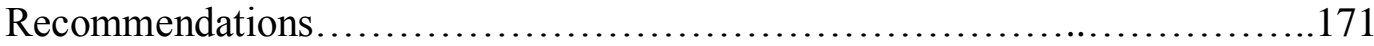




\section{Chapter I}

\section{INTRODUCTION}

Childbirth Education (CE) is a process that helps expectant parents learn about and prepare for pregnancy, labor, birth, and the newborn. Most classes take place during pregnancy to explain about the various aspects of preparing for pregnancy, how to cope with pregnancy, labor and birth, immediate post-partum care and care of the newborn (Hotelling, 2009). CE can decrease women's fear and anxiety of childbirth, increase women's knowledge about healthy behaviors during pregnancy, labor and delivery, and postpartum (Records \& Wilson, 2011).

CE may improve health promotion behaviors during pregnancy. It may also improve knowledge regarding: how to manage discomforts during pregnancy, danger signs during pregnancy, what to expect during labor and delivery, postpartum care, and contraceptive use. Accordingly, CE may lead to a decrease maternal and fetal mortality and morbidity (Nichols, \& Humenick, 2000). However, in Jordan formal educational programs are lacking in the public sector to prepare women for pregnancy, labor and delivery, and the postpartum. In addition, maternal health and education and research face many challenges including shortages in resources and facilities.

\section{Significance}

Jordan's population is nearly $7,000,000$ people with a median age of 23 years, $52 \%$ are under the age of 20 years, have about 28 births per 1000 population, and the total fertility rate was 3 or more children (3.5) per woman (Ministry of Health [MOH], 2014). Jordan is mainly consisted of urban society. About $75 \%$ of Jordan's population lives in in villages and towns and close to health care facilities (within one hour drive or 
less). Most the population are Muslims with a minority of Christians integrated within the community. Jordanian people enjoy a more stable and peaceful political regime than most of the surrounding countries (Gause, 2011; Murshidi, Hijjawi, Jeriesat, \& Eltom, 2013).

The illiteracy rate of people 15 years and older was about $10 \%$ for females and $4 \%$ for males. The young female (15-24) literacy rate was 99\%. (Department of Statistics [DOS], 2010). The institutional birth and delivery rate attended by skilled birth attendants was $98 \%$; the maternal mortality rate was 19 per 1000 total births; the infant mortality rate was 16 per 1000 live births; and the frequency of contraceptive use was 53\%. (UNICEF, 2013).

In Jordan, many health promotion initiatives have been introduced and have taken place in the last decade especially for the safety and wellbeing of mothers and children. Examples include the Millennium Summit in 2000, the National Reproductive Health/Family Planning Strategy 2013-2017, and others (Hatamleh, Sinclair, Kernohan, \& Bunting, 2013; Higher Population Council [HPC], 2015). The Jordanian government's initiative programs helped to improve obstetric emergencies and the health of women and children, and have contributed to decreased maternal morbidity and mortality rates. Nevertheless, maternal morbidity is still high when compared to rates in the developed countries (Hatamleh, Sinclair, Kernohan, \& Bunting, 2013; MOH, 2014).

Quteitat et al., (2012) published a national cohort study aimed at determining the incidence of maternal morbidity and its main causes in Jordan. The sample consisted of 4,501 Jordanian women enrolled in the study when they were pregnant with 22 gestation weeks or less. The women in the sample were followed through pregnancy, labor and 
postpartum. The instruments included data sheets and questionnaires filled by physicians. Overall morbidity was very high (61\%). The morbidity was $41 \%$ antenatal, $35 \%$ periperium, and $19 \%$ postpartum. The caesarean rate was $27.7 \%$, and caesarean births were associated with $30 \%$ of the overall morbidity cases. Women suffered from anemia (20\%) at enrollment and $26 \%$ at delivery. The most common morbidities in the sample were urinary tract infections (20\%), genital infections (19\%), and anemia (11\%). No mortalities were recorded during this study. Parity of more than 4 was significantly related to increased morbidity during the antenatal period but not during periperium (Quteitat et al., 2012).

In a study by the HPC (2008), the maternal mortality rate was significantly decreased between 1997 and 2008 from 41 to 19.1 per 100,000 respectively. This rate is considered low compared to other developing countries such as in sub-Sahara Africa (900 per 100,000) and Oceania (430 per 100,000), but considered high compared to other Arab countries such as Qatar (7 per 100,000) in 2010 (UNICEF, 2013). The Jordanian annual per capita income was 3276.8 JDs (about 5,000 USD) in 2011(HPC, 2014) compared with about 73, 000 USD in Qatar (UNICEF, 2013).

The leading cause of maternal death in Jordan in 2007-2008 was hemorrhage (74\%), followed by pulmonary embolism (24\%), and septicemia (8\%). Of the maternal deaths during 2007-2008, 19\% did not attend any antenatal care, $33.3 \%$ had 3 or fewer antenatal visits in total, and around 54\% died of preventable causes. This national study recommended that CE should be developed and evaluated for effectiveness in teaching women the life threatening risks and preventable causes of death (HPC, 2008). 
Maternity services in Jordan are primarily hospital based. Most women use public health services (65\%) (DOS, 2010). Approximately 200,000 women give birth annually in Jordan. The institutional delivery rate attended by skilled birth attendants was 98\% (DOS, 2010; UNICEF, 2013). Ninety-nine percent of pregnant women in Jordan receive antenatal care, with $94 \%$ of them receiving more than 4 visits during pregnancy (HPC, 2010). Thus pregnant women in Jordan could access maternal health education programs if they were available in the public health sector.

About $97 \%$ of the 200,000 women who give birth annually in Jordan deliver their children in hospitals away from the support of their partners and families (Oweis, 2009). Most pregnant women come to the hospitals unprepared for the labor and delivery, a situation that can affect their expectations and experiences (Oweis, 2009). In a study by Oweis and Abushaikha (2004), the majority of primiparous pregnant women expected their childbirth to be frightening, long, too difficult and painful. They also expected to have inadequate support from the midwives and nurses in labor during childbirth. The researchers suggested that these negative expectations were due to the limited advice and preparation of the women antenataly. Oweis and Abushaikha's (2004) study is one of the first studies addressing the need for antenatal education in Jordan. There is however a very limited body of reported research regarding pregnant womens' antenatal preparation and childbirth education in Jordan.

Oweis (2009) explored the perceptions of the childbirth experience of first-time mothers from North Jordan. Women reported higher levels of pain than expected, fear and anxiety of the labor process, and interventions that they did not know about such as induction and episiotomy. The majority of women rated their experiences as intense and 
painful, and was not satisfied with their childbirth experience, labor events, and the level of control over their bodies during the experience. Although the above studies have limitations of small and convenient samples, both recommended that women need to be prepared antenataly to feel less anxious and afraid, and to gain more control and satisfaction over their childbirth experience.

CE programs are available in developed countries. These programs are developed for the cultures and needs of the pregnant women in these countries. Jordan is a developing country that enjoys an important geographical and political position in the Middle East (Oweis, 2009). Jordan has a structured health system that can be considered one of the best among the near countries. Primary health care (PHC) is delivered to Jordanians through a network of public health care and private facilities including: public health centers, comprehensive PHC centers, village health centers, and private clinics. The cost is mostly free or at a subsidized cost in the public sectors. There are about 103 hospitals, 95 comprehensive health centers, 375 PHC centers, 205 peripheral (village) centers, and 448 maternal and child health centers attached to hospitals or comprehensive health centers (MOH, 2014). Irbid (A city in North Jordan) has 49 maternal and child health centers (MCH), which is the biggest number in the country (MOH, 2014).

CE can be a very valuable asset in preparing women for their childbirth experience and potentially reducing morbidity and mortality. However, most CE programs have been prepared for developed countries. It is very important to review available CE programs and to compare these with the needs of pregnant women in Jordan as a developing country. Mcintyre-Miller and Chmiel, (2013) reported that preparing a 
CE program should consider the knowledge and needs of the pregnant women and their partners who will attend and benefit from the program.

The purpose of this proposed study was to examine the perceptions of pregnant women, midwives, and physicians regarding the content, feasibility and challenges of implementing a childbirth education (CE) program in Jordan. Four focus groups of pregnant women ( 2 focus groups), midwives, and physicians were presented with the content, timing, and a description of three CE programs from the literature. Participants were asked to compare each of the three $\mathrm{CE}$ programs and suggest modifications appropriate to the educational needs of pregnant women in Jordan. Using focus groups, this study addressed the following research questions;

1. How do pregnant women learn about pregnancy and childbirth in Jordan?

2. What do pregnant women want to know about pregnancy, labor and delivery, and postpartum?

3. What do, midwives and physicians think should be in a CE program in Jordan?

4. When provided with $3 \mathrm{CE}$ programs, what modifications do pregnant women, midwives and physicians suggest in order for the programs to be appropriate for Jordanian culture?

5. What are the perceptions of pregnant women, midwives, and physicians about the feasibility and challenges of implementing CE program for pregnant women in Jordan? 


\section{Theoretical framework}

Donabedian's structure, process and outcomes (SPO) model (1980) was used to guide the proposed study. Humenick (2000) reported that for more than thirty years, CE outcomes research was guided by Donabedian's SPO model. Donabedian's model has been widely adopted as an evaluative model for the quality of health care activity. By following these concepts, quality evaluation can be more concrete.

The Donabedian model is a conceptual model that delivers a framework for examining health services and assessing and evaluating quality of health care. According to the model, three categories delineate the quality of care: "structure," "process," and "outcomes." Structure describes the circumstance in which care is being delivered, including hospital buildings, staff, cost, and equipment. Process represents the transactions between patients and providers throughout the provision of healthcare. Finally, outcomes denote the effects of healthcare on the health status of individuals and populations (Donabedian, 1980).

In the current study, structure was represented by the settings where the women receive maternity care (i.e. $3 \mathrm{MCHs}$ and one major maternity hospital in North Jordan). Process was the assessment of CE content identified by the pregnant women, midwives, and physicians; modifications to the 3 existing CE programs; and feasibility and challenges to implementing a CE program in Jordan. Outcome was the potential CE program appropriate for Jordanian culture. See figure 1. 


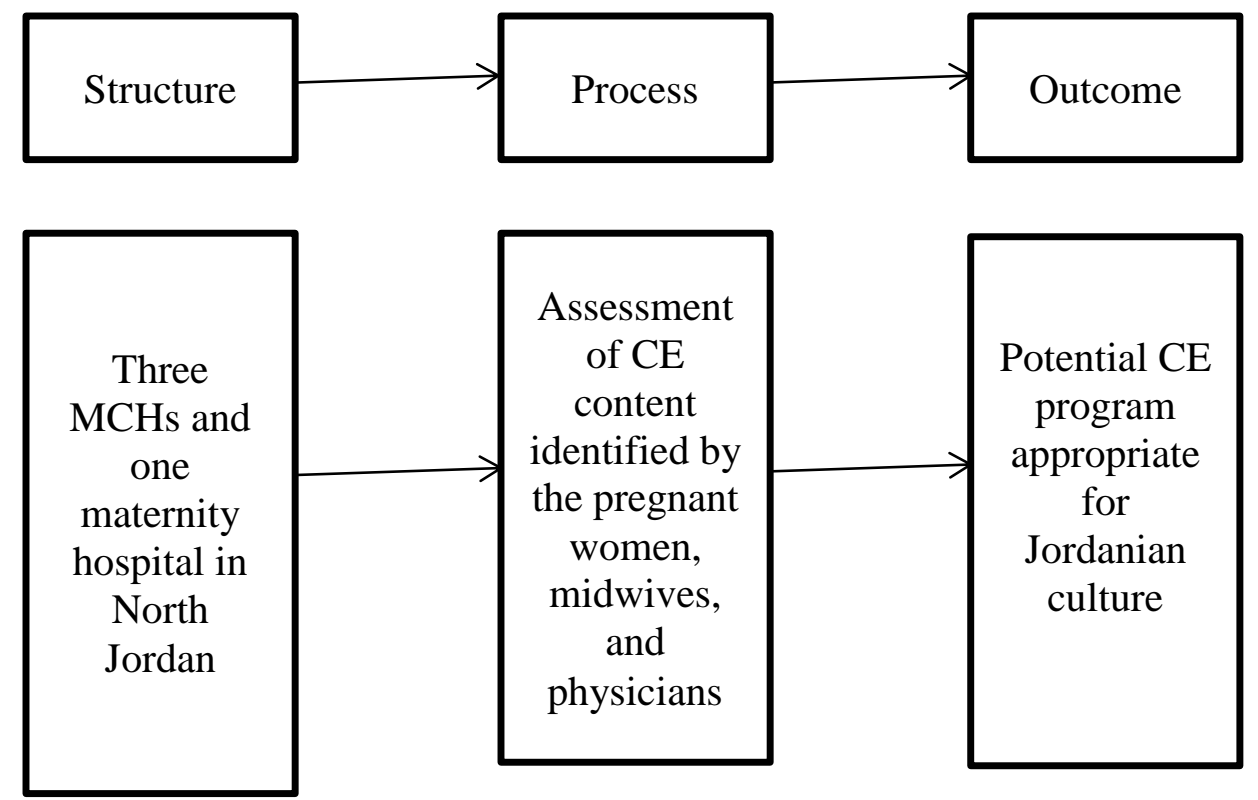

Figure 1. Integration of Donabedian's Conceptual Framework to Childbirth Education at Maternal and Child Health Centers in North Jordan. 


\section{Chapter II}

\section{LITRATURE REVIEW}

\section{Introduction}

This chapter reviewed the literature on childbirth in Jordan, the history of programs of childbirth education, types of childbirth education programs, content, timing, duration and outcomes of CE programs, and childbirth education in Jordan and the Middle East. The chapter ended with a discussion of possible childbirth education programs that might be adapted for Jordanian women.

CE programs are a set of classes planned to help expectant parents learn about and prepare for pregnancy, labor, birth, and the newborn. Most classes take place during pregnancy to explain about the various aspects of preparing for pregnancy, how to adapt with pregnancy, labor and birth, immediate post-partum care and care of the newborn (Hotelling, 2009). In evaluating the reported literature, no studies were found evaluating CE programs in the Middle East including Arab countries. However, some articles discussed the need for women to be educated about aspects of antenatal and childbirth care.

In the United States, most births took place at home before the 1930s, and were viewed as a normal part of life for women. Pregnant women were supported and cared for by other women in the family. Joint family systems were common, and women cared for each other at home (Lothian, 2008; Walker, Visger, \& Rossie, 2009). Formal CE did not start in the United States until the 1960s, when women labored and delivered their babies in hospitals. Some information was provided by the midwives or physicians but was not considered a critical part of the maternity care (Leavitt, 1986; Zwelling, 1996). 
This scenario is what is happening in Jordan in current antenatal care provided for pregnant women. Women in Jordan receive information about childbirth from informal sources such as other females in the family or from the medical staff in antenatal clinics (Owies, 2009).

Women in Jordan who delivered their babies in hospitals do not have the support they had when they used to deliver at home. In hospitals, women in labor are isolated from their support system and have to rely on midwives, nurses and medical staff to attend to them. During this time, women reported feeling unprepared for the hospital routine and experience of labor and delivery (Owies, 2009).

\section{Childbirth in Jordan}

Jordan's population is nearly 7,000,000 people with roughly a 38 per 1000 population crude birth rate, a median age of 23 years, a total fertility rate of 3.1 , a perinatal mortality rate of 22 per 1000 total births, and a neonatal mortality rate of 16 per 1000 live births (UNICEF, 2013). In total, 99\% of pregnant women receive antenatal care, and almost $98 \%$ of people in Jordan live within a one-hour walk to a health care facility that provides professional health care services (HPC, 2010).

In 2013, approximately 263,700 women received care from the maternal health care centers of the Jordanian MOH (MOH, 2014). Of those pregnant women who received antenatal care in Jordan, 71\% came for the first visit during the first trimester, $23 \%$ during the second trimester, and $6 \%$ during the third trimester. These women received a mean of 3.9 antenatal visits during pregnancy (MOH, 2014). During these visits, woman receives information if she asks about a concern or had changes in her lab tests that showed a problem during pregnancy. The midwives are required to sign a 
checklist found in the patient file provided by the $\mathrm{MOH}$. This checklist includes teaching about nutrition, danger signs during pregnancy and preparation for delivery. However, education for women is not organized or programed. Midwives complained that the high number of women that visit the $\mathrm{MCH}$ and the shortage of midwives may limit the contact time between the pregnant women and the midwife, thus, limiting the time for teaching (Registered Midwife Hiam Obeidat, personal communication, April 23, 2015). There are no organized programs that take place in the health centers to assess and cover the education needs of pregnant women (Registered Midwife Haia Al-Ajloni, personal communication, July 22, 2015). Women tend to come to prenatal care facilities to receive care in the public sector. This gives the care providers an excellent opportunity to assess and educate pregnant women for childbirth. However, most women come to the hospital unprepared (Oweis, 2009)

The situation in Jordan is complicated by the repetitive waves of immigration after war crises in the nearby countries such as Palestine, Iraq, and most recently Syria. Murshidi, Hijjawi, Jeriesat, and Eltom (2013) reported that more than half a million Syrian refugees have fled to Jordan. Jordan shares history, culture, and a long border line that was open for a long time with Syria. About 70\% of the Syrian refugees in Jordan reside within the Jordanian communities and only $30 \%$ stay in the refugee camps in $\mathrm{Al}$ Zaatari and other areas in Jordan. Jordan's MOH and other partners such as United Nations High Commissioner for Refugees (UNHCR) provide health and humanitarian support in the camps. The larger population of refugees outside the camps is not addressed in the literature, and the management of their health needs is not clear in the Jordanian statistics. However, the $\mathrm{MOH}$ provides the refugees with full access to the 
public health facilities along with the Jordanian population. Some other nongovernmental organizations provide health services to the Syrian refugees outside the camps. Most of the refugees are located in the northern part of Jordan. Health services are overstretched and overcrowded mostly by refugees. The health service professionals and facility capacities were not adjusted based on increased demand. Both people and government in Jordan are committed to help Syrians, but the demands are exceeding the availability in the health sectors and that causes potentially serious health problems to both Syrians immigrants and Jordanians (Hall, 2013; Murshidi et al., 2013).

The number of pregnant women using the public prenatal care facilities in Jordan cannot be calculated accurately because the number is continuously increasing as the Syrian refugee women escape to Jordan. These women potentially need prenatal services, especially in North Jordan near the Syrian border with Jordan. Education programs to prepare these women for their childbirth experience are lacking. Such programs have been in existence for decades in many developed countries but may not be readily adapted to developing countries where gender roles and cultural practices differ.

\section{Programs of Childbirth Education}

\section{Historical background}

In the 1940s, poor maternity and newborn outcomes were a concern in the United States. That led to the initiation of improvements in antenatal care. Women started to look for answers to help them cope with unfamiliar hospital routines and methods of care when they were isolated from their support at home. In 1933, Grantly Dick-Read published the "Childbirth without fear," which is considered the first structured program of CE in the United States (Zwelling, 1996). However, as a response to the maternal and 
infant poor health outcomes in the beginning of the $20^{\text {th }}$ century, the American Red Cross and the Maternity Center Association also prepared prenatal educational programs as early as 1908 (Nichols \& Humenick, 1988).

In 1951, a French obstetrician, Fernand Lamaze, introduced the Lamaze method for CE. His method consisted of CE classes that focused on relaxation and breathing techniques during labor to control pain. Lamaze highlighted the emotional support of women in labor, and advocated for the involvement of fathers in the process. Ultimately, Marjorie Karmel and Elisabeth Bing (both were mothers that used the Lamaze method in their own childbirths) established the American Society of Psychoprophylaxis in Obstetrics (ASPO), which helped to extend the Lamaze method throughout the United States. Eventually, the Lamaze method was used as another name for CE. Hospitals, that prepared their own CE classes started to adapt the Lamaze method and modified it to suit their needs (Walker et al., 2009).

In the United States, CE has been accepted as a part of antenatal preparation for pregnant women by the health care community. Currently, most CE classes have moved into the health care system making $\mathrm{CE}$ available for a wider variety of women in the United States (Zwelling, 1996). Women who receive hospital based CE became more comfortable with the environment and the staff of the hospital (League \& Novelli, 1994).

The goal of health care professionals in the 1990s was to improve prenatal care, and eventually, improve the health status of women and children. The goals of the pregnant women and their partners were to gain information and decrease the stress and anxiety of the pregnancy and labor experiences. The goals of the health care 
professionals and the consumers can differ, but should reach a point where the health and wellbeing of the mother and her baby take first priority (Zwelling, 1996).

In the 1990s, the initiatives to improve the maternal and neonatal morbidity and mortality resulted in positive changes. New changes were introduced in prenatal care including involving the family members in the pregnancy and birth experiences, and the introduction of home-like labor rooms. There has also been a dramatic increase in the use of medical technology in pregnancy and childbirth. This technology was used for both normal and complicated pregnancy and births including: routine epidural anesthesia and routine use of oxytocin for induction of labor. The medical team viewed pregnancy and childbirth as potentially high-risk. The model of medical management resulted in the implementation of routine tests and interventions to prevent negative outcomes during any pregnancy and childbirth (Lothian, 2008).

With the end of the twenty century, new content was added to CE as a part of antenatal preparation. The scope of $\mathrm{CE}$ has been expanded to include preconception, early pregnancy, exercise, cesarean preparation, breast feeding, newborn care, infant cardiopulmonary resuscitation, parenting classes, and the traditional classes on how to prepare for the childbirth experience (Biasella, 1993; Walker et al., 2009). The CE needs of the parents in the $21^{\text {st }}$ century are different than those of parents in the past. The fast pace of life and the new era of computers, internet and rapid changes in the life style have created a generation that are used to obtaining what they need fast, easy and at the tip of their fingers (Stoll, Hall, Jassen, \& Carty, 2014). They demand facts about the birth process and all the interventions, technology, and options available to them (Stoll et al., 2014). Modern expectant couples seek information to decrease their fear of the 
experience, and many of them will demand any interventions to decrease that feeling of pain and fear (Records \& Wilson, 2011). Some couples will ask to decrease interventions as much as possible, but they are smaller group. However, most couples these days want their childbirth to be as easy, fast and as pain-free as possible (Zwelling, 1996; Lothian, 2008). Expectant couples need help to empower their decision making. This can occur during $\mathrm{CE}$ where expectant couples can potentially get accurate, up-to-date information, which should be balanced and unbiased toward any one option in childbirth. Educators should explain to women that they should choose what is best for them from the wide range of options available (Lothian, 2008).

Understanding the history of CE development in developed countries can help in developing appropriate CE programs to use in other developing countries. The level of prenatal needs and the type of maternal care available must be considered when choosing these programs.

\section{Types of CE Programs}

The most popular CE programs are the Lamaze and the Bradley methods. Other programs have adapted aspects and principles from those two programs and added or developed new parts to meet the needs of different couples.

\section{Lamaze International}

Currently, Lamaze is not only childbirth education, but also a philosophy that helps women adapt as they prepare for their pregnancy, labor and delivery. The American Society of Psychoprophylaxis in Obstetrics (ASPO) was renamed Lamaze International to imitate the Lamaze philosophy. The overall goal of Lamaze International can be summarized as a way to increase women's confidence in their ability to give birth 
in control with freedom of choice and support of family and health care professionals (Walker et al., 2009). Pregnant women are encouraged to schedule themselves for Lamaze classes as early as possible in pregnancy. Classes consist of at least 12 hours of session time, and are held at flexible times during the week or weekends. The class size is limited to 12 pregnant women and their partners. The curriculum is clear and documented, focused on preparing the pregnant woman and her partner for normal labor and birth. Classes incorporate various activities and lessons using strategies that combined cultural values and beliefs of the participants (Lamaze International, 2013). The classes are interactive and presented by specially trained educators that obtain a license in Lamaze training. Trainees include nurses, midwives, or social workers. The program has content on 6 care practices intended to support normal labor:
a) Spontaneous initiation of labor
b) Support from loved ones (Husband and family)
c) Freedom of movement of women in labor
d) Avoidance of routine intervention
e) Avoidance of lithotomy position or positions where women lie on their backs
f) Rooming mothers and babies together after birth (Lamaze International, 2013).

\section{The Bradley method}

The Bradley method involves husband or partner coaching women based on a natural birth model. It is designed to prepare the couples for a normal birth without routine use of interventions or medications. The model was prepared by an American obstetrician, Robert Bradley. He wrote the book Husband-Coached Childbirth (Bradley, 
2008) to explain his proposed 6 needs of laboring woman: a) darkness and solitude quiet, b) physical comfort during the first stage of labor, c) physical relaxation, d) controlled breathing, e) need for closed eyes, f) and the appearance of sleep. Bradley incorporated these beliefs into his program by asking the husband or partner to provide support to the pregnant woman and ensure that the environment surrounding the laboring mother met these needs. Husband-Couched Childbirth focuses on the husband's perceptions and responses to birth. The program works on building bonds and trust between the pregnant woman and her partner by sharing the duties and activities during classes (McCutcheon, 1996). The program consists of 12 -week classes where the couples set their own goals. The quality time the couples spend in the Bradley CE classes provide opportunities to secure emotional, physical, and interpersonal skills to build their confidence in their ability to give birth. The focus of the program is sharing every aspect of the natural and unmedicated pregnancy and birth experiences between the couples (Bradley, 2008).

The American Academy of Husband-Coached Childbirth (AAHCC) trains female educators to take roles in the Bradley class series. Most of the Bradley method instructors are women who experienced unmedicated childbirth and attended the Bradley classes themselves. The Bradley classes are mostly attended by couples. No research studies were found in regards to the effectiveness of the Bradley classes. However, according to Cosans, (2004), statistics are submitted yearly to the AAHCC. Statistics showed that the Bradley classes' attenders had $88 \%$ unmedicated births and a cesarean rate of $17 \%$ (Cosans, 2004). This program is not applicable to Jordan since husbands are not allowed in the labor room in the public sectors (Abushaikha \& Massah, 2012).

\section{International Childbirth Educators Association (ICEA)}


ICEA is a professional nonprofit organization started early in the 1960s and includes more than 4000 members (ICEA, 2015). Professional CE instructors taught mainly the Lamaze curriculum after the advancement of hospital-based CE classes. The classes focus on informed choice throughout pregnancy and birth. The main principles that guide ICEA are: family-centered maternity care, freedom of choice, and the knowledge of alternatives in childbirth. Childbirth education classes that are provided by ICEA include a variety of timing, schedules, and content depending on the needs and preferences of the individuals or groups. Both private and group sessions can be available with the ICEA principles incorporated (Walker et al., 2009). This program, although very effective and working to suit women from different backgrounds, would not be applicable in Jordan because of limited resources. In Jordan, as a developing country, cost must be considered when preparing a program especially in the public sector. Variability in timing and content could be the next step after establishing a CE program in Jordan.

\section{Other models of CE}

The proceeding most known CE models may meet the needs of some expecting mothers. However, other models for CE have emerged and are attracting a growing audience. Examples include hypnobirthing, mindfulness-based childbirth and parenting, and birthing from within. These models are gaining in popularity in developed countries (Walker et al., 2009).

Hypnobirthing is a model and philosophy that uses the power within a human's body through hypnosis. Childbirth educators use hypnobirthing to help expecting parents 
to have positive expectations and experiences during pregnancy and childbirth (Walker et al., 2009).

Vandevusse, Irland, Berner, Fuller, and Adams (2007) conducted a retrospective, explanatory, and descriptive study using chart reviews of 101 charts of women who gave birth in one large tertiary medical center. The sample was divided into: a control group who chose not to have hypnosis childbirth classes (51 women - 27 primiparas and 24 multiparas), and the hypnosis group who chose to take the hypnosis classes (50 women 24 primiparas and 26 multiparas). The charts are those of clients of one physician who offered these women the chance to attend hypnosis childbirth education classes in the same hospital for 2 years before the beginning of the study.

The program consisted of 5 sessions conducted by a physician or a social worker. The classes included grouped (20 - 30 women) and individualized sessions. The content included: understanding self-hypnosis, increasing awareness of trance phenomena, expanding awareness of sensory preference (e.g., trance logic, appropriate language, visual and feeling stimulants), using trance induction with labor metaphor (resting, images, time distortion), using self-hypnosis for specific concerns associated with labor (e.g., vomiting and shaking), and increasing awareness of other pain relief methods (methods and side-effects).

Results showed no significant differences in the demographic characteristics of the 2 groups. Most of the women in the 2 groups were married $(96 \%, n=48$ and $90 \%$, $n=46)$, and white $(96 \%, n=48$ and $86 \%, n=44)$. The gestational age for delivery was 39 weeks for both groups. Women in the hypnosis group's charts revealed significantly less use of sedative medication $(p<.0001)$, analgesia $(p<.001)$, and less use of epidural 
anesthesia during labor $(p<.001)$. The neonates' mean 1-minute Apgar score was significantly lower in the control group $(p=.008)$. Vandevusse et al. (2007) concluded that hypnosis can be cost effective because of the decreased use of costly pain management procedures compared to the low cost of the hypnosis classes. However, these costs were not included or compared.

Mindfullness-Based CE model uses the Mindfullness- Based Stress Reduction (MBSR) program developed in the 1970s by Kabat-Zinn (Vieten \& Astin, 2008). MBSR skills include using the awareness of one's present experience through meditation in a non-judgmental, one-moment at a time, way. This method works by inducing a state of relaxation through observing the mental and physical changes that take place during childbirth without trying to alter this state. By deep concentration on the state of mind, the person will enter the desired state of relaxation. MBSR was adapted into Mindfullness-Based CE in 1998 and includes nine, 3-hourse weekly sessions, one long meeting, and a post-partum meeting (Vieten \& Astin, 2008). No research studies were found to evaluate Mindfullness-Based CE.

The "birthing from within" CE model was developed by Pam England after undergoing her own childbirth. Her childbirth experience inspired her to think about the needs of women during pregnancy, labor and birth. England and Rob Horowitz wrote Birthing from within: An extra-ordinary guide to childbirth preparation. The birthing from within CE classes use introspective, experiential, self-directed classes with practical information. The classes are taught from the perspectives of baby, mother, father and culture, and not from the professional perspective. No complex physiology, anatomy or hospital procedures are used in the classes. The main teaching principles that guide the 
"birthing from within" classes are: adapting natural birth, using soulful and holistic approaches (consider body, mind, and spirit during pregnancy and childbirth), building creative self-expressions (be free to express self and use that to cope), creating classes by both couples and instructors, and helping couples to cope with challenges (Walker et al., 2009). No studies were found to evaluate this method for CE.

Another CE program was introduced by Demecs, Fenwick, and Gamble (2011), who conducted a descriptive qualitative study to explore the experiences of pregnant women in a CE program intended to use creative activities. Seven pregnant women participated in 6 creative arts sessions, 2 hours each for a 2-month period. Sessions were facilitated by a midwife with a background in the creative arts. Women were enrolled in the program when they were 20-30 weeks gestation. The program sessions included: singing to establish group cohesion, dancing and moving to energize women, and storytelling and weaving to generate a relaxing atmosphere. Data for a descriptive study were collected using individual interviews, field notes, and self-administered questionnaires. Demecs et al. (2011) found that engaging pregnant women in creative activities can promote a sense of physical and mental well-being. The participants reported that coming together in a supportive sharing environment created opportunities to learn from each other and use their cultural knowledge about pregnancy. This environment increased their confidence to make the decisions that best meet their plans regarding childbirth.

Ip, Tang, and Goggins, (2009) Conducted a randomized controlled trial to test the effectiveness of a self-efficacy enhancing educational program (SEEEP), which could increase self-efficacy for childbirth and coping abilities used to reduce pain and anxiety 
during labor. The researchers used the efficiency- enhanced educational intervention based on Bandura's self-efficacy theory (1986). The study's hypotheses were that women who receive SEEEP (i.e. the experimental group) will: (a) report less anxiety, higher outcome expectancy, and higher efficacy expectancy at the three stages of labor, (b) report lower level of pain in the three stages of labor, and (c) show higher levels of coping with pain than the women in the control group.

The sample included 133 primiparous Chinese women randomly assigned to either an experimental group $(n=60)$ or a control group $(n=73)$. The experimental group had two 90-minute sessions of CE classes between the $33^{\text {rd }}$ and the $35^{\text {th }}$ week of gestation. The outcome assessment was conducted within 48 hours after delivery. Maternal self-efficacy prior to labor was measured using the form of Chinese Childbirth Self-Efficacy Inventory (CCSEI). Pain and anxiety during the three stages of labor and delivery and the coping behaviors during labor were measured by the Visual Analogue Scale and Childbirth Coping Behavior Scale respectively.

Women in the experimental group were more likely to demonstrate significantly higher levels of self-efficacy for childbirth $(p<.0001)$, lower perceived anxiety $(p<$ $.001)$ and pain during the first two stages of labor $(p<.01)$, and greater performance of coping behaviors during labor $(p<.01)$ than the control group. The researcher concluded that the educational program based on Bandura's self-efficacy theory was effective in promoting pregnant women's self-efficacy for labor and delivery and reducing their perceived pain and anxiety in the first two stages of labor.

This study stressed the importance of pain and anxiety relief during labor and delivery for both women and care givers. They suggested that the efficacy-enhancing 
educational program should be investigated further and eventually integrated into CE programs. However, no details were provided on the way the researchers avoided contamination between the two relatively small groups, as the participants received antenatal care from the same hospital.

\section{Childbirth Education in Jordan}

Pregnant women in Jordan receive information about their health from various sources. However, no formal CE programs were found in the literature or on the $\mathrm{MOH}$ Web site. $\mathrm{MOH}$ publishes various printed educational materials such as pamphlets (MOH, 2014). The MOH uses media (television, radio, and billboard advertisement) to inform women about the importance of health and screening (Jordan Breast Cancer Program, 2014). However, in Jordan, availability of information sources, such as television media and the Internet is not studied. There is no literature on the proportion of women who use these sources to look for information regarding prenatal preparation in Jordan, including CE. However, researchers have reported Internet use by pregnant women in other countries, such as Turkey (Purdy, 2011).

\section{Childbirth education in Middle Eastern and developing countries}

No studies were found examining childbirth education programs in the Middle East including Arab countries. However, some articles discussed the need for women to be educated about aspects of antenatal and childbirth care. Al-Mandeel et al. (2013) conducted a prospective cohort study to explore the Saudi women's preference, attitudes, and knowledge in regards to supportive companions during labor in Riyadh. The study used individual interviews and questionnaires in 3 governmental hospitals. The sample consisted of 402 women during their postpartum hospital stay. Only 182 women (45\%) 
preferred the presence of a companion during childbirth. Of these, 58\% $(n=106)$ preferred their mothers to be with them during childbirth and $42 \%$ ( $n=76)$ did not, and $51 \%$ ( $n=138)$ preferred their husbands as the supportive companions and the remaining $49 \%$ ( $n=89)$ did not. Only $14 \%(n=26)$ had actually experienced having a companion during their previous childbirths. There were no statistically significant effects of maternal age, level of education, and perinatal status on labor companion's preference. However, women who had any source of antenatal education classes or reading materials tended to prefer having support during labor. More than third of the participants thought that having a companion during labor would not be helpful. The most common reason (64\%) ( $n=116$ ) was that they did not like being exposed to the companion. Al-Mandeel et al. thought that the reason for not preferring a companion in labor was the lack of knowledge about the positive role of support during childbirth or the Saudi women's cultural beliefs. Al-Mandeel et al. recommended educating women during their pregnancy about the benefits of support during labor.

Evaluation of CE programs was found in Iran and Turkey. The researchers explored the content and the effectiveness of these programs. Fahami, Masoudfar, and Davazdahemami (2006) studied the effects of the Lamaze method on the outcomes of pregnancy and labor of Iranian primiparous women. Iran is a country that shares similar cultural backgrounds with Jordan. Fahami and colleagues used a quasi-experimental design. The pregnant women were assigned to one of the two groups, either the standard care or the Lamaze groups when they reached 24-26 weeks gestation. The sample included 70 women who were referred to a university hospital in Tehran. Data were collected using a questionnaire and a labor and delivery checklist. The Lamaze technique 
used for the study group included 6 training sessions in total. Each participant was administrated a questionnaire weekly to evaluate what the women learned after each session, with one final survey administered 24-hours after delivery with a labor and delivery checklist.

Although the sample was convenient and small $(N=70)$, the results showed significance. The subjects in the two groups were similar in demographic characteristics and their prior level of knowledge regarding labor and delivery and the Lamaze method. There were no differences in regard to the caesarian section rate, gestation of pregnancy, length of the first stage of labor, and Apgar scores of the newborns. However, there were significant differences in the higher rate of vaginal deliveries in the Lamaze group $(\mathrm{p}<$ .01) compared to no significance in the rates of vacuum and forceps deliveries. The mean length of the second stage was significantly shorter in the Lamaze group $(p<.001)$ and the newborn's mean weight was greater compared to the controls $(p<.01)$. Women in the Lamaze group showed higher satisfaction levels with their labor and delivery experience compared to the controls $(\mathrm{p}<.001)$. Fahami et al. (2006) concluded that adapting the Lamaze method could increase women's satisfaction after delivery, and decrease the length of the second stage of labor; therefore, they highly recommended including the Lamaze method in the maternal care program.

Sercekus and Mete (2010a) used a quasi-experimental design to assess the effects of antenatal education on prenatal and postpartum adaptation in Turkey. Maternal adaptation was defined as adaptation to changes on women's life when being pregnant and after having the baby. Maternal adaptation is affected by maternal age, support system, hospital stay, and recovery status after delivery, and neonatal health. The 
investigators hypothesized that: women who received group or individual antenatal education will have higher degrees of prenatal and postpartum adaptation than the control group; women who received group antenatal education would have higher degrees of prenatal and postpartum adaptation than those who received individual education. The sample consisted of 120 primiparous women, divided randomly into three groups. Two experimental groups attended either group or individual antenatal education with the standardized care. A control group received the standardized antenatal care only. Data were collected using Lederman's prenatal and postnatal self-evaluation questionnaire with a demographic data form. This study used the Roy Adaptation Model (2009), where human beings are seen as adaptive systems that interact with the environment and change accordingly.

The researchers found a positive effect of antenatal education on prenatal adaptation with no difference between the group and individual classes. Nevertheless, no benefits of CE were found on postpartum adaptation. Roy's Model provided effective guidance for antenatal education as adaptation occurs when the mothers feel that the content are related to their interests. The researchers also suggested that group education was favored over individual education because of the lowered cost, and the outcomes were comparable. The limitation of the study was that the control and experimental groups were not from the same setting. Nevertheless, the sample characteristics did not show significant differences between the three groups.

The content and timing of the health education sessions are given in detail. The education content included: conception, nutrition during pregnancy and postpartum, common complaints in pregnancy and ways to manage them, tests required, exercises in 
pregnancy and postpartum, childbirth, breathing and relaxation exercises, physical and emotional changes in the postpartum period, taking care of oneself, breast feeding, how to manage returning to work, social support in pregnancy and postpartum, and newborn care. This can be helpful in developing new CE programs in other developing countries. The group education consisted of 6-10 participants. They were offered a total of 14 hours class work lasting about 120 minutes weekly for 7 weeks (theoretical information for 90 minutes and exercise for 30 minutes). Individual education was about 10 hours, 120 minutes once a week, for 5 weeks (theoretical information for 90 minutes and exercise for 30 minutes).

Sercekus and Mete (2010b) conducted a qualitative study using semi-structured interviews with a sample of 15 primiparous women in Turkey. This study aimed to describe the pregnant women's perception of the effectiveness of CE on pregnancy, childbirth and postpartum periods, and their impressions of the type of education in antenatal education classes. The data were analyzed using content analysis, and no theoretical framework was reported.

Participants' ages ranged from 21 to 30 years (mean age, 26.7 years). Most of participants were high school graduates (60\%), unemployed (80\%), and most reported considering themselves as middle economic status (86.7\%). Of the women, $80 \%$ had experienced delivery by caesarean section: $66.7 \%$ by reason of actual indication and 13.3\% by choice. The results showed that the women thought antenatal education had positive effects on both knowledge about, and the process of pregnancy, childbirth, breast feeding, motherhood, and infant care. Some women (3 participants) perceived CE to decrease their anxiety and fear of labor, while others (One participant) verbalized that the 
details of labor and delivery in the classes made them fearful and more anxious. The investigators concluded that the content and the methodology of CE should be planned in a way to avoid increasing pregnant women's fears. The researchers favored group CE because it incurred a lower cost and the pregnant women preferred it. However, the sample was relatively small and the findings might be enhanced with a larger sample. This study contributed to the knowledge base about CE in Islamic countries, and can help serve as a guide to developing new CE programs.

Turan and Say (2003) conducted a study to describe the implementation and evaluation of a community-based CE program for first-time pregnant women in Istanbul, Turkey. The sample consisted of 2 groups: the childbirth education group $(n=100)$ and the control group $(n=157)$. The CE group and the control group were obtained from the same hospital but in a different period to avoid contamination. The study's hypothesis was that women who participated in the CE program would have higher rate of vaginal delivery, practice more maternal and infant healthy behaviors recommended by the program, and use contraceptive methods more than those women in the control group.

The CE program consisted of 8 daytime sessions, 2 hours each. The sessions were done 2 times a week for 4 weeks. Each session was managed by a nurse, a facilitator, and a trained community member. The content included health during pregnancy, nutrition during pregnancy, preparation for childbirth, childbirth process and care, immediate transition to motherhood, communication, feeding and care of the newborn, and contraceptive use after birth. The researchers used pre and post-tests to evaluate the change in mothers' knowledge for both groups. Then, surveys and interviews 
were administered 2 to 3 months after delivery to evaluate the differences in health behaviors between the two groups.

There were no significant differences between the childbirth education group and the control group in the demographic characteristics. Only about $15 \%$ were employed in both groups. Most of them received antenatal care in the private sector ( $84 \%$ for the CE group, $80 \%$ for the control group). No significant differences were found between the study groups in vaginal birth rates (43\% for the CE group, $33 \%$ for the controls) and postpartum check-ups within the first 6 weeks ( $88 \%$ for the CE group, $79 \%$ for the control group). However, the researchers reported significant improvement after the community-based program helped women in the childbirth education group in the following healthy behaviors; breast feeding within 2 hours after delivery (51\% CE group, $32 \%$ control group), infant check-ups and care (58\% CE group, 32\% control group), and use of contraceptive with male participation (69\% CE group, 52\% control group). The researchers concluded that the program might increase the chances other women would adapt healthy behaviors after birth after CE. It was concluded that childbirth education can influence women and their partners to adapt healthier behaviors in developing countries and the program may be adapted in other developing countries (Turan and Say, 2003).

Malata, Hauck, Monterosso, and McCaul (2007) conducted a mixed-method 3 phase study in Malawi East Africa. The researchers used Ewles and Simnett's (1999) theoretical framework to provide the steps needed to develop a CE program. The three phases were to: (a) identify Malawian women's CE needs from the literature and from four focus group interviews of Malawian midwives, (b) develop a CE program, and (c) 
test the effectiveness of the program. The investigators used a quasi-experimental design with sequential sampling to test the effects of the program. The sample was divided into a control group ( $n=104)$ and an intervention group $(n=105)$. No significant differences were found between the 2 groups in sample characteristics. The highest percentage was 19-24 years olds in both groups (50\% in the CE group, $46 \%$ for the control). Other age groups were also similar in both groups. Most the participants were married (92\% in the CE group, $89 \%$ for the control), with primary education (60\% in the CE group, $62 \%$ for the control), and unemployed (94\% in the CE group, $92 \%$ for the control).

The two groups answered a pre-test questionnaire derived from the content of the CE program. The content was displayed in a table showing three sections:

1. antenatal care; nutrition, cultural issues, common discomforts, danger signs, sexual transmitted diseases, and preparation for delivery.

2. The labor process; possible complications, caesarean birth, nonpharmacological pain relief measures.

3. Postnatal care; self-care, exclusive breast feeding, newborn care, danger signs during postpartum, and family planning.

The schedules were also presented in a table showing the detailed plan of a 6week program, 2 sessions every week, with each session around 2-3 hours. Some women requested individual sessions and were allowed 5-15 minutes of discussion time.

The researchers distributed the control group questionnaire before implementing the CE program in order to avoid contamination between the control and the experimental groups. The control group received the routine informal teaching from the midwives, and then answered a post-test questionnaire. After completion of the CE 
program, the intervention group was asked to answer an identical post-test questionnaire. The purpose of the last phase of the study was to assess the changes of childbirth knowledge after a 6-week CE program.

The findings demonstrated a significant increase in the intervention group's knowledge after the implementation of the CE program in comparison to the control group. Consequently, the researchers concluded that $\mathrm{CE}$ programs can be designed to meet specific informational needs that are culturally appropriate and can benefit pregnant women in developing countries despite poor literacy. This study provided baseline data for future studies on the content and timeframe CE programs in developing countries. Limitations included: (a) focus group numbers and characteristic of the midwives involved were not clear in the article, (b) the researchers did not ask the women in the current study what their needs in antenatal education were, and (c) they adapted the findings of the primary investigator's (PI) previous study to identify the perception of Malawian women regarding their CE informational needs. However, data on antenatal needs of the Malawian women (Malata, 2000) may have been outdated due to the extended time period between the two studies

\section{Health promotion lifestyle behaviors.}

Jordanian pregnant women's health promotion lifestyle behaviors were evaluated by Gharaibeh, Al-Ma'aitah, and Al Jada (2005) using a descriptive quantitative design. The sample consisted of 400 Jordanian pregnant women in their second half of pregnancy or beyond. The participants were recruited from 5 mother and child health centers (MCHs) in North Jordan. The instrument was an Arabic version of the Maternal Health Promotion Lifestyle Profile (MHPLSP) developed by Walker et al. (1987). The tool was 
assessed for content validity and piloted before being used in the study and was found reliable.

The participants in Gharaibeh's et al. study were mainly young women (90\%, $n=361$ ) below 36 years of age. The average family size was 4 , and most of them lived in nuclear families $(75 \%, n=304)$. The majority was multiparous $(76 \%, n=307)$, and most participants reported their husbands as their support system $(78 \%, n=312)$.

Results showed high scores of health promotion behaviors of Jordanian pregnant women compared to other social groups in Jordan or pregnant women in other cultures. Jordanian women scored high on health responsibility and self-actualization, moderate on interpersonal support and nutrition, and low in physical activity and stress management. Based on the findings, Gharaibeh et al. (2005) recommended that health promotion and healthy lifestyle regarding physical activity and stress management should be integrated into prenatal care for Jordanian women. They stressed the importance of the $\mathrm{MCH}$ centers' responsibility to increase women's awareness of health promotion during pregnancy. Consequently, awareness of health promotion during pregnancy should be included in the new CE program.

Danger signs during pregnancy. Knowledge of danger signs during pregnancy is important for any CE's needs assessment. Pregnant women in Jordan need to be educated on recognizing danger signs during pregnancy. Okour, Alkhateeb, and Amarin (2012) conducted a descriptive cross-sectional study to assess the levels of awareness of danger signs and the causes of complications during pregnancy among Jordanian pregnant women. The sample consisted of 350 women who attended prenatal care in 4 MCHs in Zarqa, Jordan. Women were included in the sample if they were 15 years old 
or older with singleton pregnancies regardless of the gestation age. The instrument was a structured questionnaire completed by the research team members during interviews. The decision was made that women were aware of danger signs during pregnancy if they could recognize 4 out of 12 danger signs and symptoms included in the study.

The mean age of women was 27 years, and most women had high school education or less, and were unemployed. Around $80 \%$ of women experienced at least one of the danger signs during the current pregnancy. Of those, $91 \%(n=319)$ contacted professional help for these signs. Only $27 \%(n=94)$ of them were informed by physicians about the danger signs and life threatening conditions during pregnancy. Only $15 \%$ of women $(n=53)$ recognized at least 4 signs and symptoms during pregnancy, $61 \%(n=$ 214) recognized at least one sign or symptom, and $38 \%(n=133)$ did not recognize any danger signs or symptoms during pregnancy. Awareness of the dangerous signs was significantly associated with more years of education, women's employment, family size (more than 5 were more aware), and provided information about danger signs by health care providers. Women in the study were mainly aware of the following dangerous signs: vaginal bleeding $(29 \%, n=102)$, dizziness $(28 \%, n=98)$, and vomiting $(27 \%, n=95)$. However they did not recognize them as dangerous signs that require seeking help.

Awareness of the danger signs during pregnancy can help women make critical decisions regarding seeking help in sufficient time to prevent complications. Accordingly, women in the study did not know danger signs and symptoms and to ask for help in a timely manner. About $85 \%(n=298)$ of women recognized less than 4 danger signs, and 39\% ( $n=137)$ could not recognize any of these signs and symptoms. Only a quarter of the participants had been informed of the danger signs during pregnancy. 
Okour et al. (2012) recommended teaching women about these danger signs and symptoms during pregnancy to help decrease the maternal morbidity rate in developing countries including Jordan. This knowledge can be achieved through CE.

Morbidity during pregnancy: associated factors and prevalence. In Jordan, maternal morbidity rates are still high when compared to rates in the developed countries. Quteitat et al. (2012) published a national cohort study aimed at determining the incidence of maternal morbidity and its main causes in Jordan. The sample consisted of 4,501 Jordanian women enrolled in the study when they were pregnant at 22 weeks gestation or less. The women in the sample were followed through pregnancy, labor and postpartum. Overall morbidity was very high $(61 \%, n=2,746)$. The morbidity was $41 \%$ $(n=1,845)$ antenatally, $35 \%(n=1,575)$ in the periperium, and $19 \%(n=855)$ in postpartum. The caesarean rate was $27.7 \%(n=1,247)$, and caesarean births were associated with $30 \%$ ( $n=554)$ of the overall morbidity cases. Women had anemia (20\%, $n=900)$ at enrollment and 26\% (n=1,170) at delivery. The most common morbidities during the current pregnancy in the sample were urinary tract infections $(20 \%, n=908)$, genital infections (19\%, $n=872)$, and anemia $(11 \%, n=492)$. All of these morbidities are potentially preventable conditions with proper antenatal care and CE (Quteitat et al., 2012). No mortalities were recorded during this study. Parity of more than 4 was significantly related to increased morbidity during the antenatal period but not during the puerperium (Quteitat et al., 2012).

Pregnant women need knowledge about nutrition and anemia during pregnancy. Al-Mehaisen, Khader, Al-Kuran, Abu-Issa, and Amarin (2011) investigated the prevalence and associated factors with anemia among pregnant women in rural Jordan. 
The cross-sectional study used a sample of 700 pregnant women. Of the participants, 34.7\% ( $n=243)$ had anemia. The prevalence was highest for women in their 3rd trimester $(42.5 \%)$ when compared to those in their 2 nd trimester $(32.7 \%)$ or 1 st trimester $(18.9 \%)$. The following factors were significantly associated with anemia: gestational age, body mass index, history of previous surgery, and multivitamin supplements intake during pregnancy (Al-Mehaisen et al., 2011). The investigators concluded that women were more likely to be anemic if they were in their 2nd and 3rd trimesters, underweight, with history of previous surgery, and regularly took multivitamins during pregnancy. The factors associated with anemia and other preventable conditions during pregnancy could be added to CE programs to help women identify the signs and symptoms of these conditions.

Maternal care services. Existing maternal health care services need to be evaluated when planning CE programs. Hatamleh, Shaban, and Homer (2013) published a retrospective explanatory study to investigate what Jordanian women's opinions were of the maternal care and service quality in Jordanian public hospitals. The researchers wanted to assess if opinions of women in Jordan were similar to those in other countries. The sample consisted of 460 women who had singleton deliveries of live births after 37 gestation weeks or longer. All women in the sample were married and 90\% $(n=414)$ were Jordanians. The mean age was 27 years ranging from 17 to 45 years. Most women (76\%,n=349) had only a high school education. Remaining participants $(24 \%, n=111)$ had a community college or university education. The majority of women were multiparous $(80 \%, n=368)$. 
Overall, women reported negative experiences after giving birth in the public hospitals. The data revealed four themes: (a) the care was dehumanized (did not experience respect or courtesy, and did not have the opportunity to clarify information or progress during labor), (b) the over use of technology (such as labor induction and episiotomies), (c) no human support (did not form any trust relationship with midwives or physicians, women had to tell their medical story to many health professionals since they kept changing during her labor; women did not have a female friend or relative support person allowed in the labor room, and many wished they could have them inside the labor room), and (d) the birth environment was inappropriate (women were unable to rest or sleep during and after delivery, and no food was allowed or available inside the labor room). This study provides a clinical picture of how women were treated during labor in the public hospitals in Jordan (Hatamleh et al., 2013). Improving the maternal care in Jordan during labor and delivery is a major research priority. However, until hospital care is improved, women can prepare themselves for the childbirth experience by attending CE.

A negative childbirth experience can have a long term effect. Researchers have indicated an adverse childbirth experience can harmfully affect the women's health and willingness to have another child. Furthermore, women with negative experiences can influence other pregnant women's expectations about childbirth (Waldenstrom, Hildingsson, Rubertsson, \& Radestad, 2004). Waldenstrom, et al. (2004) studied the effects of the negative birth experience and the woman's dissatisfaction with their experience of labor and birth in Sweden. The investigators reported that negative experiences may affect the woman's emotional well-being and willingness to have 
another baby. Waldenstrom et al. (2004) conducted a longitudinal cohort study aimed to assess the frequency and risk factors of negative birth experiences in Sweden over a oneyear period. The sample consisted of 2,541 Swedish-speaking women from all the antenatal clinics in Sweden during a three-week period.

The study used three questionnaires to gather information about the risk factors of negative experiences: during pregnancy, two months after the delivery, and one year after the delivery. The emotional status after delivery was measured using the Edinburgh Postnatal Depression Scale. Concerns during pregnancy were measured by the Cambridge Worry Scale. The one year after birth questionnaire included questions about the birth outcome and the continuity of care giver during labor and delivery.

Seven percent $(n=178)$ of the women had a negative experience. The results indicated the following factors leading to the negative experience: unexpected medical problems, social problems, insufficient time given to answer the women's questions during antenatal preparation, and factors related to feelings of the women during childbirth such as pain and lack of control. Waldenstrom et al. (2004) concluded that a majority of risk factors were related to maternal social background and these unexpected medical problems. The study demonstrated underestimated support. Moreover, listening to the women's own issues regarding their childbirth experience could decrease the negative experiences. Improving antenatal education by listening to what the women need and feel can lead to a better experience.

In Jordan, more than $98 \%$ of the deliveries take place in hospitals (HPC, 2008). Researchers have found that maternal health care in Jordan is highly over-medicalized, hospitals do not follow the normal process for labor, and delivery or postpartum 
suggested by the World Health Organization (WHO) (Hatamleh, Sinclair, Kernohan, \& Bunting, 2008). Shaban, Hatamleh, Khresheh, and Homer's (2011) study used an explorative design with non-participant observation of a sample of 460 low-risk Jordanian pregnant women. The purpose of the study was to investigate Jordanian maternity hospital practices and their consistency with the WHO's evidence-based maternity care. The researchers developed an observational checklist of labor and birth, and a questionnaire investigating maternal characteristics. The questionnaire was revised by a multidisciplinary panel for content validity, and the observation checklist was piloted for clarity and understanding before being used (Shaban et al, 2011).

Based on the results, the majority of participants were multiparous $(80 \%, n=368)$. Nevertheless, a variety of interventions were observed during the participants' normal labor and delivery, such as: augmentation of labor $(95 \%, n=437)$, continuous fetal monitoring (77\%, $n=354)$, lithotomy position (100\%), and episiotomy (37\%, $n=170)$. This study clearly shows that the practices of childbirth care in Jordanian hospitals are largely inconsistent with the WHO's evidence-based practice. Who recommended: augmentation and continuous fetal monitoring only under strict needs, using various positions for delivery and avoiding lithotomy, and performing episiotomy only in $10 \%$ of labor and delivery (Shaban et al, 2011). Based on these findings, it is suggested that more studies are needed to investigate the causes of these inconsistences. The findings were strengthened by the large sample recruited from different cities within the country. This study contributed to the knowledge base regarding the medicalization of normal vaginal childbirth in the country. Shaban et al (2011) recommended that women should 
be advocated, educated and prepared for this type of care in the Jordanian hospitals. This can be achieved through CE.

Hatamleh et al. (2013) stated that the birth memories that mothers report of their childbirth experiences are powerful factors influencing women's future fertility. This can be helpful in planning an education program when the women's opinions of their own childbirth experiences are explored. Hatamleh et al. conducted an exploratory descriptive study to explore the childbirth memories of women in Jordan. The sample consisted of 160 first-time mothers who gave birth in Northern Jordan. Data were collected using three open-ended questions within 6 weeks after delivery. Results showed that all women were married and their age ranged from 17 to 37 years. About two-thirds $(65 \%$, $n=104)$ had a high school education and $36 \%(n=58)$ had graduate education. Most of the women $(73 \%, n=117)$ were housewives. The major themes that emerged from the data were negative childbirth memories, women being processed, dehumanised birth, vivid recall, halo effect, the joy of becoming a mother, and praise for the support of Allah. Women need to be prepared for the childbirth experience (Hatamleh et al., 2013).

Hatamleh et al. (2013) concluded that women received poor care during labor and birth in hospitals. Women seemed to be processed as objects to give birth in a technological manner. They are treated as machines without feelings instead of being independent women requiring information, childbirth education, or supportive 'one to one' care. Childbirth care was based on a medical model where the birth process is established, managed, and controlled by overused birth technology. There was no evidence of woman-centered care provided for women, and little consideration of their psychological, environmental, or family relationships (Hatamleh et al., 2013). 
The practices in the Jordanian hospitals were also compared to the recommended practices of the WHO in Khresheh, Homer, and Barclay's (2009) study. They compared the practices in 3 Jordanian public maternal hospitals with the guidelines of the WHO and evidence-based recommendations. The routine use of episiotomy, electronic fetal monitoring, induction and augmentation of labor, frequent use of caesarean birth is harmful to mother and baby and not necessarily improves the birth outcomes (World Health Organization, 1996). Khresheh et al. (2009) used a descriptive, comparative design. The investigators reviewed the records of 1,254 mothers and babies and compared the findings with the WHO evidence-based guidelines. The interventions rates found in the labor records were inappropriately high. Augmentation of labor (46\%, $n=577)$ and episiotomies (53\%, $n=665)$ appeared to be done routinely and were significantly higher than those found in the WHO guidelines. WHO recommended only 10\% episiotomies in all normal deliveries (Alayande, Amole, \& OlaOlorun, 2012). About a third of women $(37 \%, n=464)$ in the study received any form of pain relief and of these $44 \%$ ( $n=552)$ received intramuscular narcotics. No epidural anesthesia was used because it is not available in the public hospitals. About 67\% (n=840) of women had normal vaginal delivery, 5\% ( $n=63)$ had instrumental delivery, and 12\% ( $n=150)$ had caesarean delivery (compared to 10\% according to WHO, 2015). Of the caesarean deliveries, $40 \%$ ( $n=60)$ were due to insufficient cervical dilatation, $40 \%(n=60)$ were due to fetal distress, and there were no records of the reasons for $20 \%(n=30)$ of the cases.

The first-minute Apgar scores were not recorded for any of the newborns. Although 19\% (n=238) of babies had a 5-minute Apgar score of less than 7, 69\% (n=265) of them received resuscitation at birth including: suction $(60 \%, n=752)$, oxygen therapy 
(50\%, $n=627)$, and intubation $(2 \%, n=25)$. Only $28 \%(n=351)$ of the babies were admitted to the neonatal intensive care units (NICU). Of the babies admitted to the NICU, 69\% ( $n=242)$ were admitted only for observations. Khresheh et al. (2009) claimed that when compared to the WHO's guidelines, the rates of augmentation, episiotomies and caesarean sections were not appropriate or explained. The WHO guidelines were against using narcotic routinely in labor due to their side-effects on the mother and baby. These data also indicated a high number of babies with Apgar scores of less than 7, resuscitation, and admissions to the NICU. The use of narcotic analgesia may affect the type of interventions and care the babies need after birth. The evidence suggested that the use of pethidine as a pain relief method may increase interventions needed by the newborns, admissions to NICU, and cost for the hospitals (WHO, 1996). The researchers concluded a need for these hospitals to consider other pain management methods that cause minimal side-effects to mothers and babies. The data indicated that the documentation system in these hospitals was not complete with much missing information in the records of mothers and babies.

Pain control and relief measures. Pain control is important in labor. The Jordanian women's perception of pain during labor was studied by Abushaikha \& Oweis (2005) in a descriptive study. The sample consisted of 100 low-risk women who delivered vaginally in a major hospital in Amman. The investigators used three Arabic versions of the following instruments: the Numeric pain intensity scale (NPIS), a pain assessment questionnaire, and a demographic questionnaire to explore labor experiences and labor pain intensity levels. The mean age of the participants was $25.5(S D=5.2)$, and all were married. Pain levels ranged from 3-10 $(M=8.8, S D=1.5)$ on the pain scale with 
1 meaning no pain to 10 meaning the pain cannot be endured. There were no significant differences between primiparas and multiparas in the pain levels. The majority of participants $(65 \%)$ did not receive pain relief. The participants reported painful labor experiences. The aggravating factors were physical exhaustion, labor physical changes (dilatation and effacement), and medical procedures during labor including vaginal examination, fetal monitoring, and procedures to induce or augment labor. The alleviating factor reported in the study was the staff support (psychological).

Abushaikha and Oweis recommended reevaluation of current maternity, nursing and midwifery practices and roles regarding labor pain management (not providing support or choices of pain control methods). They suggested that the roles of supporter and educator among maternity nurses and midwives in Jordan also need improvement. Pain control during childbirth is an essential part of the CE and what women need to know about it should be investigated.

These findings of Abushaikha and Oweis (2005) regarding labor pain management are consistent with other studies in Jordan. Oweis (2009) conducted a descriptive cross-sectional study to examine women's perceptions of the different aspects of their childbirth experience including expectations, satisfaction and self-control. The study also explored other aspects of Jordanian women's labor process including length of labor, difficulty of labor, effectiveness of pain control, expectations of pain level, perception of level of involvement in decisions among other variables. The sample included 177 Jordanian mothers recruited from three primary health-care centers located in North Jordan. Findings of the study indicated that women had a more painful labor than they expected, they were scared of the experience, they went through different 
procedures during labor including induction and episiotomy which they did not know about before, and perceived that they had an intense childbirth experience. The majority of participants was not satisfied with the different aspects of their childbirth experience and perceived little control during labor and birth. Oweis recommended that the study findings should be considered by all health-care providers, hospital administrators, and policy-makers. Policy makers need to plan and implement appropriate strategies that could help women go through the childbirth experience with less fear and anxiety. Empowering women with coping mechanisms could reduce their dissatisfaction with their childbirth experience and help them regain more control during childbirth (Oweis, 2009). Such strategies might include reconsidering staffing in the maternity units and patient to nurse or patient to midwife ratio. Having adequate knowledge about the childbirth experience may decrease the stress and anxiety women have and may improve their ability to cope with the process according to Oweis (2009) findings. This is consistent with a Hong Kong study where women reported that the main reason for them wanting to attend CE was to decrease anxiety and fear of childbirth (Lee \& Holroyd, 2009).

The expectations of first-time mothers were also investigated. Oweis and Abushaikha (2004) conducted a descriptive study to assess the Jordanian pregnant women's expectations of their first childbirth experience, and how they perceive the support of nurses and midwives in the labor room. The sample was a convenience sample, consisting of 77 primigravid women. The data were collected using two questionnaires developed for the purpose of the study. The investigators reported validity and reliability of both questionnaires before being used. The reliability coefficients were 
0.83 and 0.88 for the 2 instruments. The questionnaires used were Arabic versions of the Expectations of childbirth experience questionnaire and the Expectations of nursing support during labor and birth questionnaire. The questionnaires were translated and back translated from Arabic to English by a panel of expertise to establish validity. Oweis and Abushaikha (2004) reported that the 2 questionnaires were valid.

The majority of participants $(92 \%, n=71)$ expected a negative first childbirth experience. Findings indicated that the majority of women expected their overall childbirth experience to be frightening $(66 \%, n=51)$, very long $(63 \%, n=48)$, too difficult $(66 \%, n=51)$, and painful $(78 \%, n=60)$. The participants reported that their key source of information about childbirth was their family and friends. They did not expect nurses and midwives to provide information or include them in the decision-making regarding their own childbirth experience. The expectations of a negative childbirth experience could be explained by limited labor preparation and advice given to women. Findings also indicated that women reported that they expected inadequate nursing and midwifery support during childbirth. Oweis and Abushaikha (2004) recommended that health-care providers should emphasize the importance of childbirth preparation and improve the quality of childbirth care to better the expectations and experiences for Jordanian women. Oweis and Abushaikha (2004) also recommended that nurses and midwives should prepare childbirth education classes for women that are both realistic and culturally sensitive to Jordanian women's needs.

Fear, anxiety, and negative expectations can affect pregnancy and childbirth, detrimentally. Adams, Eberhard-Gran, and Eskild (2012) conducted a prospective study to assess the relationship between fear of childbirth and duration of labor. The sample 
consisted of 2,206 pregnant women with a singleton pregnancy (32 weeks of gestation to delivery), who intended to have vaginal deliveries. Fear of childbirth was assessed using the Wijma Delivery Expectancy Questionnaire (W-DEQ) version A (Wijma, Wijma, \& Zar, 1998) at 32 weeks of gestation. Information on labor duration, use of epidural analgesia and mode of delivery was obtained from the maternal records. Fear of childbirth (W-DEQ sum score $\geq 85$ ) was present in 7.5\% ( $n=165)$ of women. Although relatively small number, labor duration was significantly longer in women with fear of childbirth compared to women with no such fear using a linear regression model (mean difference was1 hour and 32 minutes). After adjustment for parity, counselling for pregnancy concerns, epidural analgesia, labor induction, labor augmentation, emergency caesarean delivery, instrumental vaginal delivery, newborn birth weight, and maternal age, the difference decreased but remained statistically significant (a difference of 47 minutes). Adams et al. (2012) concluded that the duration of labor was longer for women who feared childbirth, when compared to those without fear of childbirth. Consequently, decreasing fear by CE can lead to improving the childbirth outcome for women in Jordan.

Alder, Fink, Bitzer, Hosli, and Holzgreve (2007) published a literature review analyzing the link between prenatal maternal psychological distress and obstetric complications. Alder et al. (2007) reported that high levels of depression and anxiety were associated with increased obstetric complications, exaggerated pregnancy discomforts, preterm labor and delivery, and a higher use of pain management. CE can play a vital role in decreasing anxiety and fear related to childbirth for women before going through the labor and birth experience (Lee \& Holroyd, 2009). 
Postpartum care for women in Jordan was discussed in the literature by Khalaf, Abu-Moghli, Mahadeen, Callister, and Al-Hadidi (2007) using a qualitative description design to assess the Jordanian women's perceptions of what their health care needs were during postpartum, and what services need to be provided. Twenty-four women who delivered their babies and came for check-ups in three MCHs in North Jordan were included in three focus groups. The topics of discussion in the focus groups were: maternal and infant health concerns in postpartum, access to health care, health care services available, and characteristics and performances of health care providers. The findings indicated that the focus of postpartum care was child care. The main causes for visiting the postpartum health care facilities were for treatment, family planning, and child care. Most of the participants indicated that they did not receive any information about post-partum care in antenatal care visits or in the hospital after delivery. Khalaf et al. (2007) concluded a need to implement practice guidelines on post-partum care provided in health care facilities in Jordan. They suggested that the health care decision makers especially the $\mathrm{MOH}$ should develop a comprehensive plan to improve maternal educational strategies in postpartum care, ensure that all health care personnel adhere to this plan, and provide high-quality, affordable postpartum care for women in Jordan.

\section{Evaluation of Childbirth Education Programs}

Morton and Hsu (2007) argued that the basic content of CE classes has not changed much over the years despite the modifications in the maternity care services. Ustunsoz, Senel, \& Pollock (2010) compared CE conducted by nurses in Ankara (Turkey) with CE conducted by nurses in New Orleans (USA) in a descriptive survey. The sample consisted of 138 nurses (44 from New Orleans and 94 from Ankara). The 
nurses were providing antenatal care for women in hospitals in both cities. Results yielded significant differences between the nurses in Ankara and those in New Orleans in regard to the training and education levels of the educators. The content of the education classes also differed between the two settings indicating more content and wider coverage of the pregnant women's antenatal needs in New Orleans. Ustunsoz et al. listed the contents of the classes. Both groups of nurses covered the following topics in similar percentages: warning signs, supplies after delivery, nutrition during pregnancy, breast feeding, infant bathing, care of episiotomy, and family planning. However, topics not covered by most of the nurses in Ankara were as the following: fetal conception, growth and development of the fetus, changes during pregnancy, nutrition during breast feeding, delivery techniques, pain relief techniques, and exercise after delivery. Based on this study, Ustunsoz et al. suggested that a form of standardized prenatal content be prepared for nurses in Ankara. Ustunsoz et al., (2010) concluded that nurses in Ankara needed professional training and further education to deliver expanded CE classes.

The program by Malata and team described previously consisted of three sections distributed over a 6-week period (Malata et al., 2007). The sessions contained materials on antenatal (8 topics), labor process (4 topics), and postnatal (5 topics). The schedule was used to deliver the CE program to the intervention group. The classes were delivered by specially trained midwives. This program was well organized and evaluated to be effective in increasing the pregnant women's knowledge. The content and the schedules were clear and could be used in other developing countries with adaptation to the needs of women according to their cultures. 
Mcintyre-Miller and Chmiel (2013) published an article describing a program they developed to train childbirth educators in Scotland (United Kingdom) to provide consistent and professional parent education. The program was called the Scottesh childbirth parent education pack. Mcintyre-Miller and Chmiel prepared a syllabus that aimed to respect and reflect the individual knowledge and needs of pregnant women and their partners, and to provide universal services that are both accessible and available for recipients. The program recommended that the antenatal sessions be provided by the community midwives to improve the continuity of care, and those sessions should be provided in locations near the participants' residences or work places. The content of the program was divided in to 3 topics: (a) infant feeding, (b) labor and delivery, and (c) early days with the baby. The timing and duration of the session was not provided in the article, but a website was provided for further resources. However, no information was found in regards to the Scottish childbirth parent education pack in this website (Scottish Multiprofessional Maternity Development Programme, 2012).

Artieta-Pinedo et al. (2010) conducted a prospective observational study of 616 nulliparous pregnant women in Spain. The women attended different public CE classes, provided by midwives in the health centers as a part of regular antenatal care. The aim of the study was to compare the childbirth outcomes for women according to the number of antenatal classes they attended. The comparison was in regards to: a) arriving to hospital in true labor, b) receiving epidural anesthesia in active labor, c) length of first and second stages of labor, d) level of anxiety, e) type of delivery, and f) level of satisfaction with the process. 
The content was holistic with basic information about physical exercise, relaxation and breathing, anatomy, physiology, pregnancy changes, self-care, danger signs, labor and delivery preparation, instrumental and caesarian delivery, post-partum physiology and care, breast feeding and nutrition, care of the newborn, and contraception. The content was clear and the sessions sequence was logical. The end session included revision and reinforcement of previous sessions. Eight weekly sessions were provided by trained midwives in health centers. Each session was divided into a 90-minute theoretical part and a 30-minute part of body work or skill demonstration.

There were no significant differences in the length of labor or in the other physical outcomes of childbirth between women who attended or did not attend the CE classes. However, the CE had a positive effect on decreasing the level of anxiety for women who attended the classes. The researchers recommended changes to the content of CE to fit the women's individual needs and interests. This could improve the CE's benefits and positive outcomes (Artieta-Pinedo et al. 2010). Artieta-Pinedo et al. (2010) did not report a theory base for the study.

Walker et al. (2009) noted that better access to information is now available for pregnant women due to media and the Internet. In a telephone survey of 1,573 first-time mothers in the United States, women reported that books were the most important source of information to learn about pregnancy and childbirth. More of these women were influenced by TV shows than by CE classes (Declercq, Sakala, Corry, \& Applebaum, 2007).

Lee and Holroyd (2009) conducted an explanatory mixed-method, qualitative study to assess women's satisfaction with CE classes in Hong Kong. Additionally, 
researchers assessed the participants' perceptions of the $\mathrm{CE}$ influences on the labor experience in a subsequent quantitative study. The data were collected in two phases. First, the researchers used a 2-section self-reported questionnaire. The first section focused on the women's satisfaction with the CE classes. The questionnaire contained 25 items addressing the structure, process, and outcome of the classes. The participants ranked their answers on a 5-point Likert scale, ranging from (1) not at all satisfied to (5) very satisfied. The second section assessed the participants' demographic data. The participants completed at least one CE class in order to complete the questionnaires.

The CE was conducted as one class for three hours on a Thursday evening from 6:00 to 9:00 pm. The class was conducted by midwives, but it was not clear if they were trained as childbirth educators. The content included: labor process, pain relief in labor, breathing exercises and relaxation techniques, labor preparation, husband's role, and introduction to the labor ward. These topics were delivered using lecturing, sharing and discussions, videos, role play, demonstrations, and a separate clinical tour of the hospital on a subsequent day. Fifty participants were asked to answer the questionnaires after the CE classes; 40 questionnaires were returned. In phase two, semi-structured interviews were conducted with six participants asking about the labor and delivery experience. The interview was conducted 2 days after the participants delivered their babies, the interviews were tap recorded.

The mean age of participants was about 31 years. The gestational age ranged from 24 to 36 weeks. The 40 participants were most satisfied with the midwives' performance, and least satisfied with the date, time, and length of the CE classes. Additionally, all the information was included in a three-hour session. This resulted in much information for 
one session including breathing and relaxation techniques, labor process, and pain management in labor. The session was held in the evening, and no explanation was provided for choice of date or time.

The participants in the qualitative phase described the class as helpful in learning about labor, how to contribute to a smooth labor process, and cope with uncertainty and anxiety of labor. The participants reported themes of class effectiveness in advancing their knowledge about labor and delivery, acquiring skills to help in labor, and being able to control oneself. They also reported negatives about the class including structural constrains and limitations to the learning process: the class size (over 50 participants), the amount of information in one class, and the evening arrangement of the class. Lee \& Holroyd (2009) reported that using mixed-methods to evaluate this CE was beneficial. The sample was small and convenient for the two phases of the study. The researchers concluded that large classes with crowded content inhibited the learning process of the group.

A group of medical researchers, Phipps, Charlton and Dietz (2009), conducted a pilot study in Sydney, Australia, to test the effectiveness of CE. The program focused on outcomes of pushing in the second stage of labor in comparison to routine care outcomes. They used randomization to divide 100 primeparous women in two groups: intervention $(n=50)$ and control $(n=50)$. The intervention group attended two, 15-minute structured sessions, held one week apart. The sessions were carried out by midwives who were specially trained for the purpose of the study. The content of the classes included a detailed explanation of the anatomy and physiology of the second stage of labor with particular emphasis on the pelvic floor muscles. The proper way to push during the 
second stage was demonstrated using pelvic muscles and direct pressure from the midwife's finger to provide tactile biofeedback to lead the pushing and motivate relaxation of the pelvic floor muscles. This training was repeated during both sessions.

No differences were found in Cesarean births or instrumental delivery rates. Additionally, no statistically significant differences were found in the length of the second stage of labor, mode of delivery and perineal trauma between the two groups. However, women reported increased knowledge in the intervention group, and that they found helpful. Phipps et al. suggested that the negative findings may be due to the low power of the sample. Phipps et al. did not explain the difference between the CE provided in routine care and the content of the classes that might explain the findings. More research is needed to explore if women really need detailed explanations of anatomy and physiology of the second stage. New educational programs such as Lamaze report that women should follow their own inclination during pushing in the second stage of labor and be free to choose the labor position they find comfortable (Hotelling, 2009).

Renkert and Nutbeam (2001) investigated the concept of health literacy (Nutbeam, 1996) to guide the enquiry of a qualitative study about the CE's content in Australia. Health literacy is defined as the cognitive and social ability of the human being to determine the motivation and to gain access, use and understand information in a way to promote and maintain their health. Renkert and Nutbeam claimed that CE content tends to be instructional with the emphasis on the quantity of information rather than to empower the women to make informed decisions regarding her health and her families' health. He reported that content, time, goals, and instructors of CE varied widely in the United States. 
The study used two focus groups with pregnant women $(n=5)$, post-partum women $(n=7)$, and individual interviews with childbirth educators $(n=5)$. The aim of this study was to explore how to improve the content and delivery of CE to meet the pregnant women's needs. The results indicated that basic issues common among the three groups being studied were: limited time available for $\mathrm{CE}$, and anxiety and curiosity confined $\mathrm{CE}$ topics to pregnancy and childbirth. Another issue reported in the study was that antenatal classes cannot cover everything about pregnancy, childbirth, and parenting. According to the study, the three groups agreed that if the mothers leave antenatal classes with the skills and confidence to look and critically analyze additional information they need, then this will improve maternal health literacy. The study recommended further research to evaluate the content of $\mathrm{CE}$ in order to empower women and their partners to achieve the best outcomes from these classes. The findings of the study could be enriched if the sample in each group was bigger.

In a more recent study (Bergstrom, Kieler, and Waldenstrom, 2009), a group of pharmacists in Sweden, used a randomized control trial to compare the effects of a natural childbirth preparation program which included psychoprophylactic training (i.e. relaxation and breathing conditioned response to labor), and the standard CE program. Both programs were conducted by trained midwives. The content of the two programs differed in that the natural model trained the participants in breathing and relaxation, partner's coaching for labor, mental strategies, and homework was given between sessions. The standard model did not. The standard model included information about complications during labor and pharmacological pain relief. The natural model did not. For parenthood, the natural model included only breastfeeding and delivery of the baby. 
The standard model had additional 6 topics on parenthood, such as transition to parenthood, parental relationships and others.

The natural care group included 490 women and 442 men, and the standard care group included 496 women and 454 men. Epidural use was the same in both groups. There were no significant differences in the experience of childbirth or the parental stress for both men and women in the two groups. Seventy percent of the mothers in the natural group reported using psychoprophylaxis during labor, and a minority of the standard group used this method too. The researchers concluded that the natural method did not decrease the use of epidural analgesia, improve the childbirth experience, nor affect the parental stress for mothers and fathers in comparison with the standard CE program. Bergstrom et al., (2009) conducted CE for four sessions, each two hours. The group contained twelve couples in each session and was evaluated to be effective for the participants. This study was conducted with large samples and an experimental design. The randomization process was not clear in the article. However, the findings indicated that $\mathrm{CE}$ with basic knowledge can be effective in reducing stress and preparing couples to the childbirth experience.

In a national cohort study of 1197 primiparous in Sweden, Fabian, Radestad, and Waldenstrom (2005) investigated mothers' opinions regarding CE outcomes and their contact with other class participants after birth. The study used three questionnaires: early in pregnancy, two months after birth, and finally 1 year after birth. The researchers also investigated the differences between attendees and non-attendees in regard to the use of pain relief, pain experience, delivery mode, childbirth experience, breastfeeding duration, and assessment of parenting skills. No theoretical framework was reported. 
The majority of women (74\%) found CE helpful in preparing them for childbirth and $40 \%$ for early parenthood. Additionally, more than half of the women had met with other class participants one year after delivery. The data also indicated positive associations between the number of classes and these outcomes. Nevertheless, no statistical differences were found concerning pain memory, mode of delivery, overall birth experience, breast feeding duration, and parental skills. The attendants were found to use more epidural analgesia than non-attenders. Consequently, Fabian et al. concluded that the CE classes did not affect the childbirth experience or the parental skills. It did however help to increase their social networking. The generalizability of the findings is limited since the sample included only Swedish speaking pregnant women (Fabian et al., 2005). The content of the program was not clear in the article and there was no attempt to find sources of knowledge the women may have other than the CE program.

\section{Which programs should be considered as candidates in Jordan?}

Choosing the CE programs that can be used or tested in Jordan needed to be as basic as possible because of the lack of formal CE programs in Jordan. The goal of CE when it started in the beginning of the $20^{\text {th }}$ century was to teach women basic information regarding pregnancy, labor, and birth because women lacked this type information (Zwelling, 1996). In Jordan, women do not have the opportunity to learn from their mothers or other women in the family, as families often grow apart, and no formal CE programs are available (Oweis, 2009). In Jordan, availability of information sources, such as television media and the Internet need to be investigated further in order to assess the proportion of women using these sources to look for information regarding prenatal 
preparation, including CE. No studies were found regarding the availability and use of these resources by pregnant women in Jordan.

Numerous Internet websites offer information on pregnancy, childbirth, and child care. Many couples around the world seek information from the Internet regarding their health needs during pregnancy and childbirth (Larsson, 2009; Plantin \& Daneback, 2009). In Spain, Lima-Pereira, Bermudez-Tamayo, and Jasienska (2011) conducted a cross-sectional, descriptive study to describe the use of the Internet as a source of health information by the attenders of antenatal classes. Lima-Pereira et al. (2011) utilized a sample including 114 women and 21 men using a self-administered questionnaire distributed before the beginning of CE classes. The average age was 31 for women and 32 for men. The stage of pregnancy ranged from 24-38 week gestation. From the participants, $83 \%(n=95)$ were pregnant with their first baby, and 55\% ( $n=74)$ had collage or graduate degrees with no significant differences between women and men.

The results showed that $94 \%(n=127)$ of the participants used the Internet in a regular basis. Of those, $98 \%(n=132)$ searched the Internet for information regarding pregnancy online. About $65 \%(n=89)$ of the participants looked for information about pregnancy within a week before answering the questionnaire. Most of the Internet users $(86 \%, n=116)$ had access at home. Only $18 \%(n=24)$ of the Internet users received recommendations from the medical team regarding useful websites. The other participants consulted search engines or friends. However, $49 \%(n=66)$ reported that they would like to receive recommendation of useful websites from the midwives. The most searched topics were: fetal development, stages of pregnancy and changes during pregnancy, nutrition during pregnancy, stages of childbirth, and baby names and 
breastfeeding. Most of the participants $(80 \%, n=91$ for women and $83 \%, n=20$ for men) rated their family doctor to be one of their primary sources of pregnancy related health information. The Internet was rated by $47 \%(n=54)$ women and $65 \%(n=17)$ men as one of the primary sources of pregnancy related health information. Most of the participants $(78 \%, n=105)$ reported that the information in the Internet made them feel calmer and that they trust these websites. Alternately, Internet searches made 57\% ( $n=77)$ of the participants feel overwhelmed, 45\% ( $n=61)$ confused, 29\% $(n=39)$ felt frustrated, and $54 \%(n=73)$ felt slightly frightened by the information they found. The results of this study are limited. The sample was highly educated with special characteristics that are not representative of pregnant couples in other countries.

However, this study provides a perspective on the high the use of the internet and how much the Internet information can influence CE attenders. The Internet is used widely and is available for individuals around the world. It should be considered when CE programs are prepared and evaluated. Lima-Pereira et al., (2011) recommended that midwives should keep up to date with the new pregnancy and childbirth websites and give their clients links to high-quality sites.

In summary, based on the information available about Jordan, the candidate CE programs were the ones adapted by Malata et al., (2007) as it was prepared and evaluated on pregnant women who did not have CE programs before the study, and the CE program adapted by Ustunsoz et al. (2010) because the same content was compared between CE educators from the developed and developing countries. The third CE program that could be adapted was the Turan and Say (2003) from Turkey. The content and the timeframe were clear. Moreover, Turkey shares some cultural aspects with Jordan and this can 
improve the chances of content to be appropriate to Jordanian women. The best timing for CE classes should be flexible with morning and evening sessions (Lee and Holroyd, 2009), and best educators are midwives who should be trained to be professional CE educators (Phipps et al., 2009). Sessions may be 6 to 12 conducted on a weekly base, and include a maximum of 12 expectant mothers to enhance the learning experience (Bergstrom et al., 2009).

\section{Summary of the Literature}

The literature reported a severe shortage in Jordanian women's knowledge about pregnancy, childbirth, and postpartum. Women reported misconceptions regarding the childbirth experience and negative experiences in the Jordanian hospitals. Women also reported not being adequately educated regarding postpartum care. No organized childbirth education programs were found in any Middle Eastern country other than Iran and Turkey. In Iran, researchers evaluated childbirth education program adapted from the Lamaze method and concluded that adapting this program could increase women's satisfaction after delivery, and decrease the length of the second stage of labor (Fahami et

al., 2006). In Turkey, childbirth education programs were implemented and evaluated to help women cope with pregnancy and childbirth experiences. Evidence of the effectiveness of these programs in Iran and Turkey encouraged developing similar programs in other developing countries.

No literature was found on organized CE programs in Jordan for pregnant women. It was concluded that there was a need for a CE program and there is a possibility of implementing it in Jordan. There was a need to understand what the women who will attend this program think they need to learn and how they want to learn 
it according to their culture. To prepare such a CE program, the opinions and perceptions of health care professionals involved in the management and care process must also be investigated. This proposed study investigated the perceptions of pregnant women, midwives, and physicians regarding the content, timing and duration of a $\mathrm{CE}$ program that is culturally appropriate for pregnant women in Jordan. 


\section{Chapter III \\ METHODOLOGY}

\section{Research design}

Using a descriptive design with focus groups, the purpose of this proposed study was to examine the perceptions of pregnant women, midwives and physicians regarding the feasibility and challenges of implementing a childbirth education (CE) program in Jordan. A total of 4 focus groups, two of pregnant women (one focus group of primiparous women and one with multiparous women), one each of midwives, and physicians were presented with a draft of the content, timing, and a description of three existing CE programs. The three CE programs were presented by: Malata et al. (2007), Sercekus and Mete (2010a), and Turan and Say (2003). Participants were asked to compare each of the three CE programs for potential use for pregnant women in Jordan. Midwives and physicians were presented with the English versions of the CE programs. Pregnant women were presented with an Arabic translation from the programs. The English versions were translated by the PI (bilingual in Arabic and English) into Arabic and back translated into English by the PI's assistant (bilingual in Arabic and English), and then compared with the original English version for consistency across languages. Any inconsistencies were discussed by the PI and the PI's assistant until consensus was reached.

All participants were asked to review the three CE programs individually for content and characteristics, and then share what they thought about the programs with the group. Then they were asked to write any comments on the copies that they had and 
return it to the PI during or after the focus group meeting. Using focus groups, this study addressed the following research questions;

1. How do pregnant women learn about pregnancy and childbirth in Jordan?

2. What do pregnant women want to know about pregnancy, labor and delivery, and postpartum?

3. What do, midwives and physicians think should be in a CE program in Jordan?

4. When provided with $3 \mathrm{CE}$ programs, what modifications do pregnant women, midwives and physicians suggest in order for the programs to be appropriate for Jordanian culture?

5. What are the perceptions of pregnant women, midwives, and physicians about the feasibility and challenges of implementing CE program for pregnant women in Jordan?

Focus groups are used in health research because of the opportunity to involve users in care management and strategy development, needs assessment, and evaluation of the health promotion programs (Richardson \& Rabiee, 2001). Focus groups are particularly important when little is known about the topic of the discussion (Rabiee, 2004). The current study was carried out in Jordan in the Middle East which has a unique social and cultural background. Focus groups are helpful in understanding and explaining the meanings, beliefs, and cultures that influence the feelings, attitudes, and behaviors of individuals (Rabiee, 2004). Focus groups can generate large amounts of data in relatively short time periods. Participants for the focus groups were chosen purposively. They were selected on the basis of having knowledge and experience in the 
study area, and being comfortable talking to the interviewer and other group participants (Richardson \& Rabiee, 2001).

The current study was conduct 4 focus groups with participants who are involved in childbirth educational needs in North Jordan (i.e. pregnant women, midwives, and physicians). Kruger and Casey (2000) recommend 6-8 participants in a focus group. This number is large enough to produce variety of perspectives and small enough not to complicate the analysis process. The focus group members should be over-recruited to overcome non-attendance problems by 10 to $15 \%$ (Kruger \& Casey, 2000).

\section{Setting}

Participants were recruited from three maternal and child health centers $(\mathrm{MCH})$, and one major maternity hospital in North Jordan. Princess Badea'a Maternity Hospital had 27698 deliveries in 2015, 82 midwives, 24 residents, and 16 physicians $(\mathrm{MOH}$, 2015). The MCHs are: Al-Sareeh MCH (4 midwives, and 308 pregnant women); Ibn Sena MCH (6 midwives, and 210 pregnant women); and Al-Hussain MCH (4 midwives, and 241 pregnant women) in 2014 (Personal communication, Hyam Obidat, April, 28, 2015). These sites were chosen because of their high annual rates of childbirth. The total number of potential midwives (35), physicians (46) and pregnant women $(10,625)$ available at these sites provides sufficient numbers to obtain the needed sample for the focus groups.

\section{Sample}

For the current study, four focus groups were conducted. Each group included a purposive sample of 12 participants to allow for $10 \%$ non-attendance. 
Inclusion criteria for pregnant women: Jordanian, singleton, low-risk pregnant women, able to speak, read and write in Arabic, and with no physical impairments (considered high risk pregnancy and may not be considered for normal vaginal delivery). Attempts were made to include low and higher education levels, parity (primigravida and multigravida), and employment status (house wives and working women). Exclusion criteria: women not planning to deliver their babies in the hospital, have had attended any form of CE program, suffering from medical conditions during pregnancy, not able to read and write in Arabic, with mental problems (diagnosed with mental problems such as depression), or were not able to commit to the time of the planned focus group meeting.

Inclusion criteria for midwives: at least three years of experience caring for pregnant women or women in labor in the public sectors in Jordan. Exclusion criteria: midwives who have no experience working face to face with pregnant women, and midwives whose experience was in the private sectors or abroad, or cannot speak Arabic.

Inclusion criteria for physicians: at least three years of experience caring for pregnant women or women in labor in the public sectors in Jordan. Exclusion criteria: physicians who have no experience working face to face with pregnant women, and physicians whose experience were in the private sectors or abroad, or could not speak Arabic.

The requirement of 3 years of experience for midwives and physicians enriched their input in the focus groups as they included stories and support their opinions and perceptions by events they experienced during their care of pregnant women. 


\section{Data Collection Procedure}

Data collection began following Institutional Review Board (IRB) approvals from the clinical sites and Florida International University (FIU). Approvals to participation from the three MCHs and the maternal hospital were obtained first. These approvals were then submitted with the study proposal to the Ministry of Health (MOH) in Jordan and granted their approval of the study. The study proposal with the approvals from the study sites and the MOH were submitted to the IRB for approval at Florida International University. The focus groups were moderated by the primary investigator (PI), and audiotaped using a stand microphone attached to a computer, which did not need operating during the focus group. Each of the four focus groups took one to two hours.

Pregnant women. The PI met with the midwives in the three MCHs individually or in groups depending on their availability and asked for their cooperation and explained the study. The midwives were asked to identify women who were eligible for the study, explained the study to them, and handed them letters of invitation, provided by the PI, to participate in the study. Twelve primparous pregnant women and 12 multiparous pregnant women who met the eligibility criteria and agreed to participate by letting the midwives know were approached by the PI. The PI then invite them to participate in the study and arrange for the time of the focus group meeting. Pregnant women who agreed to come at the time of the focus group and planned to stay for the one to two-hour meeting time were asked to sign a consent form after all of their questions have been answered.

The meeting took place in a meeting room in Al-Sareeh $\mathrm{MCH}$ at Irbid city in North Jordan. All women who are recruited for the focus groups were given cash for the 
transportation (around \$10 each) from and to their homes or work places to the $\mathrm{MCH}$. The other two MCHs are located in the same city; therefore, the amount of money it cost to take a taxi was around 7 Jordan Dinars (equals around \$10) for the longest distance from Al-Sareeh MCH to other areas around in Irbid.

The study's modified research questions served as general questions in all focus groups (pregnant women, midwives and physicians). They were as follows:

1. How do pregnant women learn about pregnancy and childbirth in Jordan?

a. What sources of information are available for pregnant women in Jordan?

b. How do you think women use the internet, books and media in Jordan to learn about pregnancy and birth?

c. What do you think the midwives or physicians recommend about these sources to women during their visits?

2. What do you think pregnant women want to know about pregnancy, labor and delivery and postpartum?

a. How do you think CE programs will benefit the pregnant women?

b. What CE programs are available in Jordan from your knowledge?

c. What are the needs of pregnant women, antenatal, during labor, and postnatal?

d. How can the program help in:

a. Preventing diseases

b. Promoting mothers health

c. Encouraging cooperation of others in family

d. Improving psychological status of the pregnant woman. 
e. Maintaining or improving newborn health?

3. What do you think should be in a CE program in Jordan?

a. What do you think may be benefits from a CE program?

b. What do you think is the importance of such programs in Jordan?

4. What modifications do you suggest in order for the programs to be appropriate for Jordanian culture? (when provided with 3 CE programs)

a. In your opinion what would be the best time for classes for Jordanian women?

b. Who do you think should provide the classes?

c. What audiovisual materials would be helpful to deliver the information in classes?

d. What number of women would be best in a class?

e. What do you think about individual or group CE?

f. What do you think about showing women labor and delivery videos in the classes?

5. What do you think about the feasibility and challenges of implementing a CE program for pregnant women in Jordan?

a. How might cost be a factor?

b. How do you think staff might respond to the challenges of CE?

c. What do you think will be the clients' responses to the program (men and women)?

d. How do you think the program will fit with the government health policies? 
e. How might a program be financed?

f. What support do you think the program will receive and from whom (financial, staff, or time)?

Midwives. The PI met with the managers of the MCHs and the maternity hospital to explain the study and asked for their cooperation in the study. Midwives who have three or more years of experience working with pregnant women and women in labor were identified by the managers of the MCHs and the Maternity hospital. The eligible participants were approached by the PI and handed a letter of invitation to participate in the study. Every eligible participant was invited to participate. Those who agreed to participate in the focus group and were willing to spend the time in the focus group were asked to sign the consent forms after all of their questions have been answered.

The focus group was arranged in a convenient time for most midwives to encourage them to attend. The midwives' focus groups took place in a meeting room in Al-Sareeh MCH near the maternity care room. This room was suitable because it is not noisy and has adequate light and ventilation for the groups to sit for the entire time of the meeting. The meeting room was booked for the focus groups in advance and the participants were informed about the time and place of the focus groups after agreeing on the time. The same questions were used as used with the pregnant women.

Physicians. The physicians' focus group was held in the conference room which was assigned by the manager of Badea'a Maternity hospital. The room was in the first floor of the hospital near the administration offices, ventilated, quiet, and had adequate number of chairs for meetings. This room was booked for the focus group meeting in 
advanced. The PI asked the manager of the maternity hospital for his cooperation in the study after explaining about the study. The manager was asked to provide a list of the eligible physicians for the study. Physicians who had three or more years of experience working with pregnant women and women in labor were approached by the PI and handed a letter of invitation to participate in the study. Every eligible participant was invited to participate. Those who agreed to participate in the focus group and were willing to spend the time in the focus group were asked to sign the consent forms after all of their questions have been answered.

The focus group was arranged in a convenient time for most of the physicians to encourage them to attend. The meeting room was booked for the focus groups in advance and the participants were informed about the time and place of the focus groups after agreeing on the time. The same questions were used as used with the pregnant women.

By reading and signing the consent form, all participants were informed that participation was voluntary and that they were free to withdraw at any time. Participants were insured confidentiality and that the data will only be used for the study purpose and no one but the PI and PI's dissertation committee will have access to the data.

Pregnant women who agreed to participate were asked to fill a demographic form including their age, educational level, occupation, number of pregnancies, age of current pregnancy in weeks' gestation, number of living children, if she attended CE before, and if she did, who delivered the classes and did it help her in any way?

Midwives and physicians who agreed to participate were asked to fill a demographic form including their age, gender, educational level, place of work, and their 
years of experience, and if they were involved in CE before. If they were involved in CE, they were asked an open-ended question: Tell me about the CE program you were involved in?

The meetings were audio-taped. After the end of the meeting, pregnant women were offered a gift bag that contained newborn cotton pajamas, socks, and hat with a thank you card as appreciation for their time and contribution. All participants were offered coffee and snacks before and during the focus groups.

\section{Data Management}

Data including personal notes, audio tapes, transcripts, and demographic data were included in a file for each focus group and kept in a locked cabinet with ID numbers on the transcripts. The participants were given ID numbers with the name of the focus group to link them to the data. For example, midwife1, pregnant woman3, and physician5. Only the PI and the PI's dissertation committee will have access to the data. The audio tapes were transcribed verbatim by the PI's assistant (who has a bachelor degree in nursing and a post-graduate degree in midwifery, and worked as a research assistant in Jordan University of Science and Technology for more than 15 years), and then reviewed by the PI. The PI took notes during and immediately after the focus group about any situations, feelings, and body language noted from the participants that may help in the analysis of the data.

\section{Data Analysis}

After each focus group, the audio tapes were transcribed verbatim by the PI's assistant, and then reviewed by the PI. Analysis started by reading the material as many times as needed to achieve immersion into the data, and the PI had a sense of the main 
flow of ideas. The data was accompanied by the personal notes of the PI taken during the focus groups. The notes helped to understand the comments and the ideas when connected to the body language, facial expressions, and voice changes of the participants documented in the PI's personal notes. Hsieh \& Shannon (2005) reported that research using qualitative content analysis focuses on the characteristics of language as communication with attention to the content or contextual meaning of the text.

The content analysis as a method of analysis is used because it focuses on the subject of interest and context, and targets the similarities and differences between the codes and categories in the analysis. Guided by Graneheim and Lundman (2004), the PI let the codes and then themes immerge after reading and immersion in the texts.

According to Hsieh and Shannon (2005), there are three major approaches to content analysis; directed, conventional, and summative approaches. In conventional content analysis, coding categories are resulting directly from the text data. With a directed approach, analysis starts by initial codes guided by a theory or relevant research findings. A summative content analysis involves counting and comparisons keywords or content with the interpretation of the original context and meaning. A summative content analysis involves counting and comparisons, usually of keywords or content, followed by the interpretation of the underlying context (Hsieh \& Shannon, 2005). The PI used conventional content analysis to extract themes guided by the research questions. Using content analysis, the data were coded according to the topics related to the research questions. The codes were extracted also using the summative approaches to see what are the words and ideas that were mostly important for the participants and what they meant in the context of the data. Any data that did not fit any research question were 
evaluated for importance and used to explain how the participants felt about the topics. The PI also reviewed the personal notes to explain any outliers. If an item could not be explained or was not related to any research question, the outlier was not used.

The keywords appearing during analysis was counted and checked for underlying meaning. Then the conventional approach guided the analysis through finding codes that describe the opinions and perceptions of the participants regarding the CE programs. Then, the coded data were sorted into major themes. At the end, a conclusion was drawn with examples from the data to answer each research question. The $3 \mathrm{CE}$ programs drawn from the literature were compared with the suggested changes on the content, timing, ways of delivery, and duration on the CE program to come up with a new version that includes the suggested needs and culture of pregnant women in Jordan. Recommendations then were reported from the results. 


\section{Chapter IV}

\section{RESULTS}

This study examined the opinions and perceptions of pregnant women, midwives and physicians regarding the content, feasibility and challenges of implementing a childbirth education (CE) program in Jordan. The study's research questions were:

1. How do pregnant women learn about pregnancy and childbirth in Jordan?

2. What do pregnant women want to know about pregnancy, labor and delivery, and postpartum?

3. What do midwives and physicians think should be in a CE program in Jordan?

4. When provided with $3 \mathrm{CE}$ programs, what modifications do pregnant women, midwives and physicians suggest in order for the programs to be appropriate for Jordanian culture?

5. What are the perceptions of pregnant women, midwives, and physicians about the feasibility and challenges of implementing CE program for pregnant women in Jordan?

Four focus groups were used to collect data to answer the research questions. Two groups were with pregnant women (primigravida and multigravida separately), one with midwives, and one with physicians working with pregnant women and women in labor. The 4 focus groups were audiotaped and each participant was asked to complete a short demographic questionnaire.

The midwives and the physicians' questionnaire included questions about their age, gender, educational level, place of work, and their years of experience, and if they 
were involved in $\mathrm{CE}$ before. If they were involved in $\mathrm{CE}$, they were asked an open ended question: Tell me about the CE program you were involved in?

\section{Sample}

Each focus group contained a purposive sample that had different biographical characteristics. See Table 1. Therefore, each group's biographical data will be presented separately.

Table 1

Participants' characteristics

\begin{tabular}{|c|c|c|c|c|}
\hline Participants & $\begin{array}{l}\text { Primigravida } \\
\text { pregnant } \\
\text { women }\end{array}$ & $\begin{array}{l}\text { Multigravida } \\
\text { pregnant } \\
\text { women }\end{array}$ & Midwives & Physicians \\
\hline $\begin{array}{l}\text { Number of } \\
\text { participants }\end{array}$ & $\mathrm{N}=8$ & $\mathrm{~N}=6$ & $\mathrm{~N}=8$ & $\mathrm{~N}=6$ \\
\hline Age range & 18-34 years & 24- 43 years & $29-50$ years & $30-50$ years \\
\hline Mean age & 21.4 years & 34.5 years & 38.4 years & 37.3 years \\
\hline Education range & $\begin{array}{l}7^{\text {th }} \text { grade to } \\
\text { high school } \\
\text { education }\end{array}$ & $\begin{array}{l}\text { 6th grade to a } \\
\text { master degree }\end{array}$ & $\begin{array}{l}\text { 2-years degree } \\
\text { to a master } \\
\text { degree }\end{array}$ & $\begin{array}{l}\text { Obstetrics and } \\
\text { gynecology } \\
\text { residency to a } \\
\text { master degree }\end{array}$ \\
\hline $\begin{array}{l}\text { Number of } \\
\text { pregnancies }\end{array}$ & 1 to 2 & 3 to 7 & - & - \\
\hline $\begin{array}{l}\text { Number of living } \\
\text { children range in }\end{array}$ & 0 & 2 to 6 & - & - \\
\hline $\begin{array}{l}\text { Average } \\
\text { gestational age } \\
\text { for pregnant } \\
\text { women }\end{array}$ & $\begin{array}{l}4 \text { to } 37 \text { weeks } \\
\text { gestation }\end{array}$ & $\begin{array}{l}12 \text { to } 30 \\
\text { weeks' } \\
\text { gestation }\end{array}$ & - & - \\
\hline $\begin{array}{l}\text { Average } \\
\text { gestational age }\end{array}$ & 20.0 weeks & 19.7 weeks & - & - \\
\hline $\begin{array}{l}\text { Years of } \\
\text { experience }\end{array}$ & - & - & $8-30$ years & $3-25$ years \\
\hline
\end{tabular}

The primigravidas' focus group consisted of 8 women, all were house wives. Seven were pregnant for the first time and one had a previous spontaneous abortion. 
The multigravidas' focus group consisted of 6 women. All multigravidas had children ranging from 2 to 6 live children. Four of the women were house wives, one was a faculty member in the university and one was a nurse. All of the pregnant women reported that they did not attend any CE program before this focus group.

Eight midwives participated in the focus group. Only one midwife reported being involved in a CE program that took place as part of a research study which has yet to be reported. Six obstetrics and gynecology physicians participated in the $4^{\text {th }}$ focus group. Three were females and 3 were males. No physician reported being involved in a CE program.

\section{How do pregnant women learn about pregnancy and childbirth in Jordan?}

All pregnant women reported that other females in the family were their first choice when they needed to ask about pregnancy and childbirth. The second most frequent choice was the doctor. Seventy-five percent of primigravidas reported that they also used the Internet to search for pregnancy information. None of the pregnant women reported asking midwives for information on pregnancy. Most midwives reported that their perception was that the main source of childbirth knowledge is other females followed by television programs and the Internet for younger women. Books were not seen as being used as sources of information. Physicians reported that the most common source of knowledge in pregnancy and childbirth is other females in the family followed by doctors. Female physicians reported pregnant women use the internet for information. Books are seen as rarely being used.

Pregnant Women. One primigravida said: "I ask my mother or my mother-inlaw... the most people that I trust are people who have experience... my mom and my 
sisters." Multigravidas also reported other females as the first choice. One multigravida reported "I ask my neighbor what she takes and what she eats during pregnancy". Another multigravida said "I ask my mother-in-law or my neighbor who married and had children before me."

Pregnant woman also reported that they ask their doctors as the professional source that they trusted. One primigravida reported: "of course the doctor... who else I can ask." Multigravidas also reported that they asked their doctors; "of course I ask my doctor if I have any problem". Another multigravida reported "my private doctor and my mom".

However, most primigravidas (6 out of 8) reported that they used the Internet often to search for information about pregnancy and childbirth. One primigravida said: "any question I put it immediately on Google... any good information I see I share to other people," another said: "I ask my mother or the internet." Another added: "there are famous doctors on Facebook that have their own pages and they answer any question that you have.” A primigravida said "I don't use the Internet... I ask my husband and he look it up and let me read from his phone." The youngest multigravida participant said: "I searched Google first three months... what food should the pregnant eat and like this." However, older multigravidas reported that they do not use the Internet.

Primigravidas also reported unreliable information that they learned from the Internet; one said: "I read in an American study that if your belly button is pointed out it's a male and if it's inward it's a female." When asked if any doctor or midwife recommended any website to learn about pregnancy or childbirth they all replied negatively; "no...no... the doctor if he has experience will tell you from him not from 
Internet..." another added: "the same thing he will give you from what he learn... he is more educated than the Internet." When they were asked if they ask midwives for information they replied "never," and "I never asked midwives."

When asked about midwives, all pregnant women reported that they do not ask midwives for information. One multigravida said: "midwives only when we have labor," another said: "we only come to the maternity and child for the lab tests," another said: "they don't have patience for us... what can I do for you...they say."

When asked about books they replied that books are great, but they do not use them. A primigravida said: "no I did not use books but the most from the net (Internet)... I feel the Internet is more accessible to people but sometimes it's complicated." Multigravidas also reported they do not use books. One multigravida said when asked if the books are available "books are not available," another said "if you look for books you can find.... I don't use them."

Midwives. Most midwives reported that their perception was that the main source of childbirth knowledge is other females followed by television programs and the Internet for younger women. Books were not seen as being used as sources of information.

One midwife said "sure she will ask people around her...her mother... mother in-law." Another added: "when they are sitting in the waiting room they are always talking and asking even if they don't know each other..."

The midwives agreed that women ask only if they have a complaint or a problem; "some ladies if she has bleeding she will ask...what she will do...but how she will protect her pregnancy ... how to keep my health and my baby's health... she doesn't know to ask." Another midwife said; "they will not ask anything...if you try to teach 
them they will say my husband is waiting out in the car..." a midwife replied to that by: “she doesn't ask for things you know that she needs but she doesn't... but if you taught her she will be very happy about the information." Another said: "if the woman did not ask the midwife will not teach her." Another midwife who works at the maternity hospital added: "I had one lady that came to the labor room and asked me to explain labor and delivery and what will happen to her... I said you left all 9 months and came to me in these couple hours to explain everything, why you did not ask before... she said I asked and no one answered me..."

When asked about other sources of knowledge, midwives replayed that books are available but no one uses them; "I mean ladies in Jordan don't know the books, even the pamphlets when we give her she just give to her little child to play with."

Midwives said that television and media play a good role in educating women about their health in Jordan; some television programs are prepared as series to encourage women to make breast self-exams and mammogram; one midwife said: "yes television programs are very nice now... did you see Za'al and Khadra... they tell women to go check their breasts..., not smoke around children or pregnant women..." Another midwife said: "I know that people like it and a lot are watching it." Another midwife who has extensive experience argued that the knowledge that these media programs present are general and not specific to childbirth: "but is that enough for pregnant women?" A younger midwife said: "It's not specific to pregnant women, having an organized program for pregnant women will be more effective.” she added: “... there are some doctors that have their own shows and they answer questions" another added: "such as Hakeem" (Hakeem is translated to the doctor or the wise in Arabic). 
Most midwives reported that the pregnant women's Internet use is growing in the younger generation. One midwife said: "from my experience, the ladies get their information from the Internet... not what she needs of course but she gets on the net and see television and have some information about pregnancy." Another reported: "yes smart phones are with all people now... I saw women who have only $10^{\text {th }}$ grade school... when you ask them they have very nice and specific information about how to care for pregnancy and her-self and the baby from the Internet...”

Midwives reported that the information from the Internet is not complete and may have some unreliable information. One midwife said that pregnant women are selective of the knowledge they receive on the Internet depending on their complaints or needs: "it depends on the intelligence of the lady... I need this thing ... I have burning sensations I will look for it on the internet..." Another added: "it depends on the maturity of the lady," and another said "they take more from the mother and the neighbor than the Internet.”

When the midwives were asked if they recommended a website or an internet search to women they all replied negatively. They reported that many problems exist in the websites talking about pregnancy and childbirth. The most important problem was language: one said: "if I feel that the lady is interested I may recommend a website but you know the problem is with language... you know most women speak only Arabic and all the trusted webs that we know are in English." Another midwife said: "there are websites from Jordan," another added: "in Arabic you cannot find good websites," and she added: "some pregnant women from my neighbors and relatives go online and then come to me (as a friend) to ask if the information is correct or not" 
Some midwives thought they should encourage women to use the reliable websites. One midwife said: "we have to encourage women to use internet but go to reliable websites," and another said: "we have to be careful because a lot of these websites are untrusted...". One midwife added: "to tell you the truth most of these sites are chat sites everyone tells their own experience and that gets us back to that they are taking their knowledge from other females around..." The midwives suggested that some professional source (institution) in Jordan should make websites for CE. One midwife said: “... you have to encourage the Internet since they already using it... but you should be attentive she will go to trusted sites... maybe the $\mathrm{MOH}$ will make one for example or maybe the universities can do so... like Jordan Techno (Jordan University for Science and Technology) ... universities make their own websites maybe."

Physicians. Physicians reported that the most common source of knowledge in pregnancy and childbirth is other females in the family followed by doctors. Female physicians reported pregnant women use the internet for information. Books are seen as rarely being used.

One female physician said: "from the family...mother grandmother...very few are taking the matter to the academic level." Another said: "all women talk together when they are in the waiting room in the maternity clinic."

Physicians also thought that the doctor is another source for the childbirth knowledge. One physician said that they come to the doctor with prepared knowledge coming from other females. One physician said: "but I never saw a woman coming to the doctor and ask him how I will deliver the baby...impossible they all come and say my 
mother told me that delivery is hard...never I heard a lady asking a doctor what are the stages of labor..."

All female physicians listed the Internet as one source for pregnancy and childbirth knowledge. one said: "my sister who is not in the medical field...every time I want to explain something she say yes I read about it on the net." All the physicians thought that using the Internet as a source of knowledge for pregnancy and childbirth has some problems. One physician said: "they use it the wrong way," another added: "they open any website...no specific sites." They added that the Internet is not available for all women: "not every woman can go on the Internet..."

When asked about books they reported that books are available: "anyone wanting books will find." However, they reported that very few women use books: one male physician said: "only $10 \%$ to $20 \%$ do use these". Another discussed that women tend to go to the MCHs and may ask for information there, but very few actually ask for information; one male physician said: "women tend to go to the MCHs and they can ask there...the chance of them discussing this is not big not the majority...they only go to the center... do the tests...register and that's it." When asked about other sources, the physicians reported that they think that the MCH may be one source: one male physician said: "the primary health centers should be the main source." Another added: "the main problem is to deliver the information to the pregnant women... this is the problem of the health center in my opinion... the way to deliver information to the audience... this is what we need to find an answer to."

One general note during the physicians' focus group was that female physicians showed more optimism and more enthusiasm toward CE than male physicians. 


\section{What do pregnant women want to know about pregnancy, labor and delivery, and postpartum?}

Primigravida asked many wide ranging questions regarding their pregnancy. Most primigravidas wanted to know about nutrition during pregnancy and about the fetus. Multigravidas were more specific about what they wanted to learn about pregnancy. Most wanted to know about problems during pregnancy including blood pressure, infections, discharges and emotional state. Primigravidas were not sure what they wanted to know about labor and delivery. Only one multigravida wanted to know the signs and symptoms of labor. Most primigravidas wanted to learn about newborn care after delivery while others were interested in nutrition, breast care and family planning. Multigravidas wanted to know about newborn baby care and signs and symptoms of diseases or complications in the newborn. All pregnant women thought that it is acceptable and needed to include husbands in the CE program.

One said: "I had edema in my legs... what does that mean," another said: "I have severe deficiency in iron... what should I eat," she added: "tea will break iron but coffee is good for you..." "I need to know will my body return like before pregnancy..." "when my blood pressure drops what should I do..." and many more. Some primigravidas had misconceptions about pregnancy. One commented: "if you take the back needle your baby will be handicapped..." Another added: "sodas in pregnancy will give you diabetes..." Another primigravida did not know about fertilization. She said: "I'm now 6 months and still no fertilization..." when asked if she talked to her doctor she said: "yes... I had blood in the first 2 months... the doctor said no sex till the end of 
pregnancy..." Accordingly, pregnant women reported subjects that they wanted to know about in pregnancy, childbirth and postpartum.

Knowledge around pregnancy. Most primigravidas wanted to know about nutrition during pregnancy and about the fetus.

A young primigravida said: "the most thing I like... from the beginning of my pregnancy I have severe iron deficiency... what food... the healthy food." Another primigravida said: "now I'm concerned with nutrition during pregnancy," An older primigravida said: "I like to know everything about the fetus... what's his position, movement, what he eats and what medication..." Another primigravida wanted to know that she was pregnant: "when I was first time pregnant and had pain like the menstrual period and did not know...I asked my mother and she told me that I was pregnant..." One primigravida said that she does not want to learn anything: "I don't want to know anything...nothing at all."

The multigravidas were more specific about what they wanted to learn about pregnancy. Most wanted to know about problems during pregnancy including blood pressure, infections, discharges and emotional state.

One said "like what you said... when my blood pressure drops what should I do..." another added: "other signs of problems in the pressure." One multigravida reported: "some women will have secretions or blood coming out ... what does that mean," another added: "if she has infections... how she can prevent that..." A mother of 2 wanted to know about the psychological status and the mood changes during pregnancy: "I need to know why the pregnant woman becomes so anxious and moody... 
I got divorced in my first pregnancy because of that," she added: "moodiness has a treatment?"

Knowledge regarding labor and delivery process. Primigravidas were not sure what they wanted to know about labor and delivery. They appeared to have no knowledge about the process or that they could learn about it.

One primigravida when asked what she wanted to learn about labor and delivery said: "ha... what is there to know," another added regarding what she needed to know about labor and delivery: "nothing specific just general information..." However, some women reported that they wanted to learn about labor pain: "I need to know about the pain... how the woman deals... with the pain." One primigravida said: "I need to know about the injection that they give for the pain... my friend told me that it can cause paralysis... the baby will come handicapped." Only one primigravida wanted to know what happens in labor and delivery: “... how the delivery is... what happens with her in delivery." One primigravida wanted to know about caesarian sections: "I want to ask which is more difficult normal delivery or caesarian delivery..." Another primigravida wanted to know about preparation for the hospital; she said: "I need to know how I will go to the hospital... do I call them first..."

Only one multigravida wanted to know the signs and symptoms of labor: "once my water broke but I didn't know that it's the water for 2 days... and the baby was dry." Some primigravidas reported wrong information: "I heard that eating sugar during pregnancy can cause diabetes to the baby" "anything you eat...he eats...anything harm...harm him." 
Knowledge of after the delivery. Most primigravidas wanted to learn about newborn care after delivery. Others were interested in nutrition, breast care and family planning.

One primigravida said: "what happens after the delivery... how to care for the new baby to bath him and dress him." Other primigravidas wanted to learn about nutrition in postpartum. One said: "what should I eat after delivery," another added: “... what would replace the lost blood." Another participant from the same group added breast care after delivery to what they wanted to learn: "treating the sore nipple... that is very important.” Another added: “... I mean breast feeding.” The primigravidas also reported the need to know about family planning methods: "what family planning methods choices they have."

Multigravidas wanted to know about newborn baby care and signs and symptoms of diseases or complications in the newborn. One stated: "yes how to hold him and deal with him." Another added, "now when the mother first delivers the baby she will not know how to handle him." Another added, "how to change him... vaccination and weight and the umbilicus." They also stated that they needed to know about breast feeding and signs and symptoms of problems with the newborn. One woman noted "how to breast feed..." Another, "how to know if there are diseases or problems... why he cries... especially the first period always there are problems."

All pregnant women thought that it is acceptable and needed to include husbands in the CE program. However, most pregnant women were hesitant that men will come to the classes. One primigravida said: "teach the husbands how the women suffer during pregnancy." Another multigravida: "with kids...with pregnancy and delivery he should 
be with her." Another multigravida said: "some men don't know how the pregnancy and labor is to the woman... if she had mood changes that's from pregnancy." The multigravidas stated: "the husband should be there for sure...". One added: "he only see her at the bed with the baby... nothing about the process." One multigravida added: "sure they should be like women... women know about their situation so should the men."

When asked if the men will come most answered negatively: one 34-year-old primigravida said laughing: "seriously do you think they will come... my husband sure will not come". One multigravida said: "we will try... they will not come."

\section{What do midwives and physicians think should be in a CE program?}

The midwives and physicians agreed on a number of content areas that they wanted in a CE program including the labor and delivery process, free antenatal care available in the $\mathrm{MCHs}$ and to include the $\mathrm{CE}$ program with the routine prenatal care, warning signs and complications during pregnancy, and physical exercises during pregnancy. Other content was reported by midwives only or by physicians only. Midwives wanted to include the following in a CE program: psychological changes during pregnancy and postpartum, nutrition during pregnancy, breast feeding, newborn health, sexually transmitted diseases, pain management, postpartum physiology and care, and family planning. Physicians suggested to include planning for pregnancy and separate classes for husbands in the CE program.

Labor and delivery process and care. Most midwives and physicians reported that they wanted the labor and delivery process to be included in a CE program. One midwife who is working in the delivery room said: “women don't know anything about labor and delivery process... they get so stressed that causes fetal distress and the problems of fetal 
distress." She added: "I had one lady that came to the labor room and asked me to explain labor and delivery and what will happen to her... I said you left all 9 months and came to me in these couple hours to explain everything, why you did not ask before... she said I asked and no one answered me..."

Another midwife added: “they don't have any experience." A midwife explained that mothers could benefit from learning about labor and delivery in a CE program: "if the mother came to us with basic knowledge about labor and delivery, that will decrease stress and its consequences...the fetus will suffer and the rate of $\mathrm{C} / \mathrm{S}$ will go higher... we already have a very high rate of C/S." Another midwife reported that some women have misconceptions around the labor and delivery process. She said: "A woman asked me why they cut the thigh during delivery... I said what thigh they cut...oh episiotomy... the poor thing did not know how big episiotomies are..."

Most physicians also reported that they wanted the labor and delivery process to be added to a CE program; one female physician said: "and if she was educated about labor and delivery...she will know how to deal with it." A male physician added that teaching the labor and delivery process can decrease the work load on the emergency department in the hospital: "they don't know how labor starts... a lot of the primigravidas don't know the different between false and true labor...big load on the ER...and many PV exams and vaginal edema and complications... if she knows how the false and the true labor differ ...." Another female physician said: "she... tell you mama told me delivery is hard and... but if she was properly educated she will not rely on other people." A male physician wanted to add breathing techniques to the labor and delivery process in a CE 
program: "how she will make breathing in labor..." one female physician also added about the surgery consent: "and to accept or refuse surgery..."

Free antenatal care in the public mother and child health centers: Midwives and physicians agreed that a CE program should be included in routine care during pregnancy in the public MCHs. Most midwives agreed that women should be educated about prenatal care and that it be provided for free in the public $\mathrm{MCHs}$, which would be a better solution than the private doctor. One midwife reported: "the program is helpful if women will know that free quality care is available in the public centers... they don't know that they can get antenatal care for free ... better than with a cheap private doctor..." Another midwife argued that the prenatal care provided by private doctors lacks essential screening and care for the pregnant woman: "the woman goes to a cheap private doctor that even does not take her weight... blood pressure or ask for any lab tests... the ultrasound on the belly every month and that's it... fetal heart... fetal sex..." Another midwife added: "some women even when they know the fetal sex they never go back to the doctor... they had what they want... enough."

The physicians also thought that $\mathrm{CE}$ should be included during routine care in the public MCHs with the routine scheduled visits. A female physician reported: "the program should be continued all year and each pregnant woman should make all the tests and the visits with the teaching and not wait to before delivery to teach her..." A male physician added: "every pregnant woman should be in the program... I mean with her monthly visits."

Warning signs and complications during pregnancy: Midwives and physicians reported the need to include the warning signs and complications during pregnancy in a 
CE program. One midwife said: "tell the woman... if you have headache... and ...blurred vision and epigastric pain you have to go to the hospital immediately." Another added that if the woman learned the complications and the signs and symptoms, she can seek help effectively: "if she knew the signs and symptoms of problems during pregnancy she will have time to prevent complications...still birth...preterm." Another added: "signs of urinary tract infection," another problem to include was: "contraindications during pregnancy... things that she read online for pregnant women and because of a condition that she has may not be appropriate for her."

Physicians also wanted to include complications during pregnancy in a $\mathrm{CE}$ program. One physician reported: "discuss the complications..." Another added that including the warning signs and complications in a CE program will help the women when she explains about her conditions and what happen to her: "when she come to the hospital... she will know what happens with her...that help in history taking..."

Midwives also wanted to include diseases during pregnancy to a CE program: the diseases and conditions listed by the midwives were: "hypertension," "abortion," "anemia," "urinary tract infections and what complications they cause," "reproductive infections."

Physical exercises during pregnancy. Midwives and physicians also agreed on including physical exercises during pregnancy to a CE program. A midwife said: "this generation is always sitting...they don't walk...maybe that's why the $\mathrm{C} / \mathrm{S}$ rates are way high..." Another midwife added: "exercises during pregnancy are most important." A third midwife explained that physical exercises should include prenatal and postnatal exercises. She said: "in pregnancy we teach her about exercises during pregnancy and 
when we teach her about postpartum we teach her the exercises of the postpartum period and before labor of one week we teach her breathing exercise..." One physician also reported: "need to teach her exercises...every time they come with low back pain..."

Psychological changes during pregnancy and postpartum. Most midwives reported that they wanted to include psychological changes during pregnancy and postpartum. One midwife explained: "if you teach me something maybe I will not follow but if my mood was good and you supported me I will make more effort to follow what you say." Another midwife added: "pregnancy has mood changes and special psychological needs in each trimester..." Another midwife suggested: "psychological status changes should be in a separate session because we have it but women don't know that there are changes because of pregnancy."

Regarding the psychological status during postpartum and how to get the support from husband and family, one midwife reported: "the woman needs continuity during the program...tell her what will happen with her each trimester and after delivery." Another added: "signs and symptoms of postpartum depression should be included because it's found in our community sadly..." Another suggested to include the husband in these classes: "the husband should be there when the psychological status is explained in each step... he will not be angry if she is moody."

Nutrition during pregnancy. Midwives also wanted to include nutrition during pregnancy in a CE program. One midwife reported: "the biggest problem we have is anemia." Another added: "teach her basic nutrition during pregnancy." One midwife suggested including body image problems; she said: "women are concerned about their body during pregnancy and may do things to protect that image... she may not eat well or 
have stress about it...that's our job to explain that your weight can drop after delivery.... there are things that you can do like applying oils and other things to protect your skin."

Breast feeding. More than one midwife suggested including breast feeding and its techniques and care. One said: "one lady had 6 children and did not breast feed any of them because she had flat nipples...she loved to breast feed but couldn't... during 6 times no one taught her that she can do exercises or buy a synthetic nipple and breast feed... 6 children...6 times to be in postpartum wards..."

Newborn health. Midwives also wanted to include newborn health in a CE program. They said: "umbilical cord care," "newborn care such as bathing, dressing, changing, how to put him to sleep in the crib," "not to smoke or drink..." "Sudden Infant Death Syndrome," and "look for danger signs and symptoms."

Sexually transmitted diseases. Most midwives wanted to include sexually transmitted diseases in a CE program. Midwives thought that sexual transmitted diseases rates are increasing, and signs, symptoms, and prevention of transmission should be included in the CE program. One midwife said: "now the circumstances are different... we have to include sexually transmitted disease ..." One midwife suggested including screening: "we have to include the sexually transmitted disease or screening in the program." And another suggested to include the signs and symptoms of sexually transmitted diseases: "the woman should know the signs and symptoms so she can seek help for her or her husband."

Pain management. All the midwives agreed that labor pain management should be included in a CE program. One said: "pain relief in labor is needed." Another explained: "pharmacology and nonpharma are needed with the side-effects... give her all 
the options." Another midwife explained what happen in some hospitals: "we cannot do like the hospitals ... just explain about the available methods... we have epidural... it's excellent... the doctor will not tell her that instead of having her child in 2 hours she will have it in $8 \ldots$ we have to tell her before she chooses."

Postpartum physiology and care. Some midwives reported the need to include the postpartum physiology and care in a CE program. One said: "we had ladies ask about care in postpartum, bleeding, and nutrition.” Another said: “... the sexual activity ...they don't know but they don't ask." Another midwife concluded: "we have to teach them."

Family planning. Midwives also wanted to include family planning. One midwife reported: "family planning should be taught in the correct time," "I mean the lady is in her first few months and she (the midwife) teaches her about family planning... wait to 38 weeks and teach her about it... timing is everything."

Planning for pregnancy. Some physicians reported the need to include planning for pregnancy in a CE program. They suggested that classes regarding planning for pregnancy should be included in a CE program for couples planning to get married or for school girls. One physician reported: "this program should start with the beginning of pregnancy... or even before pregnancy... when they come to make tests before marriage...in schools...she should know about delivery..." Another added that including planning for pregnancy may prevent some diseases. One physician said: "she comes and we tell her she will have a $\mathrm{C} / \mathrm{S} \ldots$ she is surprised and say why...we tell her because her last baby is less than a year old and you got pregnant immediately...she said no one told me..." Another physician added: "preventable diseases can be decreased if we do 
that..." Another added: "even some unpreventable..." "yes if they knew... somethings may change before it happens.”

Physicians also suggested separate classes for husbands in the CE programs. One physician said: "when they come to this program...come as a family..." A female physician said "the husband will not come but we should try..." She explained: "here in Jordan women are affected by their husbands... I will have 4 children because my husband wants...I will go to class because my husband said... I will be pregnant because my husband... if you educate the husband before...the problem is solved" "they should come together."

\section{When provided with $3 \mathrm{CE}$ programs, what modifications do pregnant} women, midwives and physicians suggest in order for the programs to be appropriate for Jordanian culture?

The print out of the 3 CE programs presented were: Malata et al. (2007), Sercekus and Mete (2010a), and Turan and Say (2003). The program by Malata et al., (2007) was prepared and evaluated on primigravidas who did not have CE programs before the study, so the content was detailed and basic. The content was divided over 6 weeks and was included in the routine antenatal care of the women. The sessions included a pretest and posttest after the last class. The sessions included review of each week's content, physical exam, referral of pregnant women to the physician if needed, and the opportunity for women to ask for individual sessions if she wanted. The classes were provided by midwives who were trained for the purpose of the study (Malata et al., 2007). The Sercekus and Mete (2010a) CE program included nearly the same content as the program by Malata et al. (2007) but included discussion of feelings about the topics 
of all sessions. It also included discussion of the husband's and family's responsibilities in pregnancy and childbirth though the sessions. The program was provided by a nurse that had a childbirth educator certificate. The content was divided over 7 weeks for the group education and 7 weeks for the individual education, and included 6-10 participants each session. The third CE program was the Turan and Say (2003) program from Turkey. The content was very clear and direct. The program was delivered by a nurse, a facilitator, and a trained community member. The sessions were divided over 4 weeks for 8 sessions. The content included details on pregnancy nutrition, and 2 sessions on labor and delivery. Moreover, Turkey shares some cultural aspects with Jordan and this can improve the chances of content being appropriate to Jordanian women.

The most agreed upon CE program was the Turan and Say (2003) program. It had the most detailed content and included full explanations on prenatal care, nutrition during pregnancy, infant health and care, infant feeding and breast care after delivery. Midwives and physicians also suggested removing anatomy, physiology, and fertilization and adding sexually transmitted diseases. They suggested including the program with routine prenatal care in the MCHs which was done in the Malata et al. (2007) program. They also suggested including physical exercises during pregnancy and postpartum and including the husband in CE classes which were only included in the Sercekus and Mete's (2010a) program. Physicians did not want many details in the content of the CE program, and were not specific on what program they liked the most.

The participants also suggested the appropriate time of the classes, group or individual, place, provider, audiovisuals, and number of attendants. Pregnant women preferred different times during the day for the classes. Midwives thought the time should 
be flexible according to the needs of the pregnant women. Physicians reported that the time should be variable but short. Most the participants of the 4 focus groups favored group classes and thought the MCHs will be the best place for the program.

Primigravidas reported that the provider should have special education and experience. Multigravidas reported: "the sister (midwife)." Midwives all agreed that midwives should be the provider. Physicians thought the provider should be a woman with good reputation such as a midwife who has to be experienced or a doctor. Most participants in the 4 focus groups agreed that showing women labor and delivery videos is better for preparing women for the labor and delivery experience. Most participants agreed that a small number of participants (6 to 10) would be better.

Pregnant women. Pregnant women agreed to most content in the $3 \mathrm{CE}$ programs. The pregnant women read the content and indicated that they didn't understand what they need from it and what they did not. Five out of 8 did not want to include anatomy and physiology in the first session. One primigravida said: "that is not important." Another said: "we learned it in school so no need for it..." Most of the primigravidas indicated that nutrition was needed or important.

Midwives. Midwives were more specific than any other group, on the content of the 3 programs and gave suggestions and comments. The suggested modifications on the content of the three CE programs were as follows.

Most midwives wanted to remove fertilization, reproductive system, anatomy and physiology from the first session. One midwife said: "remove fertilization and reproductive system anatomy and physiology and put it with family planning in the third trimester sessions... there the woman need it more..." Another added: "the first class 
should be very interesting so they will comeback." One midwife said: "give her basic knowledge about pregnancy first instead of anatomy and physiology."

The midwives also suggested including preconception care when the couple have contact with the health center before pregnancy or before marriage. One said: "you have to have a heading called preconception care." Another added: "I mean teaching about pregnancy when she comes to remove the IUD... or when the couple comes for the premarriage tests."

Another midwife suggested keeping fetal development. She said: "because you need it when you explain about medication and how it affects the fetus in certain gestational ages." Most midwives suggested including sexually transmitted diseases, the venereal disease test, and teaching her the signs and symptoms of sexually transmitted diseases. One midwife said: "we should include sexually transmitted diseases and the venereal disease test... and teach her the signs and symptoms of the sexually transmitted diseases if she has suspicions to go and make the test." Most of the midwives also suggested including the husband in the lectures or "maybe special classes for the husband." They also suggested "including or keeping the return to sexual activity with the postpartum..." Most midwives asked to include the exercises for each trimester and postpartum exercises demonstrated by a man or by videos. One midwife added: "the exercises should be taught in each trimester and in the postpartum." Another midwife added: "exercises need demonstration or videos... maybe bring a man to do the exercises instead of a woman if you have husbands in the class."

All midwives wanted to include labor pain management including side effects of every method. One midwife said: "we need to teach her detailed pharmacological and 
nonpharmacological with the side effects so she can make a choice..." Then the midwives agreed that they liked the items that included discussion about feelings. One said: "Encourage women to discuss their feelings with their husbands... that is wonderful and it goes to most other items... I like the first program (Turan and Say, 2003) because they have detailed content... clear and direct... but this program is also good (Sercekus and Mete, 2010) add the discussion of feelings to each class and we need that."

One midwife suggested including body image and how to eat quality food during pregnancy. Another suggested including the postpartum psychological changes in a separate class. She said: "we need to put the psychological changes in a separate class... it's a major topic and should take its right."

Physicians. Physicians did not discuss the content of the $3 \mathrm{CE}$ programs in detail, but they gave general ideas about the programs and how they will modify the three suggested programs. Most physicians suggested that first session should be interesting so the pregnant women will come back. One physician said: "make the first class interesting... not anatomy, physiology and fertilization." They also suggested that the first class be done by a medical doctor. One said: "the first class should include a doctor so they will trust the program." One physician also suggested to start with pregnancy and knowledge about the antenatal care. He said: "keep it simple and just give her basic knowledge about pregnancy and care..." Most physicians complained about the pregnant women's lack of knowledge regarding the medical assessment and procedures. One physician said: "include teaching about the vaginal examination and how to cooperate with the doctor so she will not end up with a $\mathrm{C} / \mathrm{S}$ because of fear and anxiety of the procedures. At the end the physicians thought that the three program's content were long and detailed 
and reported the need to shorten them. One physician said: "Summary the information and not give details so more women will understand and join the classes."

Other physicians thought that the number of sessions and classes is very long and needed to be cut down. One physician said: "decrease the number of sessions and weeks to 4 weeks or $2 . . . "$ One physician suggested and most others agreed that a CE program should include other non-health related professions to help complete the program. One female physician said: "there should be assistances to help her like a nutritionist and some one for exercises..." Lastly, all the physicians agreed to include the process of labor and delivery so the women will be more cooperative with them when they are in the delivery room. One physician said: "just the basics... how the labor and delivery is so she knows what will happen to her in the labor room."

Time of classes. Pregnant women preferred different times during the day for the classes: all the primigravidas were housewives and preferred the morning sessions and the Multigravidas preferred short durations and class times. A primigravida said: "10 in the morning is the best" another said: "at 12 noon." A multigravida said: "it should be on a short period... not more than a month or $2 \ldots$ one will get bored," another added: "yes one will lose the interest to participate," another added: "the less the better... about one hour," and "not more than one hour."

Midwives thought the time should be flexible according to the needs of the pregnant women; one midwife said: "see if the $\mathrm{MOH}$ supported the program and assigned a midwife for the education she can make different timing and women will choose the time that is good for them...the program should be divided to three parts one for first trimester, one for second and for third...each in the same day." Another midwife said: 
"for the ladies to come you have to make it in the afternoon" another replied: "most will come in the morning if not employed."

Physicians reported that the time should be variable but short and the duration of the program should be fewer weeks than the durations in the 3 programs: "it should be always available not one date not one time," another added: "it should not be every week... you just meet them once for education and that's it..." he explained: "it's just awareness of the topics and leave everything else to the doctor..." A physician said: "there should be a day in every month...known day to have the health education session...she and her husband will come to the session..." he also added: "I suggest that all what you give in 4 weeks be given in one week I mean all the program in only 2 weeks for 2 hours instead of one every time... they will benefit more" "I think it is all about planned pregnancy... when she plans the pregnancy... teach her about delivery..." "I think they should be educated in the first 6 months and then take program on the net (online) and chat groups..."

Most physicians thought morning is better for women but other physicians thought there should be a time for employed women who cannot come in the morning. They also reported that women should be grouped according to their trimesters. One female physician said: "in the morning is better because most women will come in the morning..." another said: "I think it should be in the week ends," another added: "employed women should have time for them only..." Another summarized: "it should be always available... on the bases that no all people can come at one time one day..." Another added: "and it should be according to the trimester that she is in... I mean women in first trimester together...in second together... third trimester together..." 
Another younger female physician said: "the idea is to make the time work for working ladies... give care to the time of the class..."

Group or individual classes. Most the participants of the 4 focus groups favored the group classes. A primigravida said: "groups," another added: "groups only." A multigravida said: "group is better... so we all get the benefits" “... groups so we can talk together..."

Midwives said: "of course groups" another replied: "100 percent," another said: "no... group." One midwife said: "individual... directly between me and the client is better." Another replied to her: "individual need more time from the midwife and from..." Another opinion was: "it is difficult to gather all the women in a group you will see" another midwife replied to that: "but when the program is approved facilities will be available" "we said... let give the ladies time to change that attitude... it will not be considered an obstacle anymore and if they feel the importance of the program they will gather and accept..."

Physicians said: "groups and should be big," another replied: "nooo... group and should be good number...they like to get together."

Place of the classes. Most the participants thought the MCHs will be the best place for the program. However, they gave other options if the MCHs were not available such as schools and religious and women centers. The pregnant women and the midwives all thought that the health centers are the best place for the CE program. One midwife suggested that the program start by some MCHs who has adequate staff and then generalize the program to all the MCHs in Jordan. 
The physician reported conditions for the place that will hold the CE program: one physician said: "easy to reach... not in the community center that is located far or I don't know where... where the women can go... to Irbid or the center next to... it should be within reach..." One physician said: "it should be in the health centers..." Another added: "the MCHs that have enough staff will work on it... and also in the out-patient clinics of the maternal hospital." Another added that the program should have good reputation and be generalized: "the program when it will be implemented it will be a new thing and it should have classes everywhere and be like common... it should never stop and every pregnant woman should be included...I mean in the health centers they have the schedule of what they should do...I mean blood tests, when to refer her to the physician to be seen with ultrasound when to see the heart beat...during that will be the program and not wait tell she is in the ninth month... and then teach her...the program should start with the beginning..." Other physicians suggested to hold the CE program in other places: "now it's not a must that the program should be in the health center... it may be done in the Quran centers and the Awqaf centers" another physician said: "schools like what he said or the youth centers"

The provider. Primigravidas reported that the provider should have special education and experience. Some thought he or she should be a doctor. The primigravidas did not think that midwives would be good providers but multigravidas only reported the midwives as the provider. One primigravida said: "yes it should be someone who studied and his specialty is education" another said: "the doctor" "someone who knows and have experience." When asked about the midwife as the provider they 
said: "the midwife knows how to deliver and not to teach" Multigravidas reported: "the sister (meaning the midwife)."

Midwives all agreed that midwives should be the provider but she may need help from other professionals such as a nutritionist or with exercises. One midwife said: "I will volunteer for it seriously," another said: "in my opinion it should be a midwife" another added "yes I'm with that it should be a midwife" "another explained: "midwives are more capable of deliver the information because they saw what they are talking about... the health educator will did not see cases so..." "you tell them from what you saw" "should be qualified... and willing to learn" "so the lady is used to seeing the midwife and will take the knowledge from her" "the health educator will studied in general not specialist for the pregnant women" "... for us in Jordan it's better be a midwife" "I think it will give a message to the women I know what I'm talking about when she know that I'm a midwife... but if the health educator... what he will know... he read the information from a book and came to teach me..." "...family medicine or midwife or physician"

Physicians thought the provider should be a woman with good reputation such as a midwife who has to be experienced or a doctor. One physician said: "the person who teach the sessions should be a woman," another added: "should be a female...with good reputation," another added: "it's good if that she will have people with her... like a midwife... have someone with her..." also gave an example: “... if I'm going to attend a lecture and I know that she is a physician or a general doctor... if she is a maternal doctor I will trust the information more or a midwife with a 20-year experience." 
Audiovisual material. The most suggested audiovisuals for the CE program were videos, simulators, role models and pictures. Primigravidas reported "videos and discussions." when asked about what audiovisual materials should be used.

Multigravidas reported that they like the audiovisuals to be videos, simulators, role models and any form to help the class information delivery. One reported: "videos," another said: "discussion," and "a real fetus," another said: "exercises for the baby," "even the brochures we like to read them" "discussion is better..." and last one added: "yes videos and other things... depending on the topic..."

Midwives and physicians reported the same audiovisuals to be used in the classes such as videos, pictures, demonstration by other professionals and lectures. One midwife said: "for sure videos," another added: "maybe pictures." Another midwife added: "I think exercises need videos... maybe demonstration from an assistant or the midwife herself because it's clear and direct...nutrition should be by a specialist..." One physician said: "brochures... videos and like... pictures," another said: "you should put pictures in the brochures so to explain how the thing is done or where to find the service she needed."

Labor and delivery videos. Most participants in the 4 focus groups agreed that showing women labor and delivery videos is better for preparing women for the labor and delivery experience. One Multigravida reported: "yes...it's OK” another said when asked if she will be afraid: "no... impossible I love to see" "even with the bad psychological...it's OK." One primigravida added: "I have a delivery operation on my phone." When asked if women will not accept to see labor and delivery videos, most midwives replied: "no...no..." one added: "on the contrary." The midwife who was 
involved in the CE research study added: "no they were very happy when I showed them the video." One physician said: "I think... you should show her a video I mean she should see that."

From the 28 participants only 2 primigravidas reported that they would not be comfortable watching the labor and delivery video. One said: "no... I don't have the courage." The other primigravida added: "no... no." "it may cause a psychological situation to the woman... I'm afraid when the woman starts to have contractions..."

Number of attendants in each class. Most participants agreed that a small number of participants would be better. The numbers varied from 6 to 25 . But one physician only thought the number should be high so the program would get better publicity.

A primigravida said: "small number so we can benefit," another said: "6 to 8. " A multigravida said: "at least 10," another said: " 15 " when asked if 50 was OK, they replied: "nooo..." another added: "because there will be no comprehension," and "around 20 is acceptable."

A midwife said: "not more than $10 \ldots$... A male physician said: "above 50 that what I think." A female physician said: "noo...I think less" "50 is a lot I think 20 " "20 to 25 ," again the physician said: "it will have video and lecturing so... not every day you have classes...for 2 hours is better..." a female physician added: "the first few classes can have big numbers and then the fewer the better." The physician defended his view saying: "I think if the number was high... if few come they will say no one came... more is better reputation for the program." A female physician replied: "if 10 it will be more sharing of experience under the supervision of the provider...may be healthier..." 


\section{What are the perceptions of pregnant women, midwives, and physicians}

about the feasibility and challenges of implementing a CE program for pregnant women in Jordan?

\section{Feasibility of implementing a CE program}

Feasibility of implementing the CE program was discussed by all the participants. The program was viewed as having positive support from the majority of the community including the health team because of the benefits that it would bring to women and their children, and to the community as a whole. The benefits reported by the participants were: increasing pregnant women's knowledge about pregnancy and childbirth; increased awareness of the community regarding the importance of women's health during childbirth; preventing diseases and promoting women's health; encouraging cooperation from other family members; improving psychological status of the pregnant women; and maintaining or improving newborn health.

Most participants reported that having the CE program planned using the $\mathrm{MOH}$ facilities is the most feasible way to implement the CE program. Midwives and physicians reported that there is a need to implement the program as a trial first and then make the needed modifications according to the new variations of the program progress within the routine prenatal care. They also reported that the $\mathrm{MCH}$ of the $\mathrm{MOH}$ are the best place for the CE program to be implemented according to the midwives and physicians. Midwives and physicians reported that the $\mathrm{MCH}$ has the place and staff (midwives).

All participants reported that women will come to the CE program. The husbands and the family members support was reported as difficult to guarantee. However, 
midwives and physicians added that using media and getting good publicity is needed. To pay for the supplies and the cost of implementing the program, midwives suggested that the $\mathrm{MOH}$ has affiliations with projects within the $\mathrm{MOH}$ initiatives focused on improving mother's and children's health. This CE program can fit under one of these initiatives and projects and will have the appropriate support if the assumed benefits are explained to the publics and to the policy makers in the MOH. The midwives and physicians also suggested that it will not be easy for $\mathrm{MOH}$ to adapt the $\mathrm{CE}$ program without an external fund represented by the affiliations they have. The suggestion was to work on the organizations that give financial support to the $\mathrm{MOH}$. The midwives and the physicians thought that the community's cooperation will not be easy to get because most participants reported that husbands will not be cooperating.

Midwives thought that the midwives working in the MCHs can deliver the classes using the facilities of the public health centers. One midwife said: "MOH can... if they approved the program... can hire midwives especially for this... no matter there are midwives or not they can reassign them to this project..." A physician said: "I think we don't need special staff... midwives are already in the health center and they can do it." Another said that the health center staff are not fully functional, so they thought that the CE program would fit with their usual work load. One said: "most employees are $70 \%$ sleeping."

Midwives were very enthusiastic about the CE program. They reported that they will support the efforts for the program to reach the community and the policy makers. One midwife said: "I will volunteer..." 
The physicians thought that support people who have a power or can have influence in the $\mathrm{MOH}$ should be identified and asked for help because the CE program implementation needs support from such people. This is true even if the results of this study showed that the program will be effective and beneficial. On physician said: "I mean even if we did the study and came up with recommendations... will the people responsible for implementing this program take our word for it?" The midwives, on the other hand, were sure that the $\mathrm{MOH}$ will help the program and that it will fit into one of the initiatives that they have regarding mother and child health. A midwife said: "there are so many organizations that can finance the program with the cooperation with MOH... an example is USAID."

Midwives thought that if the program was explained to policy makers, they might then help fund and support the implementation of the CE program. A midwife suggested: "if you tell the ministry of health about the benefits and that it will cut on the cost of maternal health which is very high in Jordan... when you say it will decrease the cost of hospitalization...they will support the presence of specialist midwives for the program... and assign a place for the sessions." Pregnant women reported many benefits that can result from implementing the new CE program.

\section{Increase pregnant women's knowledge about pregnancy and childbirth.}

Primigravidas had very poor knowledge about pregnancy and childbirth and what they need to know about the process. When asked about labor and delivery knowledge: one said: "Ah...mmm..." another added: "how is that..." When asked what they want to learn about pregnancy, labor, and delivery one replied: “nothing specific just general information." A primigravida had questions around the pregnancy period but did not 
receive a satisfactory answer; she said: "I went to the doctor yesterday and I asked her what to eat or drink in pregnancy, she said nothing special just live your regular life."

Midwives also reported that the CE program may improve the pregnant women knowledge regarding pregnancy and childbirth. One midwife said: "you are surprised that the lady come and she don't know anything about pregnancy and labor." Another replied: "yes in this case the doctor will be surprised and just fashkelha (treat her carelessly)." Another midwife added: "they know nothing." One midwife who works in the labor room shared her experience: "I had one lady that came to the labor room and asked me to explain labor and delivery and what will happen to her... I said you left all 9 months and came to me in these couple hours to explain everything, why you did not ask before...she said I asked and no one answered me..."

One midwife explained what she thought would be a benefit from the CE program. She said: "if the mother came to us with basic knowledge about labor and delivery, that will decrease stress and its consequences...if not the fetus will suffer and the rate of C/S will go higher..." another said: "of course this program will help if was delivered

\section{Increase awareness of community members regarding women's health}

during childbirth. Pregnant women and midwives thought that the program would help in increasing the awareness of the community regarding women's health during childbirth. Many primigravidas thought that the CE program would benefit the community by increasing awareness of the importance of women's health during childbirth and that women who learn about their health can teach others. One primigravida said: "the pregnant woman will benefit a lot from such a program because 
she will be educated... as a pregnant for the first time..." Another added that she is confused sometimes and need help with questions: "I want to know about medication... I go to a doctor she gives me medication but I didn't get well... I went to another doctor she told me who gave you this medication it's not for pregnant women...I'm confused." Another primigravida said: "you have to know about diseases that happen in pregnancy...yes the program will help." One primigravida thought the CE program would help in care during pregnancy; she said: "if the woman knew what to eat in pregnancy she would know how to take care of herself and baby..." Another added that it may help after delivery: she said: "the mother would know her infant is good and how to care for it..." a multigravida reported that the CE program may help: "for the future ... if she knows she would teach other women... her daughters," and another multigravida added: "we defeat ignorance... the health ignorance"

The midwives thought that awareness benefits from the CE program can help the community by decreasing the mortality and morbidity of mother and children, and may decrease the beliefs that public health centers are less effective than private doctors. A midwife said: "now when the health awareness is increased the percentage of diseases is decreased and accordingly the mortality, and if the mother has good health she will take better care of her kids and family and that will reflect on the health level of the whole country... I mean the mortality and morbidity rates." Another added: "if she knows what's wrong...she will not wait on herself." Another added: "the truth is we still have high newborn and preterm mortality rates... and mothers during labor and delivery compared to the world countries." Several midwives added statements to explain how they think the CE program will increase awareness of women and community such as: 
"she will prevent the symptoms... like I will drink enough fluids," "she may prepare herself before pregnancy," "what is the most common we have in Jordan... anemia the program can help..." and "there is a mindfulness in the community that health center is not good and that the private doctor is better... this alone need education so much... if we told her about it..."

Preventing diseases and promoting women's health. Most pregnant women, midwives, and physicians reported that a CE program can have a benefit in decreasing diseases and promoting women's health. One primigravida reported that the CE program can help in preventing diseases during pregnancy. She said: “yes ...yes ...you should know about diseases so that it can help," "it will prevent diseases" another said: "she will care for what she eats and her body and the..." another added: "nutrition...she will know what the sources..."

One multigravida said: "you know when my blood pressure goes up I will know what to do," another added: "or if it goes down..." One multigravida added: "that if something you learn about... will not happen to you... like infections..." and "yes change for the better..." They added the prevention of infections; one said: "she will learn about germs...I mean the pregnant lady will have low immunity..." and she added: "she will know how to care for herself... the baby and her family."

Midwives also agreed that the CE program would promote women's health and decrease complications of pregnancy and childbirth. One midwife said: ": "frankly we have high rates of preterm and newborn's mortality... death of mother after delivery is still high..." Another added: "hypertension... for sure educating will prevent 
complications," another midwife explained: "complications of pregnancy and labor and delivery... the percentage of death and illness..."

The midwives reported that the CE program may decrease diseases during pregnancy: one said: "yea like if she is aware... decrease anemia... urine tract infection..." another added: "when she knows the signs and symptoms... she will know how to prevent the occurrence of... the symptoms will not happen... like I will drink lots of fluids..." another added: "yes and good hygiene," "the diseases will not happen...especially the conditions that follow infections..."

Most physicians also reported that it can prevent diseases and help the mother protect herself and her pregnancy; one physician said: "yes the preventable diseases can be decreased." Another male physician said: "there are the unpreventable diseases...yes like if she has a heart case or rheumatism then knowing about it early will decrease the complications..." Another physician added: "also the sexual transmitted diseases which she can know the signs and symptoms and how to use barriers this will decrease the spreading and the complication on the fetus..."

Encouraging cooperation from other family members. Most pregnant women, midwives, and physicians thought that the CE program would help in teaching the woman how to ask for help and involve her family in her health care especially the husband. One primigravida said: "it can encourage the family to help..." Another added: "she will know how to take her rights."

A number of primigravidas said that the CE program may help in encouraging cooperation of the husband; one said: "yes it will help that the husband come to education with her..." another added: "sure they have to come...yes this (the program) will make a 
change..." another added: "for me my husband will understand and cooperate if there are classes... if there is a program." When asked if they think the proposed CE program will affect the cooperation of the family, pregnant women replied: "yes sure..." "of course... yes" and "yes if it will be possible" when asked what do you mean with "possible", the multigravida said: "mentally...they will not change their minds because that was not in their days... today all life improved and ways are not like before."

The midwives and the physicians agreed that the CE program may help in the cooperation of other family members especially the husband; one midwife said: "yes the program will help... but unfortunately we don't have this." Another midwife added: "he should come" and "I think we should still include them and they will not come but we still have to try."

Most physicians reported that the CE program will improve the chances of including the husbands in the pregnancy and in the classes. One physician reported: "he has to be educated with her... I mean together..." "of course it (the program) will affect the cooperation of the husband... and the woman will be influenced by her husband ... the number of children she will have because he wants...I want to get pregnant because he wants... so she is influenced by the husband in everything... so if you educate the husband everything else will improve"

Improving psychological status of the pregnant women. Most pregnant women, midwives, and some physicians indicated that CE may improve the psychological status of the pregnant woman. One primigravida said: "when she is pregnant she will be very sensitive," and she added: "this (the CE program) will improve 
her psychological status." Another said: "if she can understand she will not be so nervous"

The midwives reported that $\mathrm{CE}$ also can improve the psychological status of the pregnant women; one midwife said: "of course especially if she is primi... having the good experience during pregnancy and about childbirth will make her relax when she go to the delivery room and she know what will happen to her..." Another added an example: "now you tell me to take the iron supplement may be I will not follow what you teach but if my mood is good and I trust you I will follow it more."

A number of physicians added that CE will improve the psychological status of the pregnant women: one female physician stated: "she will tell you by words...my mother told me this... my neighbor told me that...when she is educated from the health center she will not look for knowledge from other people." Another added: "for sure she will be more comfortable and lots of things will be improved."

Maintaining or improving newborn health. Most pregnant women reported that the CE program would help in improving the newborn health. One primigravida said: "this program will educate the mom... how to care for the baby and make his health better... the baby and herself."

The multigravida also commented on the newborn heath. One multigravida said: "It will help preserve the baby the fetus," another added: "one will benefit from it to see if her infant is good or died in her tummy... that she will not lose the baby." A mother of 2 said: "so we will not be confused when we have a baby... the circumcision... the umbilical cord... especially the first period always there are problems." Another mother replied: "yes... the signs and the symptoms of diseases or problems." 
The midwives also reported that the CE program benefits will include improving and maintain the newborn health. One midwife reported: "of course if she has UTI then she will have a preterm and he will be separated from her and a lot of problems..." and "if you teach in the part of infections and prenatal care and then teach her about the newborn care and how to clean the umbilicus and how to look for the danger signs in the newborn... even the sudden infant death syndrome will be decreased if you teach her no smoking and drinking because we have that in our community... and how to watch the way he sleep and the way she bath him...all the problems will decrease."

The physicians did not specifically mention improving newborn's health as a benefit of the program. However, they reported the following specific benefits of the $\mathrm{CE}$ program to the hospitals and health team that affect the childbirth as a process; decrease the work load on the outpatient clinics and the physicians, decrease complications during and after delivery, and changes on the delivery process.

\section{Decrease the work load on the outpatient clinics and the physicians in the}

hospital. One male physician reported: "this will decrease the load on the outpatient clinics in the hospital." Most of the benefits that physicians reported are related to their work and decreasing the load on the hospital: one male physician reported: "lots of things will change..." another said: "the load on the emergency room will decrease... we operate $50 \%$ on women with cold cases... even if she is in mid of her pregnancy... she

will come with low back pain... if she learn that this is normal for all pregnancy... if she learn exercises..." another male physician added: " a lot of the primis come with false labor... if they learn the difference... any contraction she will come to the emergency... but if she is educated she will know the false and the true labor." 
Decrease complications during and after delivery. One physician reported: "like if she knows how to breath during labor and delivery and she is educated how to deal with labor and delivery." Another added: "for example planning pregnancies... she comes to delivery and she has a $\mathrm{C} / \mathrm{S}$ and she asks why the operation... I told her because your youngest baby is less than one-year-old and you got pregnant immediately... she said if anyone told me that I will not get pregnant very soon"

\section{Challenges of Implementing a CE Program}

Opinions of the participants about challenges that the implementation of the program may face were similar in most focus groups. The participants discussed challenges including the cost, staff, client responses, governmental policies, what support the program will have, and including the husband in the program.

Most participants in the 4 focus groups felt that the program cost would not be a big challenge. Most pregnant women reported that they would pay for the program. Most midwives thought that the cost would be very low for the $\mathrm{MOH}$. This would include one time to prepare the place and setting for the CE program and then train midwives for the job. Physicians thought women should not pay for the program. They did not think the program would cost the $\mathrm{MOH}$ an enormous amount of money because they could use the facilities of the MCHs and the midwives who the physicians thought $\mathrm{CE}$ was part of their duties.

Pregnant women thought that staff may provide challenges to implementing the program since they thought staffs do not care. Midwives reported that staff of the CE program could be a challenge because of the limited time and the need for training. Physician viewpoints about staff for the CE program were negative and unsupportive. 
Regarding client responses, most women were sure that the women's responses would be good. However, midwives and physicians were divided about whether pregnant women would respond well and attend the classes.

Pregnant women were unaware of governmental policies that the MOH has or the way they would support the CE program. Midwives reported thinking pregnant women would attend the CE program more if they did not go to private doctors. Physicians showed hesitation about the support the program would get from the $\mathrm{MOH}$ and suggested having support people inside the $\mathrm{MOH}$. Most pregnant women reported they would like their husbands to attend the program with them, however, some reported their husbands would not. Midwives and physicians saw including the husband as a challenge but one that should be tried.

Cost. The general view of most of the participants in the 4 focus groups was that the cost would not be a big challenge. Most pregnant women reported that they may pay money for the cost of the sessions; one primigravida said: "yes I think we will pay..." Another said: "if the lady needed the knowledge she will pay..." A multigravida said: "I think women will pay if they wanted..." Another added: "some women will not pay because they cannot..." another said: "but if they give us gifts more women will come ... honestly..." another replied "I will come without any gifts."

Midwives discussed the cost from the perspective of the MOH. One midwife reported: "the cost... I think the $\mathrm{MOH}$ will not pay...I think will not give gifts or other things...the woman has to come in her own because she like to be educated..." another discussed the women's side of the cost: "yes transportation for the women can be a challenge..." most midwives defended the cost of the transportation by making the 
classes integrated in the routine prenatal care; one said: "but she comes every month for her visit... I think that will not be a problem...where do you want the sessions to take place...in every health center in Jordan...I think it should be applied to few centers first and see what the challenges there and build up from there..." Another added: "I think we should implement it anyway and answers will reveal from there... as a start." Other midwives discussed the cost of the program and what political or funding institution will support the program. One midwife argued: "for the cost on the MOH it will be for once...prepare rooms and train midwives..." another agreed: "yes they have training sessions for everything..." another midwife who has a master degree suggested: "or maybe they can prepare a trailer like the ones they do for immunization and for physical exam...what are they called..." more than one midwife answered: "white hands...al aydi al baidaa." But another midwife opposed: "no that is not possible because CE need follow up and not only one session... meaning for 9 months," the midwife (who made the suggestion) replied: "yes this suggestion is for people who cannot come... we go to them... or encourage the private sector to do this"

Physicians thought women should not pay for the program. They did not think the program would cost the $\mathrm{MOH}$ an enormous amount of money because they will be using the facilities of the MCHs and the midwives who the physicians thought $\mathrm{CE}$ is part of their duties. Most of the physicians suggested: "first of all it should be free for women" Another added: "I don't think that the program will be costly to the MOH... meaning the midwife is there already and take her salary and its already part of her duties... part of her work... and in any other place they will take it serious if we make it public..." Another added: "it doesn’t need materials ... just information.” 
Staff. Pregnant women thought that staff may provide challenges to implementing the programs. They thought they do not care. One primigravida reported: "yes some doctors don't care about the patients and don't give them time... these will not help in this program." Another added: "yes doctors can cause problems...there are mothers that deliver babies in street...who's fault."

When asked about midwives, the pregnant women reported negatively. One primigravida said: "the midwife knows how to deliver babies not teach," Another added: "the mother and child centers don't care to teach." Only one gave a positive answer: "I think they will be happy to teach us..." Pregnant women demonstrated lacking trust in midwives, pregnant women gave negative feelings and facial expressions when asked about midwives in hospitals or MCHs.

All multigravidas reported that the staff may react negatively to taking part in the CE program, especially midwives. One multigravida said: "we come to mother and child health center only for the tests..." Another added: "they don't have patience for us...OK what I will do for you they say..." Another expressed feeling of dissatisfaction: "I feel a burden of delivery because of the doctors and midwives...from the first month...from the way they treat women." Only one multigravida said: "I think they will be cooperative because...I think for sure they will help."

Midwives reported that staff of the CE program can be a challenge because of the limited time and the need for training. They also reported that the pregnant women both participated in the challenge; one midwife working in an $\mathrm{MCH}$ reported: "time and willingness to make the effort are from both sides...the mother have faults and the midwives have theirs..." another discussed: "having problems with the staff does not 
mean that we don't have midwives...no we have... but we have other duties..." A midwife working in the labor room replied: "the assignments can be organized in a way..." and another added: "ministry of health can... if they approved the program...can hire midwives specially for this... no matter there are midwives or not they can reassign them to this project..." Another midwife suggested: "or in the health center they assign one of the midwives... she is totally into these classes." A midwife suggested convincing the $\mathrm{MOH}$ to support the CE program: "if you tell the ministry of health about the benefits and that it will cut on the cost of maternal health which is very high in Jordan... when you say it will decrease the cost of hospitalization...they will support the presence of specialist midwives for the program... and assign a place for the sessions." A midwife added: "yes there is the item of education in the pregnant women follow up card...but it's not effective... in an organized detailed program it will be more efficient." She explained further: "here the women come in a hurry they want to take the test and leave...the woman has a problem she will ask the midwife and the midwife will give her education and tick the item in her card...I have burning sensation ...ok this is what you have to do... teaching about UTI... she ticks that... this what happen... time and the women they have a part... they are always in a hurry..."

Physician viewpoints when asked if the staff will form a challenge to the $\mathrm{CE}$ program were negative and unsupportive regarding the midwives. One female physician was positive about the midwives and that they can deliver the CE program: "I think we don't need special staff... the staff are already in the health centers and they can do it..." Another physician added: "the problem is that they don't have the knowledge in the health center..." Another female physician said: "centers that have enough staff should 
work on it... then they will work the right way and also in the out-patient clinic." A male physician also saw that the staff of the MCHs are not effective enough: "we need to activate the role of the $\mathrm{MCHs}$ more... most of the employees are 70\% sleeping there." Another physician replied: "no matter if it's active or not...no work they are lazy." Another added: "that is the most important challenge for the program..." Another male physician added: "... the educator that does not know in the first place..."

Client response. This challenge raised a mixture of responses. Most women were sure that the women's' responses would be good. However, midwives and physicians were divided about whether women will respond well and attend the classes or face many obstacles and barriers. Most pregnant women thought that client' responses to the program would be good. One primigravida reported: "I will come to the program... I need the information to care for me and the baby...I will come." Another added: "if they need to learn they will come...” A primigravida added: "anything that I learn I will tell others about."

Multigravidas were more apprehensive about their response to the CE program. One multigravida said: "the problem is societal circumstances...our children may be at home...I have class at the mosque at noon..." Another added: "depends on her spare time..." Another multigravida gave an example: "sometimes they make classes in the local community center...I think it's good to go... I did not go because I did not have time...sometime we are the problem too" another replied: "breast self-exam... very few attended."

Midwives thought women would like to learn but would find excuses not to attend. The excuses are time limitations, social commitments, and customs (habits) and 
traditions. Some women would ask about their health only if they suffer from a problem and not to improve or maintain her health. One midwife said: "traditions and habits have a big role... the pregnant lady says my mother told me that ...my aunt told me this... it's the community tradition..." Another explained: "this is the information of family and friends." The midwife who had a previous role in a research study about CE said "the ladies are very happy from the information that I give in my classes but there is no commitment to attendance...no commitment... we solved that by assigning a midwife who is always in the center and if a woman missed a class the midwives will give her a private session about what she missed..." a midwife interrupted: "the women will not come...one will have a visit from her family...one said my husband refused that I will commit to this because I will leave the house so often... we taught every 2 weeks..." another added: "sometimes we had to give them sessions at home." Another responded: "anyone that will not commit can take written material or something on the media." A midwife listed excuses that women may give for not attending: "the women always in hurry... you explain something for her she says my husband is waiting...or I have things to do... she does not give herself time... but you know there is difference between a woman and the other... some women when they hear announcement for any class they attend... I mean she looks for knowledge... others if they have a problem she asks only..." Another also added: "she doesn't ask if there are things to make pregnancy or my health better or how I can deliver without problems...now we don't know... she doesn't ask because she doesn't know that there are things that she can learn and change or because she don't have time or don't like to learn..." 
A midwife gave a summary of the midwives' opinions. She said: "I think the problem is not entirely from the women or staff... if they want to teach they will... they have it in the pregnant follow up card." See Table 2. Another midwife replied "I think this is a problem in the pregnant ladies...because they go to the private doctor clinics... they are sitting there for hours waiting to be seen with the ultrasound every month... how they find time for that... I will volunteer to make sessions at his clinic for free..." Another midwife added: "and shopping... every month they go shopping and spend a whole day..."

A midwife suggested overcoming the challenge by getting positive publicity using the media for the CE program. One midwife said: "the secret is to encourage the women to come... we have to reach them on the media... on WhatsApp ${ }^{\circledR}$ (a chat app on smart phones) ..." One midwife commented: "I think with time... listen to me... anything starts with small numbers in the beginning... with time women will start to tell each other how much they benefited and how nice the classes are..." Another midwife reported: "however, if the pregnant lady follows up from the pregnancy test comes out positive... and the health center staff are capable... she will get all the benefits." Another midwife blamed the staff and not the women: "from my experience... women are hungry for information... if there is a negligence it's from the staff... I mean the lady is in her first few months and she teach her about family planning... wait to 38 weeks and teach her about it... timing is everything" another midwife added that the staff need recurrent training to be able to teach pregnant women: "that's why timing is important... the staff need recurrent training for the midwives...the old and the new staff on the education for pregnancy," Another midwife thought that the problem was not enough observation on 
the staff work: "training about the education is needed but the experience of the midwives is excellent...if there is negligence it's because they need more observation." Another midwife explained: "no midwife will give wrong information, they give information in the wrong timing or they don't give information at all."

Table 2

MOH education table for pregnant women in prenatal care

Individual counseling during pregnancy $\quad$ Put a $(\sqrt{ })$ when you give individual

Personal hygiene and daily activity

Physiological changes during pregnancy

Signs and symptoms of obstetrics and

gynecology problems

Nutrition

Oral health

Drugs and its danger to fetus

Smoking and its danger to mother and child

Danger signs in pregnancy

Breast self-examination

Labor and delivery

Breast feeding

Newborn care

Family planning counseling

- The importance and benefits of pregnancy intervals

- Recognizing the family planning of the client

- Make sure the client knows the following family planning methods:

\section{IUCD}

Oral pills

Condom

Surgical sterilization

Amenorrhea by breast feeding

Injection

Others.

*table translated from the mother card. Mother and child health department. MOH. Jordan 
The physicians' views on the client response were mostly on the community's beliefs and ideas that lead to resisting changes. A female physician said: “ $\ldots$ the biggest challenge for the program is the preexisting ideas that we have... I mean the lady take from home that the delivery is very hard... they will face people that will not change what they believe no matter what..." A male physician added: "yes the problem is that the women talk to each other...if you have them a million in one class talking together... I mean you have to teach them individually...”

When the physicians were asked if they think pregnant women will attend the CE program, they said: "yes...yes," "I think they will be happy..." and "our community likes to gather but having big numbers will hurt the outcome..."

Governmental policies. Pregnant women gave the impression that they are unaware of the governmental policies that the $\mathrm{MOH}$ has or the way they will support the CE program. A primigravida reported: “I don't know politics..." another added: “I don't think they will mind..." Another contradicted: "I think they will help..." she added: "no obstacles...the health center will be the place..."

Midwives went back to the private sector topic and reported thinking pregnant women would attend the CE program more if they did not go to private doctors. One midwife reported: "I think what is causing the problem is the private sector." Another added: "women go to them and they don't do anything..." Another added: "even the information they give are wrong..." another midwife listed the tests that the private doctors seem to ignore: "blood pressure, weight, and tests they don't do..." another midwife gave an example: "some ladies come to the hospital and their hemoglobin level (HB) level is 9 or less... I asked where did you have your prenatal visits... she say 
private doctor...did he ask for your lab test ...no... did he measure your blood pressure...no... what did he do... put the ultrasound on your belly and that's it..." Another interrupted: "I thought this is illegal." The midwife working in the labor room "most women who come to the hospital with problems are following up with a private doctor," A midwife from the $\mathrm{MCH}$ added: "some ladies come to me and say sister we will not follow up with you. We only need the supplements iron and folic acid."

When asked how they think the program will fit with the current governmental policies one midwife reported: "if you tell the ministry of health about the benefits and that it will cut on the cost of maternal health which is very high in Jordan... when you say it will decrease the cost of hospitalization...they will support the presence of specialist midwives for the program... and assign a place for the sessions.” Another said: "they already have movements to protect mothers and children and this program will fit to one of these institution's plans that they have..." Another added: "yes there is a new USAID agreement to fund improvements in the mother and child health care and they are in the data collection phase now."

Some physicians showed hesitation about the support that the program will get from the MOH. They suggested having support people inside the MOH. An older physician said: "you are going to show this program to $\mathrm{MOH} \ldots$ are there people who are going to implement this program... I mean even if we did the study and come up with recommendations... will the people responsible for implementing this program take our word for it?" Another added: "even if the $\mathrm{MOH}$ adopted the program... the delivery of knowledge needs specialty and studies." A female physician said: "they have training programs for everything these days...they can train midwives." 
What kind of support the program will have. Most pregnant women were sure that the MOH will support and pay for the program. One primigravida reported: "I think it will be supported." Another agreed: "of course from where... I don't know but maybe the nurse will know."

The midwives were very enthusiastic and optimistic about the program. One midwife said: "of course the program will be supported... there is a severe need." Another midwife said: "as we said before... explain the benefits and they will support the program." A midwife who works in the hospital and also serves as a Hakeem project liaison officer (Hakeem, 2014) said: "there are a lot of agreements and projects that the MOH has and works on regarding mother and child health... one with USAID.”

Including husband in the program. Including the husband was discussed as a challenge in regards to the expectations that most men will not attend and will not help their wives to attend. Most pregnant women reported that they would like the husbands to attend the program with them, however, some reported that their husbands will not.

Primigravidas opinions were divided. Some said their husbands will come and others said they will not. One old primigravida started to laugh and said: "do you really think he will come if you ask him...no my husband will not come.” Another woman said: "my husband will come...I'm sure he likes to have a part of this." Another added: "some men are interested and others are not." Another added: "mine will not...oh he stays outside in the car."

Half the multigravidas thought the husband will support the program and they should attend and half thought the husbands will not come and will cause a challenge. One multigravida who works as a nurse said: "yes every husband should come to this 
program... maybe if they knew how much their wives suffer they will appreciate them more..." Another said: "yes... I mean he can help... pregnancy is on the two." The youngest multigravida: "my husband will react and appreciate the classes... if this program will happen."

The other multigravidas reported that their husbands will not cooperate. A multigravida said: "mentally...they will not change their minds because that was not in their days... today all life is improved and ways are not like before." One said: "the man doesn't feel with the woman... all pregnancy she is suffering alone...my husband will never think of this." Another said: "they don't see her until the baby is in her arms...next day they say get up and make me food." Women thought traditional ways of thinking and customs can promote this challenge. One mother of 4 said: "my mother-in-law says, when I had my babies I went directly to the fields to work..." A mother of 2 reported that husband's cooperation can improve the pregnancy: "husband's kindness to the woman has a major role for her pregnancy."

Midwives discussed the husband as a challenge because they affect the decisions and the activities of pregnant women. One midwife reported: "some women will not come because... she says my husband did not allow me." Another added: "this point is not because of religion it's mostly community traditions." A midwife added: "I see that there should be classes for husbands alone." More than one midwife stated that men will not come to these classes. One midwife said: "they will not come but we should try ...some eventually will come" Another added: "even the physical exercises he can help and encourage her." They added: "I see there should be special lectures for husbands" Another replied "they will not come," The argument continued: "but you know he is 
responsible like her for the health of the baby and her health and should care for them". When asked if they thought that this program could help they replied: "yes sure" "honestly he has a big influence."

The physicians reported that husbands have big influence on their wives and that will form a challenge of whether pregnant women will attend the program or not. Most physicians reported that husbands will not come to the CE program but that should not stop the quest for them to attend and help their wives to attend. One said: "the pregnant woman should come with her husband... or some family member..." Another shared the opinion of the midwives by saying: "oh I think the husbands will not come...very few will come..." Another physician suggested: “...the program should start with husbands in the beginning... because of that husbands cannot come every time... at least one time they should have a class...when the education is general..." One male physician discussed the challenge: "our community will not accept..." He added: "he is free to accept or not but the idea should be explained... I mean the trust with women... are they going to come with husbands and be educated with them and other women are sitting... I think it may be done individually..."

How will the program be financed? The pregnant women reported not knowing how the program will be financed: "I don't know" "I think the government will help you..." "the doctors and the ministry of health will be in charge of this..."

The midwives' opinion was that organizations with the affiliation of the MOH can finance the program. A midwife said: "there are so many organizations that can finance the program with the cooperation of the MOH...an example is USAID..." 
The physicians thought that the $\mathrm{MOH}$ will not be easily convinced of the program and that it was the only organization in Jordan that can finance the program. However, the program will need a very low amount of financial support because it will use the $\mathrm{MOH}$ facilities and midwives that are available. A female physician commented: "they have the midwives... and the place... just prepare a room and buy equipment for one time... computer, data show, and CDs one time and one midwife...they may need the help of other people such as a nutritionist and someone for exercises..."

An old physician said: "the policies of $\mathrm{MOH}$ will be challenging... but this program will not cost them a thing... they already have all what it needs." Another added: "ah... anything that needs money will not work for them...I think they need to train the staff only." Another added: "yes they already do training sessions for the staff about everything...not a problem" "and sure that the $\mathrm{MOH}$ has already a panel for health education." "you should have a specific committee... responsible for this and its implementation" "they have to have financial aid of..." "this supporting organization should help $\mathrm{MOH}$ and they do you know..." A physician added: "you need to pressure them to support this program," Another replied: "laughing... it's not pressure it's convincing..." 


\section{Chapter V}

\section{DISCUSSION}

\section{Sources of pregnant women's childbirth knowledge}

The results of the current study indicated that women learn about childbirth from other females around them and their doctors. However, the results showed that the younger generation (primigravidas and young multigravida) gained knowledge about childbirth from the Internet, which is readily available to most younger women.

Study results also showed that most participants (pregnant women, midwives, and physicians) reported that other females in the family were the pregnant women's first choice when they needed to ask about pregnancy and childbirth. The second most frequent choice was the doctors. This is consistent with Owies's (2009) findings that women in Jordan received information about childbirth from informal sources such as other females in the family or from the medical staff in antenatal clinics. In the current study, most pregnant women also reported a lack of or decreased trust of the midwives. None of them reported asking midwives for information regarding their pregnancy or childbirth. This is consistent with the findings of Owies (2009) and Oweis and Abushaikha (2004) in which pregnant women reported that they expected no support or information from the midwives or nurses in the hospitals when they deliver their children in Jordan.

The present study results also showed that most of the participants reported that books are rarely being used by Jordanian women to seek pregnancy and childbirth informational needs. No studies in Jordan investigated the sources of pregnant women's information, books, media, and the Internet. 
Pregnant women did not discuss media as a source for knowledge. Midwives thought television programs played a role in educating women about their health but not specifically about pregnancy and childbirth. After searching for the television programs that were related to childbirth and newborn care, the PI found one series on the Roya TV channel in Jordan talking about pregnancy, labor and delivery, and newborn care and problems. The television program by the name of Donia ya Donia aired weekly and a segment of the show discussed pregnancy and childbirth related issues and many aspects of health advice. The segments talked about scheduled prenatal visits and ultrasound exams and other topics. An example of one episode is Qatami (2015). This episode included questions and answers from a pregnant woman and her doctor. The educational material was presented by Rola Qatami, a pharmacist who said that she has a motherhood and early childhood care education license. Qatami claimed that she is the first and only motherhood and childhood educator in Jordan (the name of the position was reported by Qatami herself). Qatami (2016) reported that she owns and operates a private motherhood and child care education center that provide classes to pregnant women in Jordan. In her center, Qatami reported that the course includes 6 classes over 6 weeks and includes education about pregnancy, labor, postpartum, and newborn care (Qatami, 2016).

Mass media can affect the health practices of pregnant women. In Africa, pregnant women who listened to media campaigns regarding malaria were more likely to implement strategies to protect themselves from malaria (Ankomah et al., 2014). Therefore, behavior may change because of communication messages with pregnant women, and they can adopt new health care attitudes because of mass media that are 
aimed at promoting these attitudes (Ankomah et al., 2014). In a study by Martin, Bulmer, and Pettker (2013), pregnant women who were not enrolled in CE classes reported their sources of information as: written materials, friends and family, the Internet, and television reality shows about childbirth. Around $70 \%$ of pregnant women in the study watched these television shows weekly. All women who watched these shows reported feeling well-informed about events that could happen in childbirth. Entertainment and information were the reasons pregnant women reported for watching childbirth related television shows. Martin et al. (2013) reported that television programs may have some benefits for pregnant women such as showing women interventions that may be a part of their labor and delivery including fetal monitoring and emergency caesarian surgeries. The researchers also added that it helped the women to have helpful viewpoints about pregnancy since every pregnant woman has different experiences. However, Martin et al. (2013) recommended that information from informal sources be reviewed or discussed with a professional childbirth educator or health care providers especially for pregnant women not attending CE classes.

The last century witnessed a huge expansion of the sources of knowledge. For the last 10 years or more, the Internet gained fame as an important source of information (Weaver et al, 2010), especially after 2007 when smart phones came within budget for the public (Gao, Larsson \& Luo, 2013; Grimes, Forster, \& Newton, 2014).

Shieh, Mays, McDaniel (2009) reported that women's level of health literacy influence the way they seek knowledge regarding pregnancy and childbirth. Younger pregnant women in the current study reported that they frequently used the Internet to search for childbirth information. Most midwives and physicians also reported that they 
were faced with women who searched the Internet for childbirth-related information, but they never recommended any useful websites to pregnant women. That is consistent with the findings of a study with Swedish women, that showed that $84 \%$ of pregnant women used the Internet for pregnancy related information (Larsson, 2009). Another recent study indicated that $95 \%$ of women in Sweden used the Internet to look for childbirth related information (Bjelke, Martinsson, Lendahls, \& Oscarsson, 2016). In a study of Chinese pregnant women by Gao et al. (2013), 89\% of pregnant women (mostly primigravidas) used the internet to search for pregnancy related information from the beginning of pregnancy. The most searched topics were fetal development and nutrition during pregnancy. Most women in the study evaluated the Internet information as trustworthy based on the consistency of this information with what they learned from other sources such as health professionals (Gao et al., 2013).

In contrast to women in the current study, $70 \%$ of Australian women who received antenatal care by midwives rated their discussion with their midwife as the most useful source of information during their pregnancies, and of those, only $44 \%$ of them used the Internet. Alternately, women who received antenatal care from doctors rated the internet as their most useful source of knowledge. Books were evaluated the most useful source for $17 \%$ of all the participant of the study (Grimes et al., 2014). Grimes et al. (2014) recommended that discussion of informational needs with midwives is the best way pregnant women can learn about pregnancy and childbirth (Grimes et al., 2014).

Because of easy access in the comfort of their homes, many women will choose to get the information they need from the Internet. Lagan, Sinclair, and Kernohan (2010) reported that online information regarding pregnancy and childbirth allowed pregnant 
women to clarify knowledge gained from their health care providers and assisted in their decision making abilities. However, Carolan (2007) found out that the ability of pregnant women to find access to a large volume of information does not necessarily mean understanding and comprehension. Regardless of the literacy level and skills, most learners need help understanding health related information and that can be achieved with the help of health care providers (Gazmararian, Curran, Parker, Bernhardt, and DeBuono, 2005).

The results of the current study also showed that midwives and physicians thought the Internet knowledge is not always trustworthy and women need to have trustworthy sources to teach them about childbirth informational needs. In a systematic meta-analysis of evaluating websites related to health, $70 \%$ of the studies reviewed concluded that the quality of the websites on the Internet was not trustworthy (Eysenbach, Powell, Kuss, \& Sa, 2002; Gao et al., 2013).

Gao et al. (2013) reported that the Internet provides easy access to health-related information. Gao and colleagues found that $91 \%$ of pregnant women in their study had access to the Internet, and most of those (89\%) used it to look for information about childbirth from the beginning of pregnancy. The topics they looked for most were fetal development and nutrition during pregnancy. These were also the topics of most interest by the women in the current study. Gao et al. (2013) recommended that health professionals recommend trusted websites regarding childbirth in their antenatal clinics. When pregnant women use informal sources of information, most will not check the accuracy of information received. This can lead to conflicts in information, confusing 
childbirth expectations, and potentially harmful effects on the health of mother and child (Martin et al., 2013).

\section{Pregnant women's learning needs in Jordan}

In 2015, around 55 thousand women gave birth vaginally in the MOH's hospitals accounting for around 73\% of all deliveries in MOH's facilities (MOH, 2015). In total, 99\% of pregnant women receive antenatal care in Jordan (HPC, 2010). These women attended a mean of 3.9 antenatal visits during pregnancy (MOH, 2013). The midwives in the current study reported that during these antenatal visits, midwives have the opportunity and the duty to teach women about their needs during pregnancy but most did not. Health education and counseling is found on the pregnant woman's follow up card. The midwives are required to tick and sign any topic about which they teach the woman or give her counseling.

There were no studies found regarding what the women wanted to learn or their specific educational needs during pregnancy in Jordan. Other studies around the world reported the educational needs of pregnant women. In the current study, most primigravidas wanted to know about nutrition during pregnancy and about the fetus. These topics were also the most popular for pregnant women in Gao et al. (2013) and Larsson's (2009) studies.

Most multigravidas in the present study wanted to know about problems during pregnancy including blood pressure, infections, discharges and psychological status. Primigravidas were not sure what they wanted to know about labor and delivery. Only one wanted to know about the labor and delivery process. Only one multigravida wanted to know the signs and symptoms of labor. Most primigravidas wanted to learn about 
labor pain management, caesarian delivery, preparation for hospital, and newborn care after delivery. Others were interested in nutrition, breast feeding and care, and family planning. Multigravidas wanted to know about newborn baby care and signs and symptoms of diseases or complications in the newborn. All pregnant women thought that including husbands in the CE program was acceptable and needed.

In summary, what pregnant women thought they wanted to learn included the following: changes during pregnancy, nutrition during pregnancy, fetal growth and development, problems during pregnancy, psychological status, labor and delivery process, labor pain, caesarian delivery, preparation for hospital, signs and symptoms of labor, newborn care after delivery and problems, nutrition in postpartum, breast feeding and care, and family planning. All of this content is present in Turan and Say's (2003) CE program except psychological status during pregnancy, labor pain management, and including the husband. Sercekus and Mete's (2010a) CE program content in Turkey involved discussion of feelings around each topic, and how to involve and discuss responsibilities of husbands and families in each class. The content missed only family planning.

In Malata et al. (2007), the pregnant women's learning needs were articulated after asking Malawian pregnant women what they wanted to learn after they delivered their children. In a previous study (Malata, 2000) pregnant women were asked what were their perceived information needs. The researchers then asked experienced midwives about their views regarding pregnant women's informational needs in Malawi. The needed content was included in the CE program they used in Malawi et al. (2007) study. The topics perceived by pregnant women and midwives were: antenatal care, self-care 
during pregnancy, nutrition during pregnancy, cultural issues during pregnancy, common discomfort during pregnancy, danger signs in pregnancy, sexual transmitted diseases during pregnancy, preparation for delivery, the labor process, possible complications during labor and birth, caesarian birth, non-pharmaceutical pain relief, measures in labor, self-care during postnatal period, exclusive breast feeding, care of the newborn baby, danger signs of the puerperium, care of the newborn baby and family planning (Malata et al., 2007). The CE program did not include changes during pregnancy, fetal development, and including the husband as was found in the learning needs of pregnant women in the current study.

In a comparison of the content covered by childbirth educators in Turkey and those in the United States, the following were the topics covered by both groups: nutrition during pregnancy, growth and development of the fetus, changes during pregnancy, warning signs, preparation for delivery, nutrition during breast feeding, physical changes of the breast and benefits of breast feeding, nutrition during breast feeding, physical changes during delivery, delivery techniques, pain relief techniques, and family planning. Infant bathing, care of episiotomies, and exercises after delivery were the topics discussed by the childbirth educators in the United States and not much by those in Turkey (Ustunsoz et al., 2010).

In summary, pregnant women in the current study reported the topics that they thought important to learn during pregnancy and childbirth. Those topics were very similar to those found in other studies, but pregnant women in the present study did not know that they could learn about danger signs during pregnancy, labor and delivery 
intervention, physical exercises, sexual transmitted diseases, and self-care during postpartum.

Danger signs and symptoms. Okour et al. (2012), in a descriptive cross-sectional study, assessed the levels of awareness of danger signs among Jordanian pregnant women. They explored if pregnant women could recognize 4 out of 12 danger signs and symptoms during pregnancy. Most women had high school education or less, and were house wives. Around $80 \%$ of women experienced at least one of the danger signs during the current pregnancy. Of those, 91\% (n=319) contacted professional help for these signs. Only $27 \%$ ( $n=94)$ were informed by physicians about the danger signs and life threatening conditions during pregnancy. Only $15 \%$ of women $(n=53)$ recognized at least 4 signs and symptoms during pregnancy, 61\% $(n=214)$ recognized at least one sign or symptom, and $38 \%(n=133)$ did not recognize any danger signs or symptoms during pregnancy. Awareness of the danger signs was significantly associated with more years of education, women's employment, family size (more than 5 pregnancies were more aware), and being provided information about danger signs by health care providers. Women in Okour's et al. (2012) study were mainly aware of the following danger signs: vaginal bleeding (29\%, $n=102)$, dizziness $(28 \%, n=98)$, and vomiting (27\%, $n=95)$. They did not recognize them as danger signs that require seeking help. Women need to have information about danger signs from a trusted source during pregnancy especially women pregnant for the first time. This knowledge can be achieved through CE.

Awareness of the danger signs during pregnancy can help women make critical decisions regarding seeking help in sufficient time to prevent complications. Accordingly, women in the Okour's et al. study (2012) did not know danger signs and 
symptoms to ask for help in a timely manner. About $85 \%(n=298)$ of women recognized less than 4 danger signs, and 39\% (n=137) could not recognize any of these signs and symptoms. Only a quarter of the participants had been informed of the danger signs during pregnancy. Okour et al. (2012) recommended teaching women about these danger signs and symptoms during pregnancy to help decrease the maternal morbidity rate in developing countries including Jordan.

In Nigeria researchers reported that women did not recognize most danger signs in newborns in deliveries that took place mostly at home (more than 90\%). Maternal mortality in northern Nigeria is among the highest in the world (608/100,000 women) (Doctor, Findley, Cometto, Afenyadu, 2013). A survey of 5,083 women who recently delivered their babies found that only $25 \%$ attended antenatal care and less than one-third knew three or more danger signs of pregnancy or labor and delivery. They also reported that the higher the socioeconomic status of the women, the more knowledge of danger signs they had, but not with knowledge of life-threatening, critical danger signs. Antenatal care visits were not associated with increased knowledge of critical danger signs.

Process of labor and delivery. Very few pregnant women in the current study wanted to know about the process of labor and delivery. However, CE classes can help to decrease fear and anxiety of labor and delivery. Karabulut, Coskuner Potur, Dogan Merih, Cebeci Mutlu, and Demirci (2016) studied the effect of CE on fear of childbirth, acceptance of pregnancy and identification with the motherhood role. They used a quasiexperimental study design with a pre- and post-education model. The sample consisted of 192 pregnant women ( $n=69$ education group and $n=123$ control group). After the 
educational classes, the education group and control group levels of acceptance of pregnancy and their fear of childbirth levels were significantly different. However, identification with the motherhood role did not differ. Karabulut et al. (2016) concluded that CE increased the acceptance of pregnancy and reduced the fear of childbirth but did not affect the identification of motherhood. Karabulut et al. recommended including a systematic CE program in routine prenatal care to reduce fear and anxiety related to interventions and complications during labor and delivery. These recommendations were stated by the midwives in the current study in their suggestions to include CE in routine prenatal care.

\section{What midwives and physicians thought should be in the CE program}

Midwives and physicians agreed on a number of content areas they wanted in a CE program including: labor and delivery process, free antenatal care available in the $\mathrm{MCHs}$ and including the $\mathrm{CE}$ program with routine prenatal care, warning signs of complications during pregnancy, and physical exercises during pregnancy. Other content was reported by midwives only or by physicians only. Midwives wanted to include the following in a CE program: psychological changes during pregnancy and postpartum, nutrition during pregnancy, breast feeding, newborn health, sexually transmitted diseases, pain management, postpartum physiology and care, and family planning. Physicians suggested including planning for pregnancy and separate classes for husbands in the CE program.

Maternal and newborn mortality rates in Jordan are still high compared to developed countries (19 per 100,000 and 17 per 1000 live birth respectively) (MOH, 2015). Midwives thought that many of these deaths are caused by preventable 
complications that can be decreased by educating women to take care of themselves. When studying antenatal morbidity, Quteitat et al. (2012) reported that pregnant women in his study suffered from anemia (20\%) at enrollment in antenatal care and $26 \%$ at delivery when the normal hemoglobin level were $<11 \mathrm{gm} / \mathrm{dl}$. The most common morbidities in the sample were urinary tract infections (20\%), genital infections (19\%), and anemia (11\%). No mortalities were recorded during this study. Parity of more than 4 was significantly related to increased morbidity during the antenatal period but not during periperium (Quteitat et al., 2012).

In a study by the Higher Population Council (HPC, 2008), the maternal mortality rate significantly decreased between 1997 and 2008 from 41 to 19 per 100,000 respectively in Jordan. This rate is considered low compared to other developing countries such as sub-Sahara Africa (900 per 100,000) and Oceania (430 per 100,000), but considered high compared to other Arab countries such as Qatar (7 per 100,000) in 2010 (UNICEF, 2013).

The leading cause of maternal death in Jordan in 2007-2008 was hemorrhage (74\%), followed by pulmonary embolism (24\%), and septicemia (8\%). Of the maternal deaths during 2007-2008, 19\% did not attend any antenatal care, 33.3\% had 3 or fewer antenatal visits in total, and around 54\% died of preventable causes. This national study recommended that $\mathrm{CE}$ should be developed and evaluated for effectiveness in teaching women life threatening risks and preventable causes of death (HPC, 2008).

Batieha et al. (2016) investigated the neonatal mortality in Jordan and its causes and associated factors. They reviewed a total of 21,928 deliveries with gestational age $\geq 20$ weeks from 18 hospitals in Jordan. A total of 327 babies $\geq 20$ weeks of gestation 
died in the neonatal period. Excluding babies $<1000 \mathrm{~g}$ and $<28$ weeks of gestation to be consistent with the WHO and UNICEF's annual neonatal mortality reports, the neonatal mortality rate was 10.5 per1000 live birth. About $79 \%$ of all neonatal deaths occurred in the first week after birth with over $42 \%$ occurring within the first day after delivery. Most neonatal deaths were due to congenital anomalies (27.2\%), multiple births $(26.0 \%)$, and unexplained immaturity $(21.7 \%)$. Other death causes were maternal diseases $(6.7 \%)$, other infant conditions $(6.4 \%)$, and unexplained asphyxia $(4.9 \%)$. Batieha et al. (2016) concluded that $37 \%$ of neonatal deaths were preventable and another $22 \%$ possibly preventable. Approximately $37 \%$ of neonatal deaths were reported to have received adequate medical care while the remaining neonates received less than adequate care. Increased neonatal mortality was associated with: male gender, congenital defects, inadequate antenatal visits, multiple pregnancy, presentation at delivery, and gestational age (Batieha et al., 2016).

Simkhada, Teijlingen, Porter, and Simkhada (2008) reported that in developing countries, pregnant women missing antenatal visits was affected by: maternal education, husband's education, marital status, availability, cost, household income, women's employment, media exposure, and having a history of obstetric complications. Cultural beliefs and ideas about pregnancy also had an influence on antenatal care use. Parity had a statistically significant negative effect on adequate attendance. Women of higher parity tend to use antenatal care less Simkhada et al. (2008).

In Saudi Arabia, Al-Ateeq, Al-Rusaiess, Al-Dughaither (2013) used questionnaires to ask 300 Saudi women about their antenatal care and education. Most participants had 3-6 antenatal visits starting from the fourth month gestation. Being 
highly educated was significantly associated with more antenatal visits and earlier first visit. About $80 \%$ of participants were satisfied with the health education provided during their visits. Multigravidas were found to receive less health education than primigravidas. The most common informal education received from the doctor, nurse or antenatal educator was on breast feeding (83\%), signs of labor $(75.3 \%)$, and baby care (74.7\%). Most participants reported not receiving all of the important information that should be in the antenatal education. Al-Ateeq et al. (2013) found that the younger the woman, the more antenatal education she received. The pregnant women also reported that their main sources of information during pregnancy were: relatives and friends $(66 \%)$, heath care team (doctor, nurse, or health educator) $(53.7 \%)$, and other resources (28.7\%). Seventy-eight percent of participants were satisfied with the health education received during their antenatal visits. The researchers concluded that women received inadequate health education by the end of their pregnancy because organized $\mathrm{CE}$ programs are lacking.

Free antenatal care. In the current study, midwives and physicians wanted the CE program to be included in the free antenatal care provided for pregnant women in Jordan. Midwives also wanted to educate women that quality free antenatal care is available in the public MCHs. Raatikainen, Heiskanen, and Heinonen (2007) found that non-attending (no antenatal visits) or low-attending (less than 4 antenatal visits) of free antenatal care visits in Finland was associated with increased risk of adverse pregnancy outcomes such as pregnancy complications (placental abruption and chorioamnionitis), low birth weight, and neonatal and fetal death (Raatikainen et al., 20017). 
One way to improve attendance of mothers in antenatal care was to include them in a mobile phone health care intervention to improve access to vital reproductive health services. Lund et al., (2016) invited pregnant women who came to the first antenatal visit in selected primary care facilities in Zanzibar and who had mobile phones. He included them in the wired mothers' intervention. The intervention consisted of an automated short messaging service (SMS) system that provided mothers with 2-way text messaging and a mobile phone voucher that allowed 2-way communication between the pregnant women and their care providers. The randomized controlled trial in the primary healthcare facilities included 2550 pregnant women (1311 intervention and 1239 control) who attended antenatal care. The women were followed from their first antenatal visit to 42 days after delivery. The main outcome measure was attending 4 or more antenatal care visits during pregnancy. Secondary outcome measures were tetanus vaccination, preventive treatment for malaria, gestational age at last antenatal care visit, and antepartum referral. The mobile phone intervention was associated with a significant increase in antenatal care attendance; $44 \%$ of the intervention group had 4 or more visits and only $31 \%$ in the control group. More women were receiving preventive health services, more women attended antenatal care late in pregnancy, and more women with pregnancy related complications were identified and referred (Lund et al., 2016).

Physical exercises. Both midwives and physicians thought physical exercises should be included in the CE program. Several studies reported the benefits of physical exercises during pregnancy and postpartum. Exercises during pregnancy are associated with higher cardiorespiratory fitness (Ramirez-Velez, 2011), prevention of urinary incontinence (Mason, Roe, Wong, Davies,and Bamber, 2010) and low back pain (Kluge, 
Hall, Louw, Theron, \& Grove, 2011 ; Stafne \& Salvesen, 2012), reduced symptoms of depression (Songoygard et al., 2012), gestational weight gain control (Haakstad, 2011), and for cases of gestational diabetes reduced number of women who required insulin (Barakat, Cordero, Coteron, Luaces, Montejo, 2012; de Barros, Lopes, Francisco, Sapienza, Zugaib, 2010). There was no effect of physical excises during pregnancy on newborn birth weight or preterm birth rate (Haakstad, Bø, 2011). In summary physical exercise is valuable for women during pregnancy and postpartum period. It is not associated with risks for the newborn and can lead to physical changes leading to longterm benefits. The intensity of physical exercises should be mild or moderate for women who were sedentary before pregnancy and moderate to high for active women. The physical exercise recommendations are: moderate-intensity, low-impact, aerobic exercise at least three times a week. However, new guidelines suggest increasing weekly physical-activity including vigorous exercises and adding light strength training to the exercise routine of healthy pregnant women (Artal \& O'Tolle, 2003). These guidelines can be adapted for physical exercises sessions in the new CE program.

Psychological status during pregnancy and postpartum. Midwives wanted to include psychological changes during pregnancy and postpartum to the CE program. They reported that psychological distress can increase the risk of complications during pregnancy and after delivery. Alder, Fink, Bitzer, Hosli, and Holzgreve (2007) published a literature review analyzing the link between prenatal maternal psychological distress and obstetric complications. Alder et al. (2007) reported that high levels of depression and anxiety were associated with increased obstetric complications, exaggerated pregnancy discomforts, preterm labor and delivery, and a higher use of pain management. 
CE can play a vital role in decreasing anxiety and fear related to childbirth for women before going through the labor and birth experience (Lee \& Holroyd, 2009).

Midwives in the current study reported thinking that postpartum depression prevalence is high in Jordanian women. Mohammad, Gamble, and Creedy (2011) used a prospective cross-sectional study to investigated the prevalence of depression during pregnancy and postpartum for Jordanian women, and detect associated risk factors and issues regarding maternity service. The participants were assessed during the third trimester of pregnancy and again at 6 to 8 weeks and six months postpartum with telephone or face-to-face interviews. The sample consisted of 353 low-risk pregnant women. The results showed around $19 \%$ antenatal depression and around $22 \%$ postnatal depression. Prevalence of antenatal depression was associated with stress, anxiety, financial problems, perceived lack of parenting knowledge, problematic relationship with the mother-in-law, unplanned pregnancy, and low self-efficacy. At 6 to 8 weeks postpartum, the factors associated with postnatal depression were: having antenatal depression, unplanned pregnancy, problematic relationship with mother-in-law, dissatisfaction with overall care, stress, lack of social support, giving birth to a female baby, feeling pressured to birth the baby quickly, and perceived low parenting knowledge. Educating women and their families may help to decrease the effects of psychological puerperium changes.

Mohammad et al. (2011) concluded that support should be available for pregnant women in Jordan to prepare for childbirth. Routine antenatal and postnatal care should include emotional support and assessment of symptoms of depression. The discussion along with increased awareness and clarification of common misconceptions about 
antenatal and postnatal depression should be included in the perinatal care. This can be achieved during CE.

Yehia, Callister, and Hamdan-Mansour (2013) recommended the need to address the psychosocial needs of Jordanian childbearing women in perinatal care. Yehia et al. (2013) conducted a cross-sectional correlational study to assess the prevalence of symptoms and psychosocial predictors of postpartum depression (PPD) among Muslim Jordanian women serving in the military. The participants included on duty military women who gave birth within one year before the study $(n=300)$ in 4 military hospitals in Jordan. Tools used included the Edinburgh Postnatal Depression Scale, the Impact of Event Scale-Revised, and the Multidimensional Perception of Social Support. About $67 \%$ participants had mild to moderate symptoms of PPD, and $16 \%$ had high levels of symptoms of PPD. About $75 \%$ reported having adequate social support, and $75 \%$ reported noticeable stress. There was a strong positive association between perceived stress and symptoms of PPD. There was a moderate negative association between symptoms of PPD and perceived social support. The strongest predictors of PPD were income, planned pregnancy, mode of birth, family and social support, and perception of stress. There was a joint relationship between PPD and psychosocial variables, with women having low levels of perceived stress and satisfaction with social support having fewer symptoms of postpartum depression. CE can help with how to deal with stress, planning pregnancy, and family support to help in improving the pregnant women's psychological status.

Midwives in the current study thought that midwives need training and supervision to carry out CE. This is consistent with the findings of Malta et al. (2016), 
who concluded that knowledge and practices of health professionals can be improved through planned intervention designed for primary health care teams providing antenatal care. Malta et al. (2016) conducted a controlled, non-randomized study to evaluate the effect of an educational intervention to improve the knowledge and practices of health professionals regarding diet and physical activity during pregnancy. An intervention group of doctors and nurses $(n=22)$ from the family health units in a medium-sized clinic in Brazil, received training consisting of an introductory course and three workshops, whereas the control group, doctors and nurses $(n=20)$ from traditional basic health units, did not receive the training. The professionals' knowledge was assessed at two time points, 1 month before and 1 year after the beginning of the intervention. The increase in the knowledge scores for walking and healthy eating in the intervention and control groups were calculated and compared using Student's t-test. To Assess the professionals' practice, pregnant women cared for by professionals in the intervention group ( $\mathrm{n}=140)$, and 141 cared for by professionals in the control group were asked whether they received guidance on healthy eating and leisure-time walking. The women who were cared for by the intervention group were more likely to receive guidance regarding leisure-time walking $(\mathrm{PR}=2.65 ; 95 \% \mathrm{CI}=1.82-3.83)$ and healthy eating ( $\mathrm{PR}$ $=1.76 ; 95 \% \mathrm{CI}=1.34-2.31)$ when compared to the control group.

Midwives in the current study wanted to include labor pain management and include all options and not only what the hospital and doctors want women in labor to know. This relates to the findings of Madden, Turnbull, Cyna, Adelson, and Wilkinson (2013), who reported that differences existed in the personal preferences of pregnant women, midwives and obstetricians regarding pain relief for childbirth. And they 
suggested that pain relief methods should be available in maternity care settings and be reflected in the informed preferences of pregnant women. Madden et al. (2013) compared personal preferences of pregnant women, midwives and obstetricians regarding a range of physical, psychosocial and pharmacological methods of pain relief for childbirth using questionnaires in South Australia. The sample was 400 pregnant women, 500 obstetricians, and 425 midwives. Only 31\% $(n=123)$ of the pregnant women, $50 \%$ ( $n=242)$ of the obstetricians, and $49 \%(n=210)$ of the midwives returned the questionnaires. The midwives showed greater personal preference for physical pain relief methods. Obstetricians showed greater personal preference for pharmacological methods than the other groups. Pregnant women had preference for both groups but were more likely to choose the physical pain relief methods. All groups showed more preference for having a support person for labor with more than $90 \%$ reporting they personally wanted such support. The least preferred method for pregnant women was pethidine/morphine $(14 \%)$ which is used in the public hospitals in Jordan as reported by Hatamleh et al. (2008).

Women in Jordan expected their childbirth to be frightening, long, too difficult and painful. They also expected to have inadequate support from the midwives and nurses in labor during childbirth (Oweis \& Abushaikha, 2004). Moreover, first-time mothers in Jordan reported higher levels of pain than expected, fear and anxiety of the labor process, and having interventions that they did not know about such as induction and episiotomy. After the experience, women rated their labor and delivery as intense and painful (Oweis, 2009). 
Mohammad, Alafi, Mohammad, Gamble, and Creedy, (2014) also reported Jordanian women's dissatisfaction with childbirth care. This can have a negative impact on a woman's health and well-being, as well as her relationship with her infant. Implications of their study were to develop national evidence-based policies and quality assurance routines to reduce the rate of obstetric interventions and respect women's preferences during childbirth Mohammad et al. (2014).

Nutrition during pregnancy. Both midwives and pregnant women in the current study were interested in including nutrition during pregnancy and postpartum in the $\mathrm{CE}$ program. Pregnant women need knowledge about nutrition and anemia during pregnancy. The midwives stated anemia as an example of nutritional deficiencies that can be prevented with education. They reported that many Jordanian women suffer from anemia in their pregnancies. Al-Mehaisen, et al. (2011) concluded that Jordanian pregnant women were more likely to be anemic if they were in their 2nd and 3rd trimesters, underweight, with history of previous surgery, and frequently took multivitamins during pregnancy. The factors associated with anemia and other preventable conditions during pregnancy could be added to CE program to help women identify the signs and symptoms of these conditions, seek help, and take actions to prevent these conditions. Anemia prevalence was highest for women in their 3rd trimester (42.5\%) when compared to those in their 2nd trimester (32.7\%) or 1st trimester (18.9\%) (Al-Mehaisen et al., 2011).

Midwives suggested pregnant women need teaching about healthy diet and prevention of deficiencies during pregnancy. The following study found that pregnant women may not have adequate nutrient intake and CE can help them learn about healthy 
eating. Vidal et al. (2015) conducted a cross-sectional study to assess nutrient intakes and compliance with nutritional recommendations in pregnant women according to selected sociodemographic characteristics and lifestyles. The sample consisted 2,585 pregnant women using Food Frequency Questionnaires. The adequacy of food group intake was assessed considering current recommendations and from the Spanish Society of Nutrition and the Dietary Reference Intakes of the US Institute of Medicine. Pregnant women showed low compliance with the recommendations for an adequate and balanced diet. About $70 \%$ had low intake of cereals and legumes, $39 \%$ low fruit intake, $47 \%$ low vegetables, and $52 \%$ low diary intake. Fruit and vegetable consumption increased with age, educational degree, and physical activity. Around $65 \%$ of pregnant women did not meet the recommended vitamin E requirements. Vidal et al. (2015) concluded that sedentary women and those with a low education are at risk for low vitamin and antioxidant intake and non-optimal food choices during pregnancy.

Khuri-Bulos et al. (2014) reported severe incidence of low vitamin D levels in newborn infants in Amman, Jordan, that included newborns delivered in the spring and summer months. She recommended Vitamin D supplementation to all newborns in the Jordanian population.

Breast feeding. Pregnant women and midwives reported the need to add breast feeding and care in the CE program in the present study. In Jordan, Oweis, Tayem, and Froelicher (2009) conducted a descriptive cross-sectional study by asking Jordanian women to describe their breast-feeding beliefs and practices. The sample included 200 Jordanian women who were exclusively breast feeding within 6 months after the delivery of their children. Women were recruited from 
three Primary Health Care centers (PHCs) in North Jordan. The instrument was a self-administered questionnaire developed by the researchers.

The study found a high rate of early breast feeding initiation. However, most women provided supplements to the baby (i.e., water, sugar, herbs) without knowing the effects on exclusive breast feeding. The researchers recommended that women should be educated about breast feeding during antenatal care.

Additionally, teaching can be improved by incorporating religious beliefs into breast feeding education. The study's generalization was limited because of the convenient sample, and that no explanation was given regarding power analysis and the sample size chosen. The concept of exclusive breast feeding was not defined during the study and was not clear in the questionnaire. This can limit the findings about exclusive breast feeding and supplements.

Benefits of CE. Most pregnant women, midwives, and physicians thought that CE will be beneficial in improving pregnant women's knowledge and pregnancy and birth outcomes. This is consistent with several studies. In Turkey, Sercekus and Mete (2010b) conducted a qualitative study using semi-structured interviews with a sample of 15 primigravidas. This study aimed to describe the pregnant women's perception on the effectiveness of CE on pregnancy, childbirth and postpartum periods, and their impressions on the type of education in antenatal education classes.

Turkish women reported that antenatal education had positive effects on both knowledge about, and the process of pregnancy, childbirth, breast feeding, motherhood, and infant care. They perceived that it may have a positive or negative effect on their anxiety and fear of labor. The investigators concluded that the content and the 
methodology of CE should be planned in a way to avoid increasing pregnant women's fears. The researchers preferred group CE because it was what the pregnant women preferred, and it incurred a lower cost. However, the sample was relatively small and the findings might be enhanced with a larger sample.

Turan and Say (2003) conducted a study to describe the implementation and evaluation of a community-based CE program for first-time pregnant women in Istanbul, Turkey. The sample consisted of 2 groups: the childbirth education group $(n=100)$ and the control group ( $n=157)$. The CE group and the control group were obtained from the same hospital. The study's hypothesis was that women who participated in the CE program would have higher rate of vaginal delivery, practice more maternal and infant healthy behaviors recommended by the program, and use contraceptive methods more than those women in the control group.

The CE program consisted of 8 daytime sessions, 2 hours each. The sessions were done 2 times a week for 4 weeks. Each session was managed by a nurse, a facilitator, and a trained community member. The content included health during pregnancy, nutrition during pregnancy, preparation for childbirth, childbirth process and care, immediate transition to motherhood, communication, feeding and care of the newborn, and contraceptive use after birth. The researchers used pre and post-tests to evaluate the change in mothers' knowledge for both groups. Then, surveys and interviews were administered 2 to 3 months after delivery to evaluate the differences in health behaviors between the two groups.

There were no significant differences between the childbirth education group and the control group in the demographic characteristics. No significant differences were 
found between the study groups in vaginal birth rates and postpartum check-ups. However, results showed that the community-based program helped women in the childbirth education group and might increase the chances other women would adapt healthy behaviors after birth such as breast feeding, infant check-ups and care, and use of contraceptives. It was concluded that childbirth education can influence women and their partners to adapt healthier behaviors in developing countries, and the program may be adapted in other developing countries (Turan and Say, 2003).

Sexual transmitted diseases. Midwives in the present study thought that sexually transmitted diseases rates are increasing and signs and symptoms and prevention of transmission should be included in the CE program. In 2015, a total of 101 diagnosed cases of HIV were reported (MOH, 2015). Stigmatization of sexual transmitted patients has been exacerbated by misconceptions about methods of casual transmission. It also accounts for unreported cases assumed to be positive in Jordan (Nawafleh, Francis, \& Chapman, 2005). Mahafzah, Al-Ramahi, Asa'd, and El-Khateeb, (2008) conducted a cross-sectional study to assess the prevalence of the most common sexually transmitted infections among women of child bearing age in Jordan. The study aimed at determining the need for screening programs to detect sexually transmitted infections in Jordanian women. Both symptomatic or asymptomatic women who came to gynecology and family planning clinics from different areas in Jordan were tested for reproductive tract infections caused by Chlamydia trachomatis, Neisseria gonorrhoeae, Treponema pallidum, and Trichomonas vaginalis. The prevalence of $C$. trachomatis infection was $0.6 \%$ and $0.5 \%$, among symptomatic and asymptomatic women respectively, that of $N$. gonorrhoeae was $0.9 \%$ and $2.2 \%$, that of $T$. pallidum $0.0 \%$ and $0.0 \%$, and that of $T r$. 
vaginalis was $0.7 \%$ and $0.5 \%$. These prevalence rates did not differ significantly between symptomatic and asymptomatic women. The researchers concluded that the low prevalence of sexually transmitted infections detected among Jordanian women makes the need for screening programs for such infections is questionable for this population. However, educating pregnant women population can make a difference in the prevention measures taken by the Jordanian women.

Alkhasawneh, McFarland, Mandel, and Seshan (2014) assessed HIV knowledge, attitudes, and beliefs by asking 128 women and 88 men at two universities in Jordan to learn how to approach HIV risk behaviors. Of the participants, 97\% had heard of AIDS and the majority understood the common methods of transmission. The participants reported common misconceptions, and most participants did not recognize condoms as an HIV prevention method. Participants showed a sense of fatalism when thinking about the acquisition of HIV. Alkhasawneh et al. reported the following challenges to HIVprevention interventions: misconceptions about HIV transmission, gender-related differences in the readiness to discuss sexual subjects, and fatalism regarding the acquisition of HIV. Most women showed silence about sexual activity. Alkhasawneh et al (2014) recommended to adapt culturally tailored interventions to decrease stigma and gender inequalities that may contribute to increased risks of HIV in Jordan.

Postpartum care for women and newborn care in Jordan. Midwives and pregnant women in the current study wanted to include postpartum care and newborn care in the CE program. In Irbid city (the city where the current study took place), 4,581 new pregnant women were scheduled for antenatal care in public MCHs in 2014 and 
were seen by midwives. From those, 4,383 women visited the MOHs for postnatal checkups (MOH, 2015).

Khalaf, Abu-Moghli, Mahadeen, Callister, and Al-Hadidi (2007) concluded there is a need to implement practice guidelines on post-partum care provided in health care facilities in Jordan. They suggested that the Jordanian Ministry of Health (MOH) should develop a comprehensive plan to improve maternal educational strategies in postpartum care and ensure that all health care personnel adhere to this plan and provide high-quality, affordable postpartum care for women in Jordan. Khalaf et al. (2007) used a qualitative description design to assess the Jordanian women's perceptions of what their health care needs were during postpartum, and what services they best need to be provided. Twentyfour women who delivered their babies and came for check-ups in three MCHs in North Jordan were included in three focus groups. The topics of discussion in the focus groups were: maternal and infant health concerns in postpartum, access to health care, health care services available, and characteristics and performances of health care providers. The findings indicated that the focus of postpartum care was child's care. The main reasons for visiting the postpartum health care facilities were for treatment, family planning, and child's care. Most of the participants indicated that they did not receive any information about post-partum care in antenatal care visits or in the hospital after delivery (Khalaf et al., 2007).

Midwives in the current study reported the need for education and training for the MCHs' staff which is consistent with the opinions of other health care providers in a study in Jordan. Khalaf et al. (2009) used focus groups with 30 Jordanian health care providers (physicians, nurses and midwives) to explore Jordanian health care providers' 
perceptions of the health care provided for post-partum women. Khalaf et al (2009) found that the care delivered in postpartum includes breastfeeding, family planning, child care and laboratory tests. Health care providers in Khalaf's study showed confidence in the care given but indicated the need for continuing education, more resources and gratitude for the providers. Khalaf et al. suggested that the Jordanian MOH develops a comprehensive educational plan for providers to allow for a standardized educational program for post-partum women.

Contraceptive use in Jordan. Family planning and contraceptive use are found in the pregnant women's follow up card. The midwives should teach about these topics. Sueyoshi, Al-Khozahe, and Ohtsuka (2006) used interview surveys in Jordan to examine the psychological effect of reproduction norms on contraceptive use among 275 Muslim women in Amman (capital of Jordan). Sueyoshi et al. (2006) reported that men dominate the decision-making regarding childbearing in Jordan, as they are affected by the Islamic tradition rather than rules $(\mathrm{hukm})$. Men tend to pressure women to have children and evade the use of contraceptives. However, Islamic scholars declared approval of nonpermanent contraceptive use because natural contraceptive methods were proven to be used during Islamic history. However, some Muslim religious leaders have misinterpreted the concept of contraceptives and strongly share their opinions about not using family planning.

The normative interpretations used in the discussions of contraceptives were the legal provisions in Islam $(\mathrm{hukm})$, where judgment is made if a behavior is acceptable in Islamic rules or not. Two factors regarding family planning and contraceptive use were concluded: pressure of childbearing from family and society, and acceptability of 
contraceptive use. The majority of the participants were conservatives rather than unconventional thinkers when it concerned contraception practices. However, $70 \%$ of those women used contraceptive methods. Sueyoshi et al. (2006) concluded that religious leaders may have a significant role in improving the incidence of contraceptive use by Jordanian Muslim women. There was no discussion about the knowledge women have about the ways of contraceptive use and the affectivity for its use. This may be used in the CE content during discussion of religion view of contraceptives.

Khalaf, Abu-Moghli, Callister, and Rasheed (2008) used a qualitative descriptive design to study the issues and challenges of traditional family planning (TFP) use among Jordanian women. They used six focus groups to investigate the participant's use of TFP (i.e., withdrawal, periodic abstinence, and breast feeding). A total of 51 women ages 1844 years from different parts of Jordan were included.

The findings reported incorrect use of TFP that have resulted in a high failure rate, and unplanned pregnancies within short intervals. Additionally, prefer having more boys in the family have interrupted family planning methods. Women identified withdrawal, periodic abstinence, and breast feeding as the most commonly used TFP methods regardless of the efficacy of these methods. Moreover, participants had many misconceptions and fears regarding mechanical or chemical family planning methods which resulted in decreased use. This study strongly suggested the need for structural health education programs for women and their partners in terms of family planning. This study showed how misinformed the Jordanian women are regarding family planning methods. 
Planning for pregnancy. Physicians suggested including planning for pregnancy and separate classes for husbands in the CE program. Over the past 30 years in Jordan, contraceptive use has risen, and total fertility has declined (MOH, 2013; MOH, 2015).

One in three pregnancies is unintended, either a mistimed or unwanted and unplanned pregnancy in Jordan. However, the proportion of pregnancies resulting in live births that are reported as wanted when conceived has declined over time (Johnson, Al Zoubi, \& Wulfe, 2004). A secondary analysis study selected 2,030 women who had used contraceptive methods prior to pregnancy within the five years before the survey to assess the effect of the contraceptive source and method on the likelihood of having an unplanned pregnancy. The findings showed that several factors influenced the likelihood that a women would classify their recent pregnancy as unwanted or mistimed and they are: the use of modern contraception, use of contraceptive pill, and number of previous births. Factors associated with intended pregnancies included: obtaining contraceptive services from private medical providers, and the ability to pay for health care with little difficulty. An explanation of the high number of unwanted pregnancies maybe the lack of awareness of preconception care and education (Johnson et al., 2004).

Awareness of preconception care is important for the couples to have the essential adaptation and preparations for pregnancy or avoidance of pregnancy when unwanted. Al-Akour, Sou'Ub, Mohammad and Zayed (2015) conducted a study to assess the awareness of married men and women of preconception care in Jordan. The sample consisted of 763 participants (537 women and 226 men) who attended antenatal health care in north Jordan. Al-Akour et al. used the Health Before Pregnancy Questionnaire to 
collect data. Al-Akour et al. reported that awareness of preconception care was associated with: family history of chronic disorders, first-degree consanguineous marriages, and planning pregnancy. The majority of participants (93\% women and $89 \%$ men) were aware that changes should be done prior to conception and about half the participants of the importance of family history for both men and women on the health of their offspring. Around $58 \%$ of the participants knew that the health of the women is important before pregnancy, and around $40 \%$ of women and $33 \%$ of men knew that man's health can have serious effect on the health of the newborns. Using folic acid before pregnancy awareness was very low. Al Akour et al. explained this by the lack of attendance to preconception counselling and the assumption that the health care providers may not have discussed folic acid with them. Women and men mostly did know about preconception care if they did not have a cause of concern for their offspring. Unwanted or unplanned pregnancy may occur when neglecting preconception care. Unplanned pregnancy can be a strong factor for missing the early initiation of folic acid supplement in Jordan (Al-Akour et al., 2009).

\section{The modifications pregnant women, midwives and physicians suggested to make an appropriate CE program for Jordanian women}

The content. When the pregnant women, midwives, and physicians were provided with 3 CE programs, Malata et al. (2007), Sercekus and Mete (2010a), and Turan and Say (2003), they suggested modifications that are consistent with finding in the literatures.

When provide with the $3 \mathrm{CE}$ program, pregnant women (Primigravidas and Multigravidas) were not specific about content they want to learn about, and they 
reported that they liked all the content in the $3 \mathrm{CE}$ programs. The only exception was the topics of anatomy, physiology and fertilization which they thought was not necessary to know about and some reported that they learned it in school. Midwives and physicians also thought that adding anatomy and physiology will be lengthy and may make the first class boring and affect the attendance of women to the consequent classes. Anatomy, physiology, and fertilization were present in Turan and Say (2003) and Sercekus and Mete’s (2010a) CE programs, and not in Malata et al. (2007) CE program.

The most agreed upon CE program was the Turan and Say (2003) program. It had the most detailed content and included full explanations on prenatal care, nutrition during pregnancy, infant health and care, infant feeding and breast care after delivery, which pregnant women wanted to know more about. Pregnant women agreed to most content in the $3 \mathrm{CE}$ programs and the only objected to anatomy, physiology and fertilization. Pregnant women did not suggest any new content or comment on any other content that they did not like.

Also Renkert and Nutbeam (2001) claimed that CE content tends to be instructional with the emphasis on the quantity of information rather than to empower the women to make informed decisions regarding her health and her families' health. He reported that content, time, goals, and instructors of CE varied widely in the United States. They conducted a study to explore how to improve the content and delivery of CE to meet the pregnant women's needs using focus groups. The results indicated that limited time was available for $\mathrm{CE}$, and anxiety and curiosity confined $\mathrm{CE}$ topics to pregnancy and childbirth. Additionally, the antenatal classes cannot cover everything about pregnancy, childbirth, and parenting. The ultimate goal of the CE according to 
Renkert and Nutbeam, will be that the pregnant women leaving CE classes with basic information and the skills and confidence to look and critically analyze additional information they need. The current study can support the views of the participants of not including anatomy, physiology and fertilization if that will make the classes feel redundant and boring for the attendees. However, measures should be included to assess the individual needs of pregnant women and take that into consideration when planning the classes.

Preconception care was also recommended by the midwives and the physicians in the current study. This is consistent with the recommendations of Al-Akour (2015). They also suggested to include sexual transmitted diseases in the CE program. Mahafzah et al. (2008) reported that the prevalence of the STDs is very low and did not recommend screening measures for the population of pregnant women. However, according to the $\mathrm{MOH}$ (2015) and the midwives in the current study, the rates are getting higher because of the recurrent waves of immigration to Jordan. Teaching the pregnant women about the diseases and how to prevent transmission is critical in any population to promote community awareness about the diseases.

Including the husband and family members in the CE program was suggested by the 3 focus groups and was reported in the content of the Sercekus and Mete's (2010a) CE program. No studies were found to discuss including the husband or family in CE in Jordan or nearby countries. Fathers attending CE education classes with their partners may be better prepared for their role at the birth and the role changes that they will be confronted with after the birth (Fletcher et al., 2004). CE programs should be prepared in a friendly way for fathers or it can be less effective with fathers than it has been proven to 
be with mothers. The primary focus of antenatal care currently is on the educational needs of mothers, and that may have unintended consequences on fathers as the support persons. The focus should be on preparing fathers for the personal transition to parenthood and how to deal with health and support services (Bayley et al.,2009. MacDonald andHastings,2010). Burgess (2011) reported that men and women who attend CE together are more likely to have better postnatal mental health. This is achieved when they attend antenatal care prepared for couples, adopt shared infant care, address couple-relationships, and address the sensitivity of the men's role in the childbirth experience (Burgess, 2011).

Fathers reported that they felt better prepared for childbirth after attending routine CE education. But, they reported feeling unprepared for the relationship changes that happened during their transition to fatherhood (Fletcher et al., 2004). The suggested content to include in CE for fathers are: transition to fatherhood, how to be a better support person, relationships and role changes after childbirth, postnatal mental changes and how to seek help, attachment between fathers and infants, parenting teamwork and how to build a strong parenting relationship, and understanding infant cry patterns (May \& Fletcher, 2013).

Midwives and physicians in the current study also suggested adding sexually transmitted diseases, which is consistent with the recommendations of Mahafzah et al. (2008) to educate all levels of the population on STDs and the ways to prevent transmission and limit their transmissibility. They suggested including the program with routine prenatal care in the MCHs which was done in the Malata et al. (2007) program. They also suggested including physical exercises during pregnancy and postpartum and 
including the husband in CE classes which were only included in the Sercekus and Mete's (2010a) program.

Physicians did not want many details in the content of the CE program, and were not specific on what program they liked the most. CE has been associated with improved outcomes such as better utilization of antenatal care, reduced risk of preterm newborns, and increased initiation of breast feeding (Ickovics et al., 2007). The reported advantages of $\mathrm{CE}$ were linked to improved maternal knowledge and competence as a result of education and information received in details in CE classes. Limiting the content and the time allowed for classes can jeopardize the desired outcomes from the education (Ickovics et al., 2007).

Different between professionals and pregnant women's CE content. When planning the CE programs, attention should be given to the differences between what women want to learn and what the professional care givers may think women want to learn. Freda, Andersen, Damus, and Merkatz (1993) assessed the differences between pregnant women and health-care provider perceptions about health topics. They asked women in their first antenatal visit to rate their interest in $38 \mathrm{CE}$ topics. The health care providers were asked to answer to the same topics in a public prenatal clinic and a private clinic. The sample consisted of pregnant women ( $n=250$ prenatal clinic and $n=135$ private clinic) and their health care providers ( $n=32$ nurses and physicians). The results showed significant differences in 9 topics of interest between pregnant women and their care givers. Also there were significant differences between women in the public and private clinics. The differences were affected by parity and not by maternal education level. Freda et al. (1993) concluded that nurses and other health professionals should be 
careful of the range of topics in which clients expressed interest. Freda et al. suggested that background and parity should be considered when developing prenatal health education.

In the current study, pregnant women were not specific on what they wanted to learn. Svensson, Barclay, Cooke (2007) assessed the learning needs of pregnant women and new parents for $\mathrm{CE}$ from the health professionals' perspectives. The sample consisted of 73 participants $(n=34$ antenatal educators and $n=39$ midwives from 2 large hospitals). The results indicated that health professionals thought women needed to know what happens with them during pregnancy, childbirth, and postpartum through milestones that pregnant women inquire about. Svensson's et al. second concern was that professionals thought some topics should be included in the teaching and expectant parents were not interested in, such as caring for the new baby and dealing with the mothers' body as a whole (including actions and psychological status of the mother). The health professionals also reported feeling committed to give balanced information to help the parents in making informed decisions. The midwives and educators in Svensson et al. (2007) suggested making sessions in schools, using media and television, preconception sessions, reaching the pregnant women if they cannot reach the CE, and allow women to get together and discuss CE topics under supervision of a health educator. The midwives and physicians in the current study suggested making the same modifications in the CE program except allowing the women to get together and discuss because they thought women will not give accurate information.

\section{Program time, group or individual, place of classes, provider, audiovisuals}

schedule, and number of attendants in each class. The participants also suggested the 
appropriate time of the classes, group or individual, place, provider, audiovisuals, and number of attendants. Most participants in the current study thought the time should be flexible and according to the needs of the pregnant women who will attend. According to Lee and Holroyd (2009), the best timing for CE classes should be flexible with morning and evening sessions. This will allow convenient times for employed women and house wives to attend the CE program (Lamaze International, 2013). Turan and Say's (2003) CE program consisted of 8 daytime sessions, 2 hours each. The sessions were done 2 times a week for 4 weeks. Each session was managed by a nurse, a facilitator, and a trained community member. In Lee and Holroyd's (2009) CE program, sessions were only in the evenings once a week and for 3 hours each. Women in the study expressed dissatisfaction with the timing and the huge amount of information in one session (3 hours). Most participants in Lee and Holroyd's study did not like the evening classes.

Most participants in the current study preferred group classes because of the interaction between the pregnant women and the time saving. Only one midwife preferred individual classes because she thought individual face-to-face interaction can improve the education experience. Most pregnant women and educators in the literature preferred group classes because of the interaction with the group and the lower cost (Renkert \& Nutbeam, 2001; Toran \& Say, 2003). Sercekus and Mete (2010a) suggested that group education was favored over individual education because of the lowered cost, and the outcomes were nearly the same.

All the participants thought that MCHs are the best place for the CE program. Physicians suggested that CE can be held in other sittings such as religious and youth centers and any place easy for women to reach. CE programs in the literature were held 
in hospitals (Lee and Holroyd 2009; Vusse et al., 2007), education centers (Lamaze International in Fahami et al., 2006; Bradley, 2008; Demeces et al., 2011), and health centers (Ustunsoz et al., 2010; Demecs et al., 2011; Malata et al., 2007; Bergsrtom et al., 2009).

Most pregnant women thought that someone that had education and experience or the doctor is the one that should provide the $\mathrm{CE}$ classes. Midwives thought the midwife is the best professional for the job but she will need assistance with nutrition and exercises content. Physicians thought the provider should be a female with good reputation such as a midwife who has long experience or a doctor. In the literature, the provider always had special training for the education. Some programs and studies had a physician or a social worker providing the classes (Vusse et al., 2007). Others had professional educators as the providers (Bradley, 2008). Most CE had trained midwives as the providers (Bergstrom et al., 2009; Demeces et al., 2011; Lee \& Holroyd, 2009; Malata et al., 2007; Ustunsoz et al., 2010). No studies discussed which provider is better but midwives and physician in the current study thought that experience would help the provider gain the trust of pregnant women.

Most participants in the 4 focus groups favored group classes and thought the MCHs will be the best place for the program. This was consistent with most literature when pregnant women and educators favored group classes because of the preference of the mothers and the low cost (Sercekus and Mete, 2010a; Sercekus and Mete, 2010b). The Malata et al. (2007) program was delivered through group education with the opportunity open to any pregnant woman to ask for individual sessions if she felt the need for extra explanations or personal assistance. Other CE programs offered pregnant 
women both individual and group education sessions such as Bradley (2008) and Vusse et al. (2007). Most participants reported that the number of participants in the CE group session should be from 6 to 25 and not more to allow for discussion and comprehension of the content. That is consistent with the literature. Lamaze International limited the number of participants to 12 women and their partners (Fahami et al., 2006). Vusse et al. (2007) groups included 20 to 30, and Demecs et al. (2011) limited the number to 12 participants. One physician in the current study thought that 50 participants would be the best for publicity for the CE program, but other physicians objected to that number because it would not help in the discussion. Pregnant women in the Lee and Holroyed's study (2009) reported negatives about the class structural constrains and limitations to the learning process because of the class size (over 50 participants).

In the current study, participants suggested using audiovisuals that are appropriate for the topic of the class. Pregnant women stated that they prefer pictures, discussions, and demonstration. This is consistent with the literature that used lecturing, sharing and discussions, videos, role play, demonstrations, and a separate clinical tour of the hospital on a subsequent day (Lee \& Holroyed, 2009). Most pregnant women and all midwives and physicians agreed on showing women labor and delivery videos. Only 2 primigravidas thought they would have more fear and anxiety if they saw a video of the process. This is consistent with the findings of Karabulut et al. (2016) and Sercekus and Mete (2010b) who reported that most women in their studies reported decreased fear and anxiety after having details about labor and delivery process, and very few pregnant women reported increased fear if they saw a video about labor and delivery. 


\section{Feasibilities and challenges of implementing the CE program}

All the participants viewed the program as having positive support from the majority of the community including the health team because of the benefits that it would bring to women and their children, and to the community as a whole. This is consistent with studies that reported benefits of CE classes. CE classes can help to decrease fear and anxiety of labor and delivery (Artieta-Pinedo et al. 2010; Karabulut et al., 2016), increase postpartum adaptation (Sercekus \& Mete, 2010a), increase social networking (Fabian et al., 2005), increase pregnant women's knowledge about labor and delivery process, and improve their self-control and cope with the uncertainty and anxiety of labor (Hotelling, 2009). The participants reported themes of class effectiveness in advancing their knowledge about labor and delivery, acquiring skills to help in labor and being able to control oneself, and healthy behaviors during postpartum (Records \& Wilson, 2011). CE may also improve knowledge regarding: how to manage discomforts during pregnancy, danger signs during pregnancy, what to expect during labor and delivery, postpartum care, and contraceptive use. Accordingly, CE may lead to a decrease in maternal and fetal mortality and morbidity (Nichols, \& Humenick, 2000). All these reported benefits can help if explained and promoted about the CE program to gain support for the program from the community and the decision-makers.

Midwives and physicians reported that $\mathrm{MOH}$ may approve using the public facilities of the MCHs to implement the CE program. They explained that this will decrease the cost for the $\mathrm{MOH}$ and will be undertaken by the midwives who already work in the $\mathrm{MCH}$ and teaching is part of their work duties. Most of the $\mathrm{CE}$ programs in the 
developing countries take place in the public facilities such as Malata (2007), Svensson, et al. (2007).

All participants in the current study agreed on the importance of the role of men and the importance of including them in the CE program. However, they were hesitant that men will not come to the classes. In a study by Fletcher, Silberberg, and Galloway (2004), new fathers reported that CE classes helped them to be prepared for labor and delivery but classes were not very helpful in the new changes in lifestyle and relationships. CE classes helped the participants be more familiar with the available services needed for mother and newborn care. However, in Ireland, Symon (2003), men and women who attended CE with male provider reported that they talked more freely in the single-sex classes.

Physicians in the study reported that a CE program can help to reduce the load on the emergency room in the hospital because women can recognize false and true labor. This is consistent with the findings of Lumluk, Kovavisarach (2011) who found that women who attended CE classes were more accurate in recognizing the onset of their labor and differentiate true from false labor.

\section{Challenges of implementing a CE program}

Pregnant women and Midwives were not optimistic regarding compliance with attendance to the CE program. Time restrains from the pregnant women side were expected by pregnant women and midwives. They thought that social and husband support can improve attendance to the CE classes and that feeling interested and needing the knowledge provided in the CE classes may make the pregnant women prefer attending CE over social activities. Tighe (2010) reported that in Ireland, barriers to CE 
attendance included no interest, difficult transportation, work inflexible employer, and husband non-attendance. To improve attendance, Tighe (2010) suggested flexible classes time, providers applying the principles of adult learning to guide classes, and include fathers in the classes. She suggested that CE should adopt a parent centered and needs driven CE program.

Most participants in the current study shared opinions of the challenges of implementing the new CE program. Midwives and physicians agreed that if the program needs financing from the $\mathrm{MOH}$, it will not be successful. However, many health initiatives were introduced by the governmental policies for the continuous improvement of mother and child health that have affiliations with sponsors with the $\mathrm{MOH}$ that can provide financial support.

In Jordan, many health promotion initiatives have been introduced and have taken place in the last decade especially for the safety and wellbeing of mothers and children. Examples include the Millennium Summit in 2000, the National Reproductive Health/Family Planning Strategy 2013-2017, and others (Hatamleh, Sinclair, Kernohan, \& Bunting, 2013; Higher Population Council [HPC], 2015).

A meeting of national maternal, neonatal and child health program directors was held to address the main causes of maternal, neonatal and child mortality in the World Health Organization (WHO) Eastern Mediterranean Region in Amman, Jordan, from 29 March to 2 April 2015. The organizations that were represented at the Amman meeting were the WHO Regional Office for the Eastern Mediterranean, United Nations Children's Fund (UNICEF) Regional Office for the Middle East and North Africa, and United Nations Population Fund (UNFPA) Regional Office for the Arab States. The conclusions 
and recommendations that resulted from Amman meeting are as follows: confirm maternal, neonatal and child health strategic priorities and guidelines for 2016-2020 coordinated with the maternal and child health post-2015 agenda, attention in strategic plans on key evidence-based and cost-effective interventions with that highly effect maternal, neonatal, child and adolescent health (WHO, 2016).

Individuals who will work on seeking funds for the CE program will have to take these initiatives and governmental policies into consideration. The midwives in the current study thought that the CE program could fit into one or more of these initiatives. The CE program could achieve financial support from one of the above mentioned organizations after distributing the results of the current study that shows the benefits and the potential cost saving of implementing such a program.

\section{Recommendations}

1. The access to the Internet and the frequency of Internet use for knowledge around childbirth should be investigated in a quantitative study.

2. Midwives in the study suggested that a professional establishment should invest in making professional Arabic websites that give trusted information regarding Childbirth to women in Jordan.

3. The new CE program should assess the needs of the pregnant women in each session before starting to avoid overloading them with information they already know from other sources.

4. Assess the sources of information the women have and how accurate the information they have is. 
5. Prepare a cost effectiveness study for the CE program in Jordan to be presented to the MOH for approvals of the program implementation.

6. After implementing the CE program, prepare and conduct a mix-method study to assess the effect of the CE program on the pregnancy and childbirth outcomes in Jordan.

7. Conduct a study regarding the perception of men about the $\mathrm{CE}$ and the implementation of the CE program in Jordan. 


\section{References}

Abushaikha, L., \& Massah, R. (2012). The roles of the father During childbirth: The lived experiences of Arab Syrian parents. Health Care for Women International, 33(2), 168-181. doi:10.1080/07399332.2011.610534

Abushaikha, L., \& Oweis, A. (2005). Labour pain experience and intensity: A Jordanian perspective. International Journal of Nursing Practice, 11(1), 33-38. doi:10.1111/j.1440-172X.2005.00496.x

Adams, S. S., Eberhard-Gran, M., \& Eskild, A. (2012). Fear of childbirth and duration of labor: a study of 2206 women with intended vaginal delivery.. British Journal of Obstetrics and Gynaecology, 119(1), 1238-1246. doi:10.1111/j.14710528.2012.03433.x

Al-Akour, N. A., Sou'Ub, R., Mohammad, K., \& Zayed, F. (2015). Awareness of preconception care among women and men: A study from Jordan. Journal of Obstetrics and Gynecology, 35(3), 246-250. doi:10.3109/01443615.2014.958145

Al-Ateeq, M. A., Al-Rusaiess, A. A., \& Al-Dughaither, A. A. (2013). Perceptions and effects of antenatal education. Saudi Medical Journal, 34(12), 1-5. Retrieved from: http://www.smj.org.sa/index.php/smj/article/view/2416

Al-Mandeel, H. M., Al-Mufleh, A. S., Al-Damri, A. T., Al-Bassam, D. A., Hajr, E. A., \& Al-Shehri, S. M. (2013). Saudi women's acceptance and attitudes towardscompanion support during labor: Should we implement an antenatal awareness program? Annals of Saudi Medicine, 33(1), 28-33. doi:10.5144/02564947.2013.28

Al-Mehaisen, L., Khader, Y., Al-Kuran, O., Abu Issa, F., \& Amarin, Z. (2011). Maternal anemia in rural jordan: room for improvement. Anemia, 2011(2), 1-7. doi:10.1155/2011/381812

Alayande, B. T., Amole, I. O., \& OlaOlorun, D. A. (2012). Relative frequency and predictors of episiotomy in Ogbomoso, Nigeria. Internet Journal of Medical Update, 7(2), 41-44. Retrieved from http://www.akspublication.com/ijmu

Alder, J., Fink, N., Bitzer, J., Hosli, I., \& Holzgreve, W. (2007). , I., \& Holzgreve, W. (2007). Depression and anxiety during pregnancy: A risk factor for obstetric, fetal and neonatal outcome? A critical review of the literature. Journal of MaternalFetal and Neonatal Medicine, 20(3), 189-209. doi:10.1080/14767050701209560

Alkhasawneh, E., McFarland, W., Mandel, J., \& Seshan, V. (2014). Insight into Jordanian thinking about HIV: Knowledge of Jordanian men and women about 
HIV prevention. The Journal of the Association of Nurses in AIDS Care, 25(1), e1-e9. doi:10.1016/j.jana.2013.06.001

Ankomah, A., Adebayo, S. B., Arogundade, E. D., Anyanti, J., Nwokolo, E., Inyang, U., \& Meremiku, M. (2014). The effect of mass media campaign on the use of insecticide-treated bed nets among pregnant women in Nigeria. Malaria Research and Treatment, 2014(1), 1-7. Retrieved from http://dx.doi.org/10.1155/2014/694863

Artieta-Pinedo, I., Paz-Pascual, C., Grandes, G., Remiro-Fernandezdegamboa, G., Odriozola-Hermosilla, I., Bacigalupe, A., \& Payo, J. (2010). The benefits of antenatal education for the childbirth process in Spain. Nursing Research, 59(3), 194-202. doi:10.1097/NNR.0b013e3181dbbb4e

Batieha, A. M., Khader, Y. S., Berdzuli, N., Chua-Oon, C., Badran, E. F., Al-sheyab, N. A., \& Al-Qutob, R. J. (2016). Level, causes and risk factors of neonatal mortality, in Jordan: Results of a national prospective study. Maternal and Child Health Journal, 20(5), 1061-1071. doi:10.1007/s10995-015-1892-xObjective

Bellin, E. (2012). Reconsidering the Robustness of Authoritarianism in the Middle East: Lessons from the Arab Spring. Comparative Politics, 44(2), 127-149. doi:dx.doi.org/10.5129/001041512798838021

de Barros, M. C., Lopes, M. A., Francisco, R. P., Sapienza, A. D., \& Zugaib, M. (2010). Resistance exercise and glycemic control in women with gestational diabetes mellitus. American Journal of Obstetrics and Gynecology, 203(556), e1-e6. Retrieved from http://dx.doi.org/10.1016/j.ajog.2010.07.015

Bergstrom, M., Kieler, H., \& Waldenstrom, U. (2009). Effects of natural childbirth preparation versus standard antenatal education on epidural rates, experience of childbirth and parental stress in mothers and fathers: A randomized controlled multicenter trial. BJOG, 116(1), 1167-1176. doi:10.1111/j.14710528.2009.02144.x

Biasella, S. (1993). A comprehensive perinatal education program. A WHONN's Clinical Issues in perinatal and Women's Health Nursing, 4(1), 5-19.

Bjelke, M., Martinsson, A. K., Lendahls, L., \& Oscarsson, M. (0216). Using the Internet as a source of information during pregnancy: A descriptive cross-sectional study in Sweden. Midwifery, 40(1), 187-191. Retrieved from http://dx.doi.org/10.1016/j.midw.2016.06.020

Bradley, R. A. (2008). Husband-coached Childbirth (Rev ed.). New York, NY: Bantam Deli. 
Carolan, M. (2007). Health literacy and the information needs and dilemmas of first-time mothers over 35 years. Journal of Clinical Nursing, 16(1), 1162-1172. doi:10.1111/j.1365-2702.2007.01600.x

Cosans, C. (2004). The Meaning of Natural Childbirth. Perspectives in biology and medicine, 47(2), 266 - 272. doi:10.1353/pbm.2004.0022

Declercq, E. R., Sakala, C., Corry, M. P., \& Applebaum, S. (2007). Listening to Mothers II: Report of the Second National U.S. Survey of Women's Childbearing Experiences. The Journal of perinatal education, 16(4), 9-14. doi:10.1624/105812407X244769

Declercq,, E. R., Sakala, C., Corry, M. B., \& Applebaum, S. (2007). Listening to mothers II: report of the second national U.S. survey of women's childbearing experiences. lournal of Perinatal Education, 16(4), 15017. doi:10.1624/105812407X244778

Demecs, I. P., Fenwick, J., \& Gamble, J. (2011). Women's experiences of attending a creative arts program during their pregnancy. Women and Birth, 24(1), 112-121. doi:10.1016/j.wombi.2010.08.004

Department of Statistics (DOS). (2010). Jordan Population and Family Health Survey 2009. Retrieved from http://www.dos.gov.jo/sdb_pop/sdb_pop_e/pop_2009.pdf

Department of Statstics. (2013). Registered Live Births by Governorate, 2007 - 2011. Retrieved from http://www.dos.gov.jo/dos_home_e/main/vitality/Births_and_deaths/2011/live_Bi rths1.pdf

Doctor, H. V., Findley, S. E., Cometto, G., \& Afenyadu, G. Y. (2013). Awareness of critical danger signs of pregnancy and delivery, preparations for delivery, and utilization of skilled birth attendants in Nigeria. Journal of Health Care for the Poor and Underserved, 24(1), 152-70. doi:10.1353/hpu.2013.0032

Donabedian, A. (1980). A guide to medical care administration : medical care appraisal :(1st). Washington, DC: The American Public Health Association.

Ewles, L., \& Simnett, I. (1999). Promoting Health: Apractical Guide (4th ed.). Edinburg: Balliere Trindall.

Eysenbach, G., Powell, J., Kuss, O., \& Sa, E. R. (2002). Empirical studies assessing the quality of health information for consumers on the World Wide Web: A systematic review. The Journal of the American Medical Association, 287(1), 2691-2700. doi:10.1001/jama.287.20.2691 
Fabian, H. M., Radestad, I. J., \& Waldenstrom, U. (2005). Childbirth and parenthood education classes in Sweden. Women's opinion and possible outcomes. Acta Obstetricia et Gynecologica Scandinavica, 84(1), 436-443. dio: 10.1111/j.00016349.2005.00732.x

Fahami, F., Masoudfar, S., \& Davazdahemami, S. (2006). Effect of Lamaze practice on the outcome of pregnancy and labor in primipara women referred to selected university hospitals in 2005. Iranian Journal of Nursing and Midwifery Research, 11(4), 1-2. Retrieved from http://ijnmr.mui.ac.ir/index.php/ijnmr/article/view/102

Fletcher, R., Silberberg, S., \& Galloway, D. (2004). New fathers' postbirth views of antenatal classes: Satisfaction, benefits, and knowledge of family services. The Journal of perinatal education, 13(3), 18-26.

Freda, M. C., Andersen, H. F., Damus, K., \& Merkatz, I. R. (1993). What pregnant women want to know: A comparison of client and provider perceptions. Journal of Obstetrics, Gynecology and Neonatal Nursing, 22(3), 237-244. Retrieved from http://dx.doi.org/10.1111/j.1552-6909.1993.tb01805.x

Gao, L. L., Larsson, M., \& Luo, S. (2013). Internet use by Chinese women seeking pregnancy-related information. Midwifery, 29(7), 730-735. Retrieved from http://dx.doi.org/10.1016/j.midw.2012.07.003

Gause, F. (2011). Why Middle East Studies missed the Arab spring: The myth of authoritarian stability. Foreign Affairs, 90(4), 81-90. Retrieved from http://search.proquest.com.ezproxy.fiu.edu/docview/873487200?pqorigsite $=360$ link

Gazmararian, J. A., Curran, J. W., Parker, R. M., Bernhardt, J. M., \& DeBuono, B. A. (2005). Public health literacy in America: An ethical imperative. American Journal of Preventive Medicine, 28(3), 317-322. doi:dx.doi.org/10.1016/j.amepre.2004.11.004

Gharaibeh, M., Al-Ma'aitah, R., \& Al Jada, N. (2005). Lifestyle practices of Jordanian pregnant women. ., \& Al Jada, N. International Nursing Review, 50(1), 92-100.

Graneheim, U. H., \& Lundman, B. (2004). Qualitative content analysis in nursing research: concepts, procedures and measures to achieve trustworthiness. Nurse education today, 24(2), 105-112. doi:

10.1016/j.nedt.2003.10.001

Grimes, H. A., Forster, D. A., \& Newton, M. S. (2014). Sources of information used by women during pregnancy to meet their information needs. Midwifery, 30(1), e26e33. doi:10.1016/j.midw.2013.10.007 
Hakeem National E-Health Program. (2014). Welcome to Electronic Health Solutions. Retrieved from http://www.ehs.com.jo/en

Hall, M. (2013). The Syrian Crisis in Jordan. Retrieved from http://www.merip.org/mero/mero062413?utm_source=facebook\&utm_medium=li nk\&utm_campaign=zaatari

Hatamleh, R., Sinclair, M., Kernohan, W. G., \& Bunting, B. (2008). Technological childbirth in northern Jordan: Descriptive findings from a prospective cohort study. Evidence Based Midwifery, 6(4), 130-135.

Hatamleh, R., Shaban, I. A., \& Homer, C. (2013). Evaluating the experience of Jordanian women with maternity care services. Health Care for Women International, 34(6), 499-512. doi:10.1080/07399332.2012.680996

Hatamleh, R., Sinclair, M., Kernohan, G., \& Bunting, B. (2013). Birth memories of Jordanian women: Findings from qualitative data. Journal of Research in Nursing, 18(2), 235-244. doi:10.1177/1744987112441911

Higher Population Council (HPC). (2008). Maternal morbidity in Jordan. Retrieved from http://www.hpcpromise.org.jo/sites/default/files/researches/articles/Maternal+Mor bidity+in+Jordan_1.pdf

Higher Population Council (HPC). (2010). Annual report. Retrieved from http://www.hpc.org.jo/hpcdefault.aspx?tabid=97

Higher Population Council. (2014). Annual Report. Retrieved from http://www.hpc.org.jo/hpc/tabid/467/ctl/details/mid/1008/articleID/596/checkTyp e//Default.aspx

Hotelling, B. A. (2009). Teaching normal birth, normally. The Journal of Perinatal Education, 18(1), 51-55. doi:10.1624/105812409X405876

Hsieh, H. F., \& Shannon, S. E. (2005). Three approaches to qualitative content analysis. Qualitative health research, 15(9), 1277-1288. doi:10.1177/1049732305276687

Humenick S. S. Program evaluation. 2000. In F. H. Nichols \& S. S. Humenick (Eds.), Childbirth education: Practice, research, and theory (2nd ed., pp. 593-608). Philadelphia: W.B. Saunders Company.

International Childbirth Educators Association (ICEA). (2015). History. Retrieved from http://www.icea.org/content/history 
Ip, W., Tang, C., \& Goggins, W. B. (2009). An education intervention to improve women's ability to cope with childbirth. Journal of Clinical Nursing, 18(1) 21252135. doi:10.1111/j.1365-2702.2008.02720.x

Johnson, K., al Zoubi, O., \& Wulfe, M. (2004). Mistimed and unwanted pregnancies in Jordan. Retrieved from https://dhsprogram.com/pubs/pdf/FA44/FA44.pdf

Jordan Breast Cancer Program. (2014). Jordan Breast Cancer Program. (2014). Public awareness and health education. Retrieved from http://www.jbcp.jo/node/61

Karabulut, O., Potur, D. C., Merih, Y. D., Mutlu, S. C., \& Demirci, N. (2016). Does antenatal education reduce fear of childbirth? International Nursing Review, 63(1), 60-67. doi:10.1111/inr.12223

Khalaf, I. A., Abu-Moghli, F. A., Callister, L. C., Mahadeen, A. I., Kaawa, K., \& Zomot, A. F. (2009). Jordanian health care providers' perceptions of post-partum health care. International Nursing Review, 56(1), 442-449.

Khalaf, I. A., Abu-Moghli, F. A., Mahadeen, A. I., Callister, L. C., \& Al-Hadidi, M. (2007). Khalaf, I. A., Abu-Moghli, F. A., Mahadeen, A. I., Callister, L. C., \& AlHadidi, M. (2007). Jordanian women's perceptions of post-partum health care. «International Nursing Review, 54»(1), 288-294.

Khalaf, I., Abu-Moghli, F., Callister, L. C., \& Rasheed, R. (2008). Jordanian women experience with the use of traditional family planning. Health Care for Women International, 29(1), 527-538. doi:10.1080/07399330801949632

Khresheh, R., Homer, C., \& Barclay, L. (2009). A comparison of labor and birth outcomes in Jordan with WHO guidelines: A descriptive study using a new birth record. A comparison of labor and birth outcomes in Jordan with WHO guidelines: A descriptive study using a new birth record Midwifery, 25(1), e11e18. doi:10.1016/j.midw.2007.10.007

Khuri-Bulos, N., Lang, R. D., Blevines, M., Kudyba, K., Lawrence, K. L., Davidson, M., \& Halasa, N. B. (2014). Vitamin D deficiency among newborns in Amman, Jordan. Global Journal of Health Science, 6(1), 162-171. doi:10.5539/gjhs.v6n1p162

Kluge, J., Hall, D., Louw, Q., Theron, G., \& Grové, D. (2011). Specific exercises to treat pregnancy-related low back pain in a South African population. International Journal of Gynecology and Obstetrics, 113(1), 187-191. Retrieved from http://dx.doi.org/10.1016/j.ijgo.2010.10.030 
Lagan, B. M., Sinclair, M., \& Kernohan, W. G. (2010). Internet use in pregnancy informs women's decision making: A web-based survey. Birth, 37(2), 106-115. doi:10.1111/j.1523-536X.2010.00390.x

Lamaze International. (2013). Lamaze Childbirth Education Training. Retrieved from http://www.lamazeinternational.org/ChildbirthEducationTraining?utm_source=go ogle\&utm_medium=cpc\&utm_campaign=couses_training_grant

Larsson, M. (2009). A descriptive study of the use of the Internet by women seeking pregnancy-related information. Midwifery, 25(1), 14-20.

League, J., \& Novelli, L. (1994). Going, going, gone? Childbirth Instructor, 4(4), 30-33.

Leavitt, J. (1986). Brought to Bed: Childbearing in America, 1750-1950 (Rev ed.). New York, NY: Oxford University Press.

Lee, L. Y., \& Holroyd, E. (2009). Evaluating the effect of childbirth education class: A mixed-method study. International Nursing Review, 56(1), 361-368.

Lima-Pereira, P., Bermudez-Tamayo, C., \& Jasienska, G. (2011). Use of the internet as a source of health information amongst participants of antenatal classes. Journal of Clinical Nursing, 21(1), 322-330. doi:10.1111/j.1365-2702.2011.03910.x

Lothian, J. A. (2008). Childbirth education at the crossroads. The Journal of perinatal education, 17(2), 45-49. doi:10.1624/105812408X298381

Lumluk, T., \& Kovavisarach, E. (2011). Effect of antenatal education for better selfcorrect diagnosis of true labor: A randomized control study. Journal of the Medical Association of Thailand, 94(7), 772-774.

Lund, S., Nielsen, B. B., Hemed, M., Boas, I. M., Said, A., Said, K., \& Rasch, V. (2014). Mobile phones improve antenatal care attendance in Zanzibar: A cluster randomized controlled trial.. BioMed Central Pregnancy and Childbirth, 14(29), 1-10. Retrieved from http://www.biomedcentral.com/1471-2393/14/29

Madden, K. L., Turnbull, D., Cyna, A. M., Adelson, P., \& Wilkinson, C. (2013). Pain relief for childbirth: The preferences of pregnant women, midwives and obstetricians. Women and Birth, 26(1). Retrieved from http://dx.doi.org/10.1016/j.wombi.2011.12.002

Mahafzah, A. M., Al-Ramahi, M. Q., Asa'd, A. M., \& El-Khateeb, S. (2008). Prevalence of sexually transmitted infections among sexually active Jordanian females. Sexually Transmitted Diseases, 35(6), 607-610. doi:10.1097/OLQ.0b013e3181676bbd. 
Malata, A. (2000). First-time mothers' satisfaction with labor and childbirth information received: A Malawian perspective. Clinical Excellence for Nurse Practitioners, 4(2), 83-89.

Malata, A., Hauck, Y., Monterosso, L., \& McCaul, K. (2007). Development and evaluation of a childbirth education program for Malawian women. Journal of Advanced Nursing, 60(1), 67-78. doi:10.1111/j.1365-2648.2007.04380.x

Malta, M. B., Leite Carvalhaes, M. A., Takito, M. Y., Tonete, V. L., Barros, A. J., de Lima Parada, C. M., \& Benício, M. H. (2016). Educational intervention regarding diet and physical activity for pregnant women: changes in knowledge and practices among health professionals. BioMed Central Pregnancy and Childbirth, 16(1), 1-9. doi:10.1186/s12884-016-0957-1

Martin, D. K., Bulmer, S. M., \& Pettker, C. M. (2013). Childbirth expectations and sources of information among low- and moderate-income nulliparous pregnant women. The Journal of Perinatal Education, 22(2), 103-112. Retrieved from http://dx.doi.Org/10.1891/1058-1243.22.2.103

May, C., \& Fletccher, R. (2013). Preparing fathers for the transition to parenthood: Recommendations for the content of antenatal education. Midwifery, 29(1), 474478. Retrieved from http://dx.doi.org/10.1016/j.midw.2012.03.005

McCutcheon, S. (1996). Natural Childbirth the Bradley Way (Rev ed.). London: Penguin Books Ltd.

Mcintyre-Miller, A., \& Chmiel, C. (2013). NHS Tayside: Implementing the Scottish antenatal parent education pack. The Practising Midwife, April(1), 28-30.

Ministry of Health. (2014). Annual Statistical Book. Retrieved from http://www.moh.gov.jo

Minstry of Health. (2015). Annual Statistical Book. Retrieved from http://www.moh.gov.jo/EN/Pages/Periodic-Newsletters.aspx

Mohammad, K. I., Alafi, K. K., Mohammad, A. I., Gamble, J., \& Creedy, D. (2014). Jordanian women's dissatisfaction with childbirth care Dissatisfaction with childbirth care. International Nursing Review, 61(2), 278-284. doi:10.1111/inr.12102

Mohammad, K. I., Gamble, J., \& Creedy, D. K. (2011). Prevalence and factors associated with the development of antenatal and postnatal depression among Jordanian women. Midwifery, 27(6), e238-e245. doi:10.1016/j.midw.2010.10.008 
Morton, C. H., \& Hsu, C. (2007). Contemporary dilemmas in American childbirth education: Findings from a comparative ethnographic study. The Journal of perinatal education, 16(4), 25-37. doi:10.1624/105812407X245614

Murshidi, M. M., Hijjawi, M. Q., Jeriesat, S., \& Eltom, A. (2013). Syrian refugees and Jordan's health sector. The Lancet, 382(20), 206-207. doi:10.1016/S01406736(13)61506-8

Nawafleh, H., Francis, K., \& Chapman, Y. (2005). The influence of HIV/ AIDS on the practice of primary care nurses in Jordan: Rhetoric and reality. International Journal of Nursing Practice, 11(1), 200-205. Retrieved from http://dx.doi.org.ezproxy.fiu.edu/10.1111/j.1440-172X. 2005.00528.x

Nichols, F., \& Humenick, S. (1988). Childbirth Education: Practice, Research, and Theory (1st ). Philadelphia, PA: WB Saunders.

Okour, A., Alkhateeb, M., \& Amarin, Z. (2012). Awareness of danger signs and symptoms of pregnancy complication among women in Jordan. International Journal of Gynecology and Obstetrics, 118(1), 11-14. doi:10.1016/j.ijgo.2012.01.020

Oweis, A. (2009). Jordanian mother's report of their childbirth experience: Findings from a questionnaire survey. International Journal of Nursing Practice, 15(1), 525533. doi:10.1111/j.1440-172X.2009.01774.x

Oweis, A., Tayem, A., \& Froelicher, E. S. (2009). Breastfeeding practices among Jordanian women. International Journal of Nursing Practice, 15(1), 32-40. doi:10.1111/j.1440-172X.2008.01720.x

Oweis, A., \& Abushaikha, L. (2004). Jordanian pregnant women's expectations of their first childbirth experience. International Journal of Nursing Practice, 10(1), 264271. doi:10.1111/j.1440-172x.2004.00488.x

Phipps, H., Charlton, S., \& Dietz, H. P. (2009). Can antenatal education influence how women push in labour? A pilot randomised controlled trial on maternal antenatal teaching for pushing in the second stage of labour (push study). Australian and New Zeland Journal of Obstetrics and Gynaecology, 49(1), 274-278. doi:10.1111/j.1479-828X.2009.00984.X

Plantin, L., \& Daneback, K. (2009). Parenthood, information and support on the Internet. A literature review of research on parents and professionals online. BMC Family Practice, 10(1), 1-12. 
Purdy, C. H. (2011). Using the Internet and social media to promote condom use in Turkey. Reproductive Health Matters, 19(37), 157-165. doi:10.1016/S09688080(11)37549-0

Qatami, R. (2015). Breathing for labor pain and delivery.. Retrieved from https://www.youtube.com/watch?v=GJ0AB37WB7I

Qatami, R. (2016). Preparation classes for pregnant woman with Dana Abu Kheder. Retrieved from http://Qatami, R. (2016,March 21) Preparation classes for pregnant woman with Dana Abu Kheder. Retrieved from https://www.youtube.com/watch?v=Z_szeKjPrM0

Quteitat, A., Shraideh, I., Abdel Malek, A. M., Gowieri, A., Alnashash, H., \& Amarin, Z. O. (2012). Maternal morbidity: Results of a country-wide review.. Archives of Gynecology and Obstetrics, 286(1), 1357-1362. doi:10.1007/s00404-012-2458-4

Raatikainen, K., Heiskanen, N., \& Heinonen, S. (2007). Under-attending free antenatal care is associated with adverse pregnancy outcome. BioMed Central Public Health, 56(1), 1-8. doi:10.1186/1471-2458-7-268

Rabiee, F. (2004). Focus-group interview and data analysis. Proceedings of the Nutrition Society, 63(4), 655-660. doi:10.1079/PNS2004399

Records, K., \& Wilson, B. (2011). Reflections on Meeting Women's Childbirth Expectations. Records, K., \& Wilson, B., L. (2011) Reflections on Meeting Women's Childbirth Expectations. Journal of Obstetric, Gynecologic, and Neonatal Nursing, 40(4), 394-398. doi:10.1111/j.1552-6909.2011.01269.x

Renkert, S., \& Nutbeam, D. (2001). Opportunities to improve maternal health literacy through antenatal education: an exploratory study. Health Promotion International, 16(4), 381-389. doi: 10.1093/heapro/16.4.381

Richardson, C. A., \& Rabiee, F. (2001). A question of access: an exploration of the factors that influence the health of young males aged 15 to 19 living in Corby and their use of health care services. Health Education Journal, 60(1), 3-16. doi:10.1177/001789690106000102

Saunders., F. H., \& Humenick, S. (2000). Childbirth Education: Practice, Research and Theory (2nd ed.). Philadelphia, PA: Saunders..

Scottish Multiprofessional Maternity Development Programme. (2012). About the Scottish Multiprofessional Maternity Development Programme. Retrieved from http://www.scottishmaternity.org/Programme\%20and\%20Group/about_SMDU.ht $\mathrm{ml}$ 
Sercekus, P., \& Mete, S. (2010a). Effects of antenatal education on maternal prenatal and postpartum adaptation. Journal of advanced nursing, 66(5), 999-1010. doi:10.1111/j.1365-2648.2009.05253.x

Sercekus, P., \& Mete, S. (2010b). Turkish women's perceptions of antenatal education. International Nursing Review, 57(3), 395-401. doi:10.1111/j.14667657.2009.00799.x

Shaban, I., Hatamleh, R., Khresheh, R., \& Homer, C. (2011). Childbirth practices in Jordanian public hospitals: consistency with evidence-based maternity care? International Journal of Evidence-Based Healthcare, 9(1), 25-31. doi:10.1111/j.1744-1609.2010.00197.x

Shieh, C., Mays, R., \& McDaniel, A. (2009). Health literacy and its association with the use of information sources and with barriers to information seeking in clinicbased pregnant women. Health Care Women International, 30(1), 971-988. Retrieved from http://dx. doi.org/10.1080/07399330903052152.

Simkhada, B., Teijlingen, E. R., Porter, M., \& Simkhada, P. (2008). Factors affecting the utilization of antenatal care in developing countries: Systematic review of the literature.. Journal of Advanced Nursing, 61(3), 244-260. doi:10.1111/j.13652648.2007.04532.x

Stafne, S. N., Salvesen, K. A., Romundstad, P. R., Stuge, B., \& Morkved, S. (2012). Does regular exercise during pregnancy influence lumbopelvic pain? A randomized controlled trial. Acta Obstetricia et Gynecologica Scandinavica, 91(1), 552-559.

Stoll, K., Hall, W., Janssen, P., \& Carty, E. (2014). Why are young Canadians afraid of birth? A survey study of childbirth fear and birth preferences among Canadian University students. Midwifery, 30(2), 220-226.

Sueyoshi, S., Al-Khozahe, H. O., \& Ohtsuka, R. (2006). Effects of reproduction norms on contraception practice among Muslim women in Amman, Jordan. The European Journal of Contraception and Reproductive Health Care, 11(2), 138145. doi:10.1080/13625180500539430

Svensson, J., Barclay, L., \& Cooke, M. (2007). Antenatal education as perceived by health professionals. Journal of Perinatal Education, 16(1), 9-15. doi:10.1624/105812407X171067

Symon, A. (2003). Including men in antenatal education: Evaluating innovative practice. Evidence Based Midwifery, 26(3), 294-303. Retrieved from http://dx.doi.org/10.1016/j.midw.2008.06.005 
Tighe, S. M. (2010). An exploration of the attitudes of attenders and non-attenders towards antenatal education. Midwifery, 26(3), 294-303. Retrieved from http://dx.doi.org/10.1016/j.midw.2008.06.005

Turan, J. M., \& Say, L. (2003). Community-based antenatal education in• Istanbul, Turkey: effects on health behaviours. Health Policy and Planning, 18(4), 391398. doi: 10.1093/heapol/czg047

UNICEF. (2013). Jordan Statistics. Retrieved from http://www.unicef.org/infobycountry/jordan_statistics.html

UNICEF. (2008). Statistics/ Jordan. Retrieved from http://www.unicef.org./infobycountry/jordan_statistics.html\#72

Ustunsoz, A., Senel, N., \& Pollock, C. C. (2010). Comparison of prenatal education delivered by nurses in Ankara (Turkey) and New Orleans (USA). Journal of Clinical Nursing, 20(1), 1133-1140. doi:10.1111/j.1365-2702.2010.03262.x

Vandevusse, L., Irland, J., Berner, M. A., Fuller, S., \& Adams, D. (2007). Hypnosis for childbirth: A retrospective comparative analysis of outcomes in one obstetrician's practice. American Journal of Clinical Hypnosis, 50(2), 109-119. doi:10.1080/00029157.2007.10401608

Vidal, M. V., Amiano, P., Bernal, C. R., Santa Marina, L., Mozo, I., Vioque, J., \& Ibarluzea, J. (2015). Compliance of nutritional recommendations of Spanish pregnant women according to sociodemographic and lifestyle characteristics: a cohort study. Nutricion Hospitalaria, 31(4), 1803-1812. doi:10.3305/nh.2015.31.4.8293

Vieten, C., \& Astin, J. (2008). Effects of a Mindfullness-based intervention during pregnancy on prenatal stress and mood: Results of a pilot study. Archives of Women's Mental Health, 11(1), 67-74.

Waldenstrom, U., Hildingsson, I., Hildingsson, C., \& Rådestad, I. (2004). A Negative Birth Experience: Prevalence and Risk Factors in a National Sample. Birth, 31(1), 17-27. doi:

10.1111/j.0730-7659.2004.0270.x

Walker, D. S., Visger, J. M., \& Rossie, D. (2009). Contemporary childbirth education models. Journal od Midwifery and Women's Health, 54(6), 469-476. doi:10.1016/j.jmwh.2009.02.013

Weaver, J. B., Mays, D., Weaver, S. S., Hopkins, G. L., Eroglu, D., \& Bernhardt, J. M. (2010). Health information-seeking behaviours, health indicators, and health risks. 
American Journal of Public Health, 100(1), 1520-1525.

doi:10.2105/AJPH.2009.180521

Wijma, K., Wijma, B., \& Zar, M. (1998). Psychometric aspects of the W-DEQ; a new questionnaire for the measurement of fear of childbirth. Journal of Psychosomatic Obstetrics \& Gynecology, 19(2), 84-97.

World Health Organization. (1996). Care in normal birth: a practical guide. Retrieved from http://whqlibdoc.who.int/hq/1996/WHO_FRH_MSM_96.24.pdf?ua=1

World Health Organization. (2015). Summary report on the meeting of national maternal, neonatal and child health programme managers: addressing main causes of maternal, neonatal and child mortality. Retrieved from http://applications.emro.who.int/docs/IC_Meet_Rep_2015_EN_16334.pdf?ua=1

Yehia, D. B., Callister, L. C., \& Hamdan-Mansour, A. (2013). Prevalence and predictors of postpartum depression among Arabic Muslim Jordanian women serving in the military. The Journal of Perinatal \& Neonatal Nursing, 27(1), 25-33. doi:10.1097/JPN.0b013e31827ed6db

Zwelling, E. (1996). Childbirth Education in the 1990s and Beyond. Journal of obstetric, gynecologic, and neonatal nursing, 25(5), 425 - 432. doi:10.1111/j.15526909.1996.tb02447.x 